Portland State University

PDXScholar

6-2014

\title{
Durability Assessment of Recycled Concrete Aggregates for Use in New Concrete Phase II
}

Jason $\mathrm{H}$. Ideker

Oregon State University

Matthew P. Adams

Oregon State University

Jennifer Tanner

University of Wyoming

Angela Jones

University of Wyoming

Follow this and additional works at: https://pdxscholar.library.pdx.edu/trec_reports

Part of the Transportation Engineering Commons, and the Urban Studies Commons Let us know how access to this document benefits you.

\section{Recommended Citation}

Ideker, Jason H., Matthew P. Adams, Jennifer Tanner, Angela Jones. Durability Assessment of Recycled Concrete Aggregates for Use in New Concrete Phase II - Revised. OTREC-RR-13-01. Portland, OR: Transportation Research and Education Center (TREC), 2014. https://doi.org/10.15760/trec.44

This Report is brought to you for free and open access. It has been accepted for inclusion in TREC Final Reports by an authorized administrator of PDXScholar. Please contact us if we can make this document more accessible: pdxscholar@pdx.edu. 


\title{
S)OTREC
}

FINAL REPORT

\section{Durability Assessment of Recycled Concrete Aggregates for Use in New Concrete Phase II}

\author{
OTREC-RR-13-01 \\ June 2014
}





\title{
DURABILITY ASSESSMENT OF RECYCLED CONCRETE AGGREGATES FOR USE IN NEW CONCRETE
}

\author{
Phase II - Final Report
}

OTREC-RR-13-01

\author{
by \\ Jason H. Ideker, Ph.D., PI \\ Assistant Professor \\ jason.ideker@oregonstate.edu \\ Matthew P. Adams, Graduate Research Assistant \\ Oregon State University \\ Jennifer Tanner, Ph.D., P.E., Co-PI \\ Associate Professor \\ tannerj@uwyo.edu
}

Angela Jones, Graduate Research Assistant

University of Wyoming

for

Oregon Transportation Research

and Education Consortium (OTREC)

P.O. Box 751

Portland, OR 97207

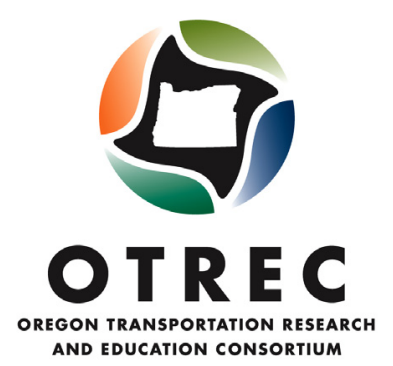

June 2014 



\section{Technical Report Documentation Page}

\begin{tabular}{|l|l|l}
\hline $\begin{array}{l}\text { 1. Report No. } \\
\text { OTREC-RR-13-01 }\end{array}$ & 2. Government Accession No. & 3. \\
\hline
\end{tabular}

\section{Title and Subtitle}

Durability Assessment of Recycled Concrete Aggregates for Use in New Concrete - Phase II Report

\section{Author(s)}

Jason H. Ideker, Jennifer E. Tanner, Matthew P. Adams, Angela Jones

\section{Performing Organization Name and Address}

Oregon State University, School of Civil and Construction Engineering, 220 Owen Hall, Corvallis, Oregon, 97330

The University of Wyoming, Laramie, Wyoming

12. Sponsoring Agency Name and Address

Oregon Transportation Research and Education Consortium (OTREC)

P.O. Box 751

Portland, Oregon 97207

15. Supplementary Notes

16. Abstract: This Phase II investigation into the durability of new concrete incorporating recycled concrete aggregates (RCA) focused on several goals: 1) Provide corroboration of results obtained in Phase I for a multi-laboratory study related to assessing alkali-silica reactivity (ASR) of RCA in accelerated laboratory tests; 2) Investigate the efficacy of mitigation methods to control ASR in concrete containing potentially reactive RCA; 3) Establish long-term data through placement of concrete blocks containing RCA in an outdoor exposure site in Laramie, WY; and 4) Survey state DOTs and other transportation agencies about their perceptions and usage of RCA ASR in concrete within their agency and how that may be improved through the use of a database tracking tool. From Phase II the following main conclusions were drawn: 1) The coefficient of variation limits in ASTM C 1260-07 do not apply to concrete mortar bars incorporating RCA. It is recommended that further testing, using different RCA and more laboratories (at least six), should be completed before a new standard for RCA and/or incorporation of RCA into the current ASTM C 1260 test may be allowed. 2) Generally, as the replacement level of RCA was reduced, the amount of SCM needed to control deleterious ASR also decreased for the RCA sources investigated in this study. 3) Ternary blends containing metakaolin resulted in the most significant decrease in expansions compared to the mixtures with no SCMs.

The results of the transportation agency survey showed the following: 1) A vast majority of agencies believed that sustainability was important to their agency and that it was addressed in a clear and meaningful way. 2) A majority, 54\%, of agencies believed they had specific guidance for the use of RCA in new concrete; however, only $15 \%$ believed that there was strong information from the federal level about the use of RCA in new construction. 3) Of all respondents, 77\% indicated their agency was concerned about alkali-silica reaction in concrete in general for their agency. 4) The biggest barriers to using RCA were noted as concerns about quality, a lack of standards and specifications, and unclear guidance on the testing of RCA. 5) The biggest concerns specific to a source of RCA when considering it for use in new construction were increased shrinkage concerns, ASR and residual chlorides. 6) The most sought-after information about a potential RCA source when considering it for use were the existing condition of the RCA when it was taken out of service, the reason it was taken out of service, whether repairs were performed to the structural element taken out of service, and the age of the RCA.

\section{Key Words}

Recycled concrete aggregate, alkali-silica reaction, accelerated testing, testing methods, durability, long-term performance, mitigation of alkali-silica reaction, fly ash, metakaolin, silica fume

19. Security Classification (of this report)

20. Security Classification (of this page)
Unclassified

\section{Distribution Statement}

No restrictions. Copies available from OTREC: www.otrec.us

Unclassified

21. No. of Pages
110

22. Price 


\section{ACKNOWLEDGEMENTS}

This project was funded by the Oregon Transportation Research and Education Consortium (OTREC), Oregon State University and the University of Wyoming. Their support is greatly appreciated. The authors would also like to thank CalPortland, Inc. for supplying sources of recycled concrete aggregate. The help of Dr. Medhat Shehata and Dr. Benoit Fournier helped with data collection for the four-laboratory study.

\section{DISCLAIMER}

The contents of this report reflect the views of the authors, who are solely responsible for the facts and the accuracy of the material and information presented herein. This document is disseminated under the sponsorship of the U.S. Department of Transportation University Transportation Centers Program in the interest of information exchange. The U.S. Government assumes no liability for the contents or use thereof. The contents do not necessarily reflect the official views of the U.S. Government. This report does not constitute a standard, specification, or regulation. 


\section{TABLE OF CONTENTS}

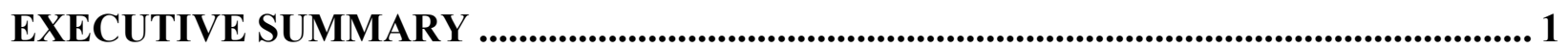

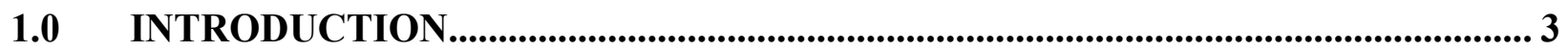

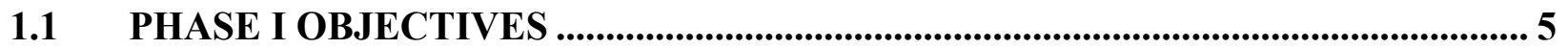

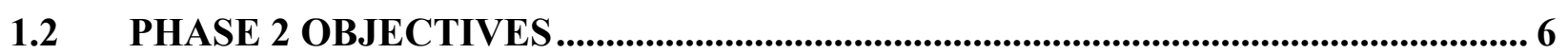

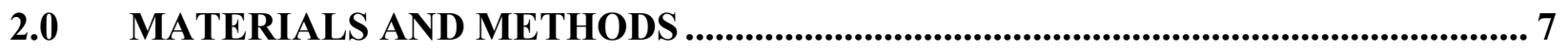

2.1 RCA AND NATURAL AGGREGATE SOURCES ............................................... 7

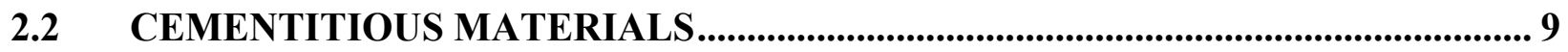

2.3 AGGREGATE CHARACTERIZATION ................................................................... 10

2.3.1 AGGREGATE PREPARATION ................................................................................. 11

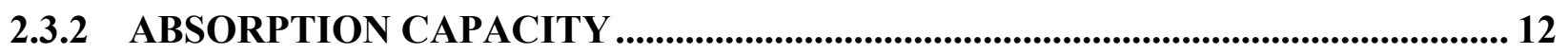

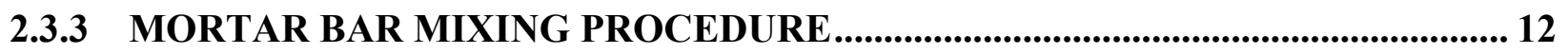

2.4 ASTM C1260 AND ASTM C1567 GENERAL DESCRIPTIONS ............................... 12

2.4.1 DISCUSSION OF AMBT TESTING METHODS ................................................. 14

2.4.2 MULTI-LABORATORY AND DUAL-LABORATORY STUDIES (ASTM C1260) TESTING PROGRAM............................................................................................................ 14

2.4.3 MITIGATION STUDY (AMBT C1567) TESTING PROGRAM................................ 15

2.5 OUTDOOR EXPOSURE BLOCKS ……....................................................................... 18

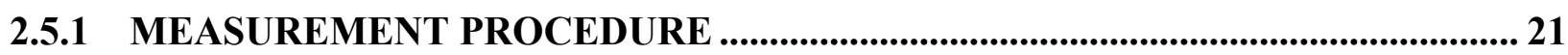

3.0 PHASE I SUMMARY ........................................................................................................ 23

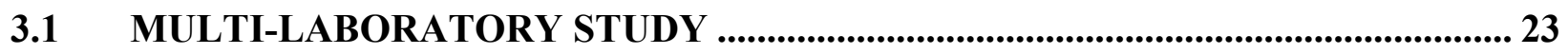

4.0 PHASE II TESTING RESULTS AND DISCUSSION ................................................... 25

4.1 MULTI-LABORATORY AMBT TESTING .................................................................... 25

4.2 OUTDOOR EXPOSURE BLOCKS ……................................................................. 33

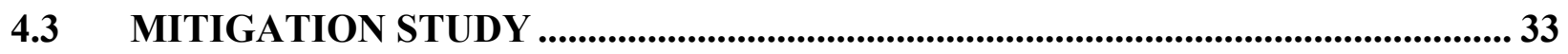

5.0 TRANSPORTATION AGENCY SURVEY ................................................................. 41

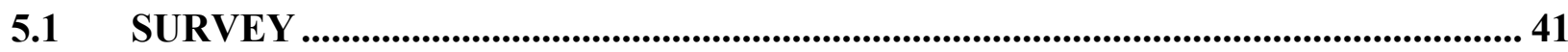

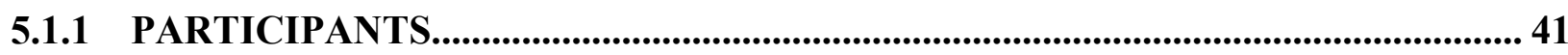

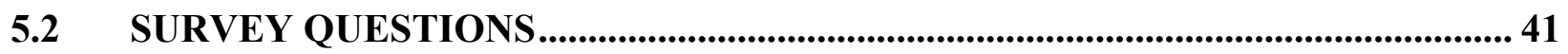

5.2.1 START OF LETTER TO DOTS.................................................................................. 42

5.3 SURVEY RESULTS AND DISCUSSION.................................................................. 52

5.3.1 GENERAL QUESTIONS ABOUT RCA AND SUSTAINABILITY ........................52

5.3.2 DURABILITY AND LONG-TERM PERFORMANCE OF RCA IN NEW

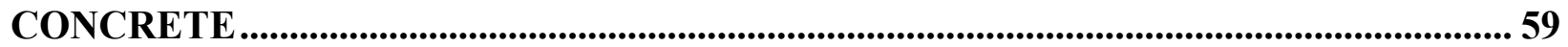

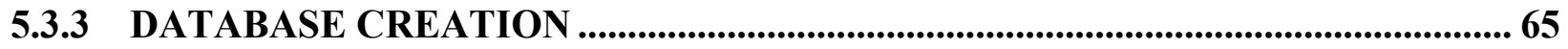

6.0 CONCLUSIONS AND RECOMMENDATIONS................................................69

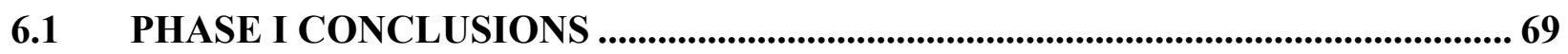


6.2 PHASE II CONCLUSIONS.................................................................................... 69

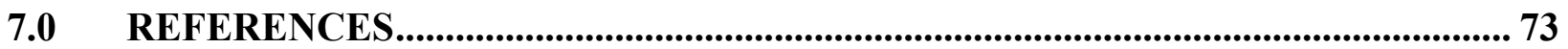

8.0 APPENDIX A - TABULATED RESULTS OF TRANSPORTATION AGENCY

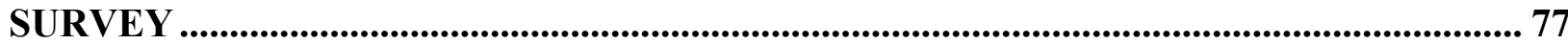




\section{LIST OF TABLES}

TABLE 2-1: RCA AND NATURAL AGGREGATE SOURCES AND INFORMATION.... 9

TABLE 2-2: CEMENTITIOUS MATERIALS OXIDE ANALYSIS ................................... 10

TABLE 2-3: MULTI-LABORATORY MORTAR BAR SETS FOR PHASES I AND II... 15 TABLE 2-4: FLY ASH MITIGATION REQUIREMENTS PER MALVAR AND LENKE EQUATION............................................................................................................................. 17

TABLE 2-5: CEMENTITIOUS MATERIAL CONTENT BY MIXTURE FOR

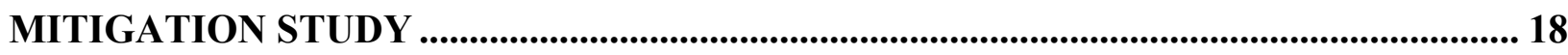

TABLE 2-6: CEMENT, COARSE AND FINE AGGREGATE PROPORTIONS FOR LARGE-SCALE FIELD SPECIMENS ............................................................................. 21

TABLE 4-1: DUAL-LABORATORY EXPANSION AVERAGES, COEFFICIENTS OF VARIATION, AND PRECISION LIMITS FOR PHASE II RCA. 30

TABLE 4-2: ASTM C 1260 WITHIN-LABORATORY AVERAGES AND COEFFICIENTS OF VARIATION FOR BOTH UW AND OSU SPECIMENS FOR EACH MIXTURE TYPE ................................................................................................ 32

TABLE 4-3: SUMMARY OF MITIGATION STUDY MORTAR BAR EXPANSIONS AT 14 AND 28 DAYS ............................................................................................................... 37

TABLE 5-1: PARTICIPATING AGENCIES IN RCA SURVEY ........................................ 41 


\section{LIST OF FIGURES}

FIGURE 2-1: OUTDOOR EXPOSURE SITE 19

FIGURE 2-2: A) THREADED STEEL INSERT ASSEMBLY B) PORTION OF THE INSERT ASSEMBLY ON THE INSIDE OF THE FORM (LEFT) AND C) PORTION OF THE INSERT ASSEMBLY ON THE OUTSIDE OF THE FORM (RIGHT). 19 FIGURE 2-3: FIELD SPECIMEN DIAGRAM SHOWING THE LAYOUT OF THE MEASUREMENT LOCATIONS. 20

FIGURE 2-4: A) MEASUREMENT STUDS AFTER INSTALLATION INTO LARGESCALE FIELD BLOCKS B) USE OF OFFSET MARKINGS IN MEASUREMENT STUD 21

FIGURE 4-1: EXPANSION FROM 0 TO 28 DAYS FOR 100\% CALPORT, 100\% STEPS AND 100\% OPP RCA (OSU SAMPLES ONLY). 26

FIGURE 4-2: AVERAGE 14-DAY RESULTS FOR CALPORT RCA SETS........................ 27

FIGURE 4-3: AVERAGE 14-DAY RESULTS FOR STEPS RCA SETS .............................. 28

FIGURE 4-4: AVERAGE 14-DAY RESULTS FOR OPP RCA SETS ................................. 29

FIGURE 4-5: ASTM C1260 PRECISION LIMITS VS. DUAL-LABORATORY STUDY DATA FOR PHASE II RCA

FIGURE 4-6: TWENTY-THREE MONTH DATA FROM LARGE-SCALE FIELD SPECIMENS 33

FIGURE 4-7: EXPANSION FROM 0 TO 28 DAYS FOR THE JOBE-R RCA MORTAR BARS AND VARIOUS REPLACEMENT LEVELS OF CLASS F FLY ASH. 34 FIGURE 4-8: EXPANSION FROM 0 TO 28 DAYS FOR THE JO-R RCA MORTAR BARS WITH TERNARY BLENDS. 35

FIGURE 4-9: EXPANSION FROM 0 TO 28 DAYS OF CA-R MORTAR BARS WITH VARIOUS REPLACEMENTS OF FLY ASH AND TERNARY BLENDS 36 FIGURE 5-1: IMPORTANCE OF SUSTAINABILITY TO SURVEY PARTICIPANTS. 53 FIGURE 5-2: SUSTAINABILITY IS ADDRESSED WITHIN PARTICIPANTS' AGENCIES IN A CLEAR AND MEANINGFUL WAY. 53

FIGURE 5-3: USING RCA INSTEAD OF LANDFILLING IS VIEWED AS AN IMPORTANT PART OF SUSTAINABILITY TO YOUR AGENCY 54

FIGURE 5-4: AGENCY HAS SPECIFIC GUIDANCE FOR THE USE OF RCA IN NEW CONCRETE. 55

FIGURE 5-5: THERE IS STRONG INFORMATION FROM THE FEDERAL LEVEL FOR THE USE OF RCA IN NEW CONSTRUCTION 55 FIGURE 5-6: THE USE OF RCA WILL NEGATIVELY AFFECT ECONOMICS OF TRANSPORTATION-RELATED CONSTRUCTION ................................................56 FIGURE 5-7: AGENCY CONSIDERS BOTH COST AND EMBODIED ENERGY TO ASSESS BENEFITS WHEN CONSIDERING RCA 57 FIGURE 5-8: WHEN DETERMINING WHETHER TO USE RCA, OUR DOT CONSIDERS SUSTAINABILITY AS THE MOST IMPORTANT FACTOR 58 
FIGURE 5-9: AGENCY BELIEVES THAT GOVERNMENT INCENTIVES COULD EFFECTIVELY PROMOTE THE USE OF RCA..................................................................5 59

FIGURE 5-10 ASR IS A CONCERN TO OUR DOT ........................................................6 60 FIGURE 5-11: MOST SIGNIFICANT BARRIERS TO USING RCA IN NEW

CONCRETE. 61

FIGURE 5-12: KNOWING THESE CHARACTERISTICS WOULD MOST BENEFICIALLY ENABLE RCA USAGE 62

FIGURE 5-13: RCA ATTRIBUTES MOST IMPORTANT TO MAKING DECISIONS FOR USAGE 63

FIGURE 5-14: POTENTIAL ATTRIBUTES OF RCA THAT CAUSE CONCERN FOR USAGE 64

FIGURE 5-15: MOST INTEREST IN USING RCA FOR PARTICULAR APPLICATIONS 65

FIGURE 5-16: IF A DATABASE WAS PROVIDED TO TRACK RCA SOURCES, WHAT ARE THE MOST DESIRED FIELDS FOR INPUT? 66 FIGURE 5-17: IF A DATABASE WAS PROVIDED TO TRACK RCA SOURCES, WHAT ARE THE MOST DESIRED FIELDS FOR INPUT (PART 2)? 67 


\section{EXECUTIVE SUMMARY}

This Phase II investigation into the durability of new concrete incorporating recycled concrete aggregates (RCA) focused on several goals: 1) Provide corroboration of results obtained in Phase I for a multi-laboratory study related to assessing alkali-silica reactivity (ASR) of RCA in accelerated laboratory tests; 2) Investigate the efficacy of mitigation methods to control ASR in concrete containing potentially reactive RCA; 3 ) Establish long-term data through placement of concrete blocks containing RCA in an outdoor exposure site in Laramie, WY; and 4) Survey state departments of transportation (DOTs) and other transportation agencies about their perceptions and use of RCA, ASR in concrete within their agency, and how that may be improved through the use of a database tracking tool. This report is divided into six main sections:

- Introduction

- Materials and Methods

- Phase I Summary

- Phase II Results and Discussion

- Transportation Agency Survey

- Conclusions and Future Recommendations

From Phase I the following conclusions were drawn:

- Modifications to standard aggregate testing and characterization standards are necessary for RCA.

- Absorption capacity testing required at least a 24 -hour soaking period to take up $95 \%$ of the aggregate's total absorption.

- Modifications to ASTM C 305 were required for properly mixing mortars containing RCA, including a soaking period of 30 minutes for all aggregate (including RCA) to ensure proper absorption by dry aggregate and adequate mixing.

- Based on testing in this research project, precision and bias statements in ASTM C 1260 (for virgin aggregate) should be modified for RCA. Additional testing of the same materials by at least six laboratories would be needed to properly establish precision and bias statements.

From Phase II the following main conclusions were drawn:

- ASTM C 1260-07 currently recommends a within-laboratory coefficient of variation (COV) of $2.94 \%$. This COV limit was exceeded by 18 sets of bars, or $50 \%$ of the tests completed in Phase II research. This data matches data seen in Phase I of this project that showed that when using the ASTM C1260 test to examine RCA, the COV limit may need to be modified. It is recommended that further testing, using different RCA and more laboratories (at least six), should be performed to confirm the results shown in this study. 
This must be completed before a new standard for RCA and/or incorporation of RCA into the current ASTM C 1260 test may be allowed.

- Generally, as the replacement level of RCA was reduced, the amount of supplementary cementitious material (SCM) needed to control deleterious ASR was also reduced for the RCA sources.

- The specific amounts of fly ash predicted by the Malvar and Lenke equation needed to control deleterious ASR in concrete incorporating RCA produced conflicting results. In about half of the cases, the chemical index equation was capable of predicting the required amount of fly ash to reduce ASR-related expansion for RCA and fly ash combinations. However, not all RCA followed this trend.

- The amount of adhered mortar can affect the level of reactivity in an aggregate, and subsequently may affect the efficacy of an SCM to mitigate ASR.

- Ternary blends containing metakaolin resulted in the most significant decrease in expansions compared to the mixtures with no SCM.

- Exposure blocks were cast and placed in an outdoor site for realistic exposure to environmental fluctuations in Laramie, WY. One of the exposure blocks incorporated RCA from a set of concrete steps on the University of Wyoming campus, and is showing significant deterioration (Expansion $>1.2 \%$ ) after only one year of outdoor exposure.

A survey of all state DOTs and several other transportation agencies, including the Federal Highway Administration and Canada's Ministries of Transportation, was conducted to determine current perceptions and use of RCA and concerns with alkali-silica reaction. The type of information that would be most useful in a database tracking-type tool for RCA sources was also requested. The survey drew 27 responses, viewed as a strong response rate by the research team. The following main conclusions were drawn:

- A vast majority of agencies believed that sustainability was important to their agency and that it was addressed in a clear and meaningful way.

- More than half (54\%) of agencies believed they had specific guidance for the use of RCA in new concrete. However, only $15 \%$ believed that there was strong information from the federal level about the use of RCA in new construction.

- The use of RCA in new construction is viewed as an important sustainability measure; however, there are other benefits of using RCA as well.

- The majority (77\%) of respondents indicated that their agency was concerned about alkali-silica reaction in concrete in general for their agency.

- The biggest barriers to using RCA were noted as concerns about quality, a lack of standards and specifications, and unclear guidance on RCA testing.

- The biggest concerns specific to a source of RCA when considering it for use in new construction were increased shrinkage concerns, ASR and residual chlorides.

- The most sought-after information about a potential RCA source when considering it for use were the existing condition of the RCA when it was taken out of service, the reason it was taken out of service, whether repairs were performed to the structural element taken out of service, and the RCA's age.

- The applications of interest for using RCA, in decreasing rank from most interest to least interest, included base material; sub-base material; fill material; pavements; sidewalks; and structural concrete. 


\subsection{INTRODUCTION}

The U.S. Department of Transportation reported that a goal for fiscal years 2006-2011 would involve improving "DOT-owned or controlled facilities for the benefit of host communities by energy conservation, preventing pollution, recycling, and using recycled products" (Strategic Plan F-Y2). As the need grows for environmentally sustainable work practices, the construction industry seeks ways to reduce or recycle waste from both construction and demolition processes. One of the largest components of building demolition waste is concrete. According to a Federal Highway Administration (FHWA) survey, 41 states currently use recycled concrete in construction, but most of these states limit its use to base or subbase applications (FHWA, 2003). While this is a positive trend, the use of recycled concrete aggregate (RCA) has greater potential for helping the USDOT meet its environmental stewardship goals. The low usage rate of RCA in new concrete is partially because it is considered a sub-standard construction material (Lauritzen, 2004; Melton, 2004), and also because of a lack of proper technical guidance, testing standards, and specifications for using RCA as a replacement for aggregate in new concrete. An area of particular concern is how RCA that is produced from a parent concrete that is affected by alkalisilica reaction (ASR) may affect new concrete (FHWA, 2003; Melton, 2004).

RCA is produced by crushing demolished concrete into appropriate gradations for use in civil engineering applications. Large concrete elements are broken up using mobile impact units, which have attachments able to remove reinforcing steel during this initial crushing phase. The rubble is then typically shipped to a large-scale crushing facility where it is crushed further into the sizes needed for use in construction. At this phase, magnets can be passed over the crushed material to remove any remaining reinforcing steel in the concrete (American Concrete Institute, 2001).

RCA are a two-phase particle consisting of the original natural coarse aggregate and the adhered mortar. The adhered mortar contains cement paste, and the original natural fine aggregate (Froundistou-Yannis, 1977; Fathifazl, Razaqpur et al., 2010). Research into the mechanical properties of concrete containing RCA has shown that, by limiting the amount of RCA used as replacement material in a given mixture and through proper design of a concrete mixture, similar or better concrete than that which is made with natural aggregates can be produced (SagoeCrentsil, Brown et al., 2001; Fathifazl, Abbas et al., 2009; Kou, Poon et al., 2011). RCA that is produced from parent concrete that has shown deterioration due to ASR has shown to be reactive when incorporated into new concrete (Gress, 2000; Shayan and Xu, 2003; Scott and Gress, 2004; Li and Gress, 2006; Gress, Snyder et al., 2009; Shehata, Christidis et al., 2010; Adams, Ideker et al., 2012). ASR is one of the most prevalent causes of premature concrete deterioration.

ASR deterioration occurs when the ASR gel [formed due to a reaction between the alkalies $\left(\mathrm{Na}^{+}\right.$ and $\left.\mathrm{K}^{+}\right)$, hydroxyl ions $\left(\mathrm{OH}^{-}\right)$, and reactive silica)] absorbs water and swells. The swelling of the gel causes tensile forces in the concrete, and if these tensile forces exceed the tensile capacity of the concrete, cracking can occur. The reactive silica is supplied by the aggregates, with the 
hydroxyl ions present in the pore solution of the concrete to maintain charge balance with the cations (namely $\mathrm{Na}+$ and $\mathrm{K}+$ ). The alkalis are provided by the cement, other admixtures and can also come from external sources such as seawater or deicing/anti-icing chemicals. The RCA may also contain additional alkalis in the adhered mortar or from ASR gel already present in the RCA (Scott and Gress, 2004). Cracking will allow more moisture to enter the system, which will subsequently be absorbed by the ASR gel and likely result in further expansion and additional cracking. ASR can be mitigated through the use of supplementary cementitious materials (SCM) such as fly ash, ground granulated blast furnace slag, metakaolin, or silica fume incorporated into the fresh concrete mixture (Fournier and Malhotra, 1996; Shehata and Thomas, 2000; Quanlin and Naiqian, 2004; Mirdamadi, Layssi et al., 2008; Thomas, 2011). Though the mechanisms by which SCM works to mitigate ASR are not fully understood, it is believed that during hydration they help to bind alkalis, either through the creation of calcium silicate hydrate $(\mathrm{C}-\mathrm{S}-\mathrm{H})$ or the conversion of calcium hydroxide $(\mathrm{CH})$ to $\mathrm{C}-\mathrm{S}-\mathrm{H}$, making them less available for the ASR reaction (Folliard, Thomas et al., 2006; Thomas, 2011). SCM also help to reduce ASR by reducing the cement content, which can have a dilutional effect in reducing the amount of available alkalis in the system. The SCM also create physical changes in the concrete by strengthening the system, which increases the amount of pressure required by the ASR gel to cause cracking. In addition, SCM reduce the system's permeability, preventing the ingress of moisture (Folliard, Thomas et al., 2006).

The most used accelerated test method for ASR on virgin aggregates is the ASTM C1260 Accelerated Mortar Bar Test. Another available test includes the ASTM C 1293, but it is not an option for this study due to its year-long required testing period. The other options offer a faster testing period but often at the expense of accuracy (Thomas, Fournier et al., 2006). Since it has been shown that, on average, aggregates expand more quickly in warmer conditions than cooler conditions (Fournier, Ideker et al., 2009), and these accelerated tests require extreme temperatures for testing, results are obtained faster. While it can produce false results, ASTM C 1260 is generally accepted as a good screening test for aggregates (Fournier, Nkinamubanzi et al., 2006).

The best approach for accurate prediction of reactivity is the use of several complimentary tests. However, when separate tests produce opposite results (e.g., one passing result and one failing result), the test with the worst result, or the most conservative result, should be taken into consideration. Preference should be given to the more reliable, longer-term ASTM C 1293 test results (Berube and Fournier, 2000).

Determining the amount of SCM required for mitigating ASR in concrete requires testing. ASTM C1567 (AMBT) and ASTM C1293 (concrete prism test (CPT)) can be used to determine what levels of SCMs need to be incorporated to reduce expansions to acceptable levels (ASTM C1567, 2007; ASTM C1293, 2008b). The CPT test method is generally considered the most accurate (Thomas, Fournier et al., 2006). However, the test takes two years to complete when assessing SCM whereas the AMBT can be completed in 16 days. It is generally recommended to run both tests concurrently. Malvar and Lenke (2006) developed a chemical index to determine the amount of fly ash required to mitigate ASR in concrete made with natural aggregates. The equation was developed by examining the results of combinations of a wide range of cements, fly ashes and various reactive aggregates in the AMBT. The chemical index uses the characteristics of the particular fly ash and cement to predict how much fly ash, by weight 
percent replacement of cement, will be required to mitigate ASR for a particular combination of cement and aggregate. In essence, this can provide a strong starting point to eliminate the need for vast quantities of testing where an optimum dosage can be predicted and then that dosage rate - and rates slightly higher and slightly lower - can be tested to confirm the amount of fly ash needed to control the reaction. However, it is not known if this methodology applies to concrete produced with RCA.

From these studies it has been demonstrated that the ASTM C1260 test is capable of detecting aggregate reactivity (Shayan and Xu, 2003; Li and Gress, 2006; Shehata, Christidis et al., 2010). It is still unclear, however, if the test can accurately predict the level of reactivity seen in field concrete. Several key pieces of information still have not been elucidated upon:

- The reliability of results when compared to other ASR testing procedures and results from field exposure;

- The reproducibility of results; and

- The effect of crushing procedures on measured reactivity due to change in particle composition during the crushing process.

This study examined the last two bullet points noted above, including the applicability of the current ASTM C1260 test method to detect RCA reactivity due to ASR.

The amount of expansion observed due to ASR from the RCA is dependent on the amount of RCA incorporated into the mixture, the reactivity of the original natural aggregates, and the amount of processing the RCA goes through to attain correct gradation for the requisite tests (Shehata, Christidis et al., 2010; Ideker, Tanner et al., 2012). It has also been determined that the ASTM C1260/C1567 AMBT is an effective way to detect alkali-silica reactivity (ASR) in RCA (Shehata, Christidis et al., 2010; Adams, Ideker et al., 2012). Previous work has shown, however, that SCM are not as effective at mitigating ASR in concrete made with RCA compared to concrete made with natural aggregates (Shehata, Christidis et al., 2010). In other words, higher dosages of the same SCM may be needed to control ASR in concrete incorporating RCA compared to the concrete produced with original natural aggregate (the same type present in the $\mathrm{RCA})$.

The objectives of this study are discussed below in sections 1.1 and 1.2.

\subsection{PHASE I OBJECTIVES}

This phase focused on whether ASTM C 1260 could adequately determine the reactivity of mortars incorporating varying replacement levels of RCA. Because aggregate size requirements for ASTM C 1260 involve extensive crushing and could remove fractions of RCA that would otherwise be reactive, multiple levels of RCA crushing were examined. In addition, the original procedural steps for ASTM C 1260 were modified due to higher absorption rates in RCAs than regular aggregate.

State surveys performed by the FHWA indicated a need for increased quality control and quality assurance in the use of RCA in new applications (FHWA, 2003). It was thus advantageous to 
include the two additional research teams (Laval and Ryerson) to expand the statistical reliability of the overall results.

The RCA used in this research came from large concrete block specimens at a location in Ottawa, Canada. These blocks displayed expansions from ASR in the field. The blocks were crushed and samples were distributed to the four participating universities. Four types of RCA were reviewed: Bernier, Potsdam, Alberta and Springhill. Bernier, Springhill and Potsdam come from a sedimentary geologic environment and contain varying forms of reactive rock types. Virgin Bernier aggregate is siliceous/argillaceous limestone; virgin Springhill aggregate is a mixture of greywacke and argillite; and virgin Potsdam aggregate is siliceous sandstone. Virgin Alberta aggregate is natural gravel composed of fragments of sandstone, limestone, quartzite, and fine-grained volcanic rocks.

\subsection{PHASE 2 OBJECTIVES}

Further multi-laboratory testing on an additional three RCA between the University of Wyoming and Oregon State University was performed as a part of Phase II. These RCA were all from nonlaboratory-created sources and provided a complimentary set of data to the multi-laboratory work performed in Phase 1. Furthermore, these aggregates have uncertainties that will almost always exist in RCA available to engineers. One of these RCA was received from an Oregon ready-mix concrete producer that stockpiles RCA produced from returned concrete waste; this RCA represented a mixed material (various cementitious material and w/c compositions) using a similar reactive siliceous river gravel throughout. The remaining two RCA were obtained from a demolished structure and existing steps that had undergone ASR damage on the University of Wyoming campus. Outdoor concrete exposure blocks were also cast at the university using two RCA obtained there. Preliminary field expansions are presented in Phase II results.

Additionally, two RCA that were classified as reactive were examined to determine if mitigation techniques can be used to incorporate RCA into new concrete. One of these RCA was a laboratory-created concrete produced with the highly reactive Jobe virgin aggregate - a cherty fine aggregate. The second was the RCA produced from returned concrete mentioned above. The mitigation techniques involved using binary and ternary blends of ordinary portland cement and SCM. For this study, a class F fly ash, silica fume and metakaolin were used.

The survey presented in Phase I was sent to government transportation agencies (U.S. federal and state and Canadian), and results from the 27 respondents are included in Phase II. 


\subsection{MATERIALS AND METHODS}

Nine different recycled aggregates and four natural aggregates were used in this study. The research team sought out collaborative efforts with researchers at two Canadian universities: Dr. Benoit Fournier at Université Laval in Quebec City, Quebec, and Dr. Medhat Shehata at Ryerson University in Toronto, Ontario. Both Drs. Fournier and Shehata have been working on RCA and the potential for alkali-silica reaction for a combined total of 10 years. The research teams at OSU and UW were fortunate to establish a strong collaboration with these researchers, which resulted in the ability to initiate and perform a large multi-laboratory study on the efficacy of ASTM C 1260 to detect aggregate reactivity from RCA and on the repeatability of testing results from Phase I. This is the first large-scale attempt to correlate the results of ASR testing on RCA from the same sources, tested at different laboratories. The research team investigated four different RCA obtained from long-term outdoor exposure testing performed at CANMET in Ottawa. Prior to his academic position at Université Laval, Dr. Fournier was a researcher at CANMET-MTL and was directly responsible for the casting of the outdoor exposure blocks used in this current project. The four additional RCA were used at OSU and UW in phases I and II. The four natural aggregates were also used in both phases to supplement specimens cast with RCA at various replacement levels of RCA for natural aggregate. More information on these aggregates is provided in this section.

\subsection{RCA AND NATURAL AGGREGATE SOURCES}

For initial modifications to standard testing procedures, reclaimed concrete from an undergraduate materials course at OSU was used so that the RCA from outdoor exposure blocks (available in limited quantity) was not depleted. Test results from this aggregate were only used to demonstrate modifications to standard laboratory testing (e.g., specific gravity and absorption capacity testing). A summary of this work can be found in Section 3.0, with a more complete description in the Phase I report (Ideker, Tanner et al., 2012).

Four sources of RCA were used in the Phase I multi-laboratory studies. These RCAs were produced by crushing outdoor exposure blocks previously used in long-term aggregate reactivity testing and correlation to accelerated laboratory testing in Ontario. Drs. Fournier and Ideker have research affiliations with these sites, and these strong ties enabled the research team to obtain blocks on which testing had already been completed for inclusion in this project. In short, the outdoor exposure blocks were selected for their age, extent of alkali-silica reaction damage (coming from the reactive virgin aggregates originally included in the mixture designs), and variation in mineralogy of reactive aggregate type. Data on these aggregates is presented in Section 2.1, with a more complete analysis available in the Phase I report (Ideker, Tanner et al., 2012).

Four sources of RCA were used in the Phase II studies as well. One of these, Jobe, was produced from a laboratory-created exposure block that was kept in an outdoor exposure condition at the 
University of Texas, Austin. The original block measured, nominally, 0.70 meters in length and 0.40 meters in height and width. This block was originally produced as part of a long-term aggregate reactivity testing and correlation to accelerated laboratory testing. Dr. Ideker has a research affiliation with the site, and was able to procure this block on which testing had previously been completed. This exposure block was selected for its age and the extent of alkalisilica reaction damage (coming from a reactive virgin fine aggregate contained in the original mixture for the concrete block). This RCA was used only for the mitigation study presented in Section 4.3.

A second RCA source, CalPort, was provided by an Oregon ready-mix concrete producer. This material was produced from returned concrete. Returned concrete is excess concrete material that was not used on a construction site and was returned to the plant. Once the concrete truck returns to the plant, it discharges the concrete. Once the discharge concrete hardens, it is then crushed and placed into a pile with other crushed, returned concrete. This source of RCA represents a "stockpiled" material because it is comprised of various concrete mixtures that contain various water-to-cementitious-material ratios, admixtures, and SCM. However, the same aggregate source was used in the concrete mixtures that made up the returned concrete received. This aggregate was used in the mitigation study presented in Section 4.3 and the dual-laboratory study presented in Section 4.0. An additional two RCA sources were produced from demolished field structures on the UW campus: UW Steps (Steps) and UW Old Power Plant (OPP). Relatively little is known about the original aggregates and cement from which these RCA sources were produced. The Steps RCA was produced from a set of concrete steps that were significantly damaged. Although the steps are still in use, a section was removed to provide RCA for this study. The OPP RCA was created from an indoor foundation that had undergone moderate ASR deterioration. These two RCAs were used in the dual-laboratory study presented in Section 4.01, the exposure block study presented in Section 4.2 .

These last three RCA (CalPort, Steps and OPP) provided a complementary set of data to that which was produced in the Phase I multi-laboratory study. Phase I's study used exclusively RCA that was produced from lab-created RCA. From the data generated in Phase II, a study of whether the variability of testing increased when "stockpiled" or unknown material was used to create the RCA and compared to material that was created in a lab.

Additionally, two natural aggregates were used as a supplement to the RCA in all of the testing, when the aggregate in the test specimens was not replaced with RCA at a 100\% replacement level. Two of these - the CANMET sand, and the Brighton aggregate - are classified as nonreactive materials (expansions in the ASTM C1260 test $<0.1 \%$ ). All aggregates are described in Table 2-1. This table includes information on the aggregates source, whether the natural aggregate was a coarse or fine aggregate, and the ASR according to ASTM C1260 and C1293. 
Table 2-1: RCA and Natural Aggregate Sources and Information

\begin{tabular}{|c|c|c|c|c|c|}
\hline \multicolumn{6}{|c|}{ Recycled Concrete Aggregates } \\
\hline $\begin{array}{l}\text { Recycled } \\
\text { Concrete } \\
\text { Aggregate }\end{array}$ & $\begin{array}{c}\text { Virgin Aggregate } \\
\text { Mineralogy } \\
\text { (Gradation) }\end{array}$ & $\begin{array}{c}\text { Recycled Concrete } \\
\text { Aggregate Origin }\end{array}$ & Source Type & \begin{tabular}{|} 
Natural Aggregate \\
Mortar Bar \\
Expansion in ASTM \\
C1260 Test (14 d exp. \\
$\%$ )
\end{tabular} & $\begin{array}{l}\text { Natural Aggregate } \\
\text { Concrete Prism } \\
\text { Expansion in ASTM } \\
\text { C1293 Test (1-year } \\
\text { exp \%) }\end{array}$ \\
\hline Alberta & $\begin{array}{l}\text { Mixed mineralogy } \\
\text { gravel (Coarse) }\end{array}$ & $\begin{array}{l}\text { Exposure block from } \\
\text { Ontario, Canada }\end{array}$ & $\begin{array}{l}\text { Laboratory } \\
\text { created }\end{array}$ & 0.36 & 0.09 \\
\hline Bernier & $\begin{array}{c}\text { Argillaceous } \\
\text { limestone (Coarse) }\end{array}$ & $\begin{array}{l}\text { Exposure block from } \\
\text { Ontario, Canada }\end{array}$ & $\begin{array}{l}\text { Laboratory } \\
\text { created }\end{array}$ & 0.17 & 0.04 \\
\hline Potsdam & Sandstone (Coarse) & $\begin{array}{l}\text { Exposure block from } \\
\text { Ontario, Canada }\end{array}$ & $\begin{array}{l}\text { Laboratory } \\
\text { created }\end{array}$ & 0.09 & 0.13 \\
\hline Springhill & Greywacke (Coarse) & $\begin{array}{l}\text { Exposure block from } \\
\text { Ontario, Canada }\end{array}$ & $\begin{array}{l}\text { Laboratory } \\
\text { created }\end{array}$ & 0.46 & 0.22 \\
\hline Jobe & $\begin{array}{c}\text { Mixed quartz/ chert/ } \\
\text { feldspar (Fine) }\end{array}$ & $\begin{array}{c}\text { Exposure block from } \\
\text { Austin, Texas }\end{array}$ & $\begin{array}{l}\text { Laboratory } \\
\text { created }\end{array}$ & 0.64 & 0.59 \\
\hline CalPort & $\begin{array}{l}\text { Silicious river gravel } \\
\text { (Fine and Coarse) }\end{array}$ & $\begin{array}{l}\text { Returned concrete } \\
\text { stockpile at Oregon } \\
\text { readymix facility }\end{array}$ & Stockpile & $\begin{array}{l}\text { FA: } 0.81 \\
\text { CA: } 0.59\end{array}$ & Unknown \\
\hline UW Steps (Steps) & Unknown & $\begin{array}{c}\text { ASR affected stairs in } \\
\text { Wyoming }\end{array}$ & Field structure & Unknown & Unknown \\
\hline $\begin{array}{l}\text { UW Old Power } \\
\text { Plant (OPP) }\end{array}$ & Unknown & $\begin{array}{c}\text { ASR affected } \\
\text { foundation in Wyoming }\end{array}$ & Field structure & Unknown & Unknown \\
\hline $\begin{array}{l}\text { OSU Materials } \\
\text { Course RCA }\end{array}$ & $\begin{array}{c}\text { Silicious river sand } \\
\text { and gravel (Coarse } \\
\text { and Fine) }\end{array}$ & $\begin{array}{c}\text { OSU Undergraduate } \\
\text { Materials Laboratory } \\
\text { Course }\end{array}$ & $\begin{array}{l}\text { Laboratory } \\
\text { created }\end{array}$ & $\begin{array}{c}\text { FA: } 0.10 \\
\text { CA: Unknown }\end{array}$ & Unknown \\
\hline \multicolumn{6}{|c|}{ Natural Aggregates } \\
\hline CANMET & $\begin{array}{c}\text { Natural granitic } \\
\text { (Fine) }\end{array}$ & N/A & N/A & $\begin{array}{c}<0.1 \% \text { (Classified as } \\
\text { non-reactive) }\end{array}$ & $\begin{array}{c}<0.04 \% \text { (Classified } \\
\text { as non-reactive) }\end{array}$ \\
\hline Brighton & Limestone (Fine) & N/A & N/A & $\begin{array}{c}<0.1 \% \text { (Classified as } \\
\text { non-reactive) }\end{array}$ & $\begin{array}{c}<0.04 \% \text { (Classified } \\
\text { as non-reactive) }\end{array}$ \\
\hline
\end{tabular}

\subsection{CEMENTITIOUS MATERIALS}

The research team used a single type of cement supplied by CANMET for all of the multilaboratory testing performed in phases I and II because the main interest was to determine the ability of and reproducibility of results from ASTM C 1260 to properly characterize potential ASR of RCA. As a result, the only differences were the type of equipment used for testing and the different researchers preparing, monitoring and analyzing samples. A second cement, Type I/II HA, was used for the mitigation study performed at OSU, along with the SCM: a class F fly ash (according to ASTM C618) (ASTM C618, 2012), silica fume and metakaolin. Holcim-UW was used for testing. These cements were of specific interest to determine the influence of cement alkali content on testing results. Thus, this was the only information requested from independent testing of Steps and OPP aggregates at both OSU and UW. An oxide analysis of all the cementitious materials used is provided below in Table 2-2. 
Table 2-2: Cementitious Materials Oxide Analysis

\begin{tabular}{|c|c|c|c|c|c|c|c|}
\hline Oxide & $\begin{array}{l}\text { Oxide } \\
\text { Short } \\
\end{array}$ & \begin{tabular}{|c|} 
CANMET Type \\
I Cement
\end{tabular} & $\begin{array}{c}\text { Holcim - } \\
\text { UW }\end{array}$ & $\begin{array}{c}\text { Type I/II } \\
\text { HA Cement } \\
\end{array}$ & \begin{tabular}{|c|} 
Class F Fly \\
Ash \\
\end{tabular} & $\begin{array}{l}\text { Silica } \\
\text { Fume }\end{array}$ & Slag \\
\hline Silicon Dioxide & $\mathrm{SiO}_{2}$ & 19.57 & - & 19.43 & 53.15 & $>85.00$ & 30.76 \\
\hline Aluminum Oxide & $\mathrm{Al}_{2} \mathrm{O}_{3}$ & 4.88 & - & 4.95 & 16.84 & - & 13.08 \\
\hline Iron Oxide & $\mathrm{Fe}_{2} \mathrm{O}_{3}$ & 2.91 & - & 2.41 & 6.13 & - & 0.77 \\
\hline $\begin{array}{c}\text { Total }\left(\mathrm{SiO}_{2}+\right. \\
\left.\mathrm{Al}_{2} \mathrm{O}_{3}+\mathrm{Fe}_{2} \mathrm{O}_{3}\right)\end{array}$ & & 27.36 & - & 26.79 & 76.12 & - & 44.61 \\
\hline Calcium Oxide & $\mathrm{CaO}$ & 60.82 & - & 62.41 & 11.33 & - & 41.78 \\
\hline $\begin{array}{l}\text { Magnesium } \\
\text { Oxide }\end{array}$ & $\mathrm{MgO}$ & 2.52 & - & 2.48 & 3.93 & - & 4.50 \\
\hline Sodium Oxide & $\mathrm{Na}_{2} \mathrm{O}$ & 0.27 & 0.21 & 0.23 & 3.34 & $<3.0$ & 0.21 \\
\hline Potassium Oxide & $\mathrm{K}_{2} \mathrm{O}$ & 0.97 & 0.76 & 0.88 & 1.99 & - & 0.49 \\
\hline Total Alkalies & $\mathrm{Na}_{2} \mathrm{O}_{\text {eq }}$ & 0.97 & 0.71 & 0.81 & 1.40 & - & 0.53 \\
\hline Titanium Dioxide & $\mathrm{TiO}_{2}$ & - & - & 0.26 & 1.08 & - & 0.45 \\
\hline $\begin{array}{c}\text { Manganese } \\
\text { Dioxide }\end{array}$ & $\mathrm{MnO}_{2}$ & - & - & 0.05 & 0.10 & - & 0.65 \\
\hline $\begin{array}{c}\text { Phosphorus } \\
\text { Pentoxide }\end{array}$ & $\mathrm{P}_{2} \mathrm{O}_{5}$ & - & - & 0.24 & 0.31 & - & 0.04 \\
\hline Strontium Oxide & $\mathrm{SrO}$ & - & - & 0.23 & 0.33 & - & 0.07 \\
\hline Barium Oxide & $\mathrm{BaO}$ & - & - & 0.02 & 0.56 & - & 0.06 \\
\hline Sulfur Trioxide & SO3 & 3.32 & - & 3.32 & 0.64 & - & 5.15 \\
\hline Loss on Ignition & & 2.82 & - & 3.08 & 0.27 & 6.00 & 2.58 \\
\hline Insoluble Residue & & - & - & - & - & - & - \\
\hline
\end{tabular}

\subsection{AGGREGATE CHARACTERIZATION}

Virgin aggregates are typically characterized for standard properties for many types of laboratory testing and field applications. In this research project it was necessary to characterize the RCA, which consists of four main phases: cement paste, fine aggregate, coarse aggregate (whole and fractured), and air voids. These methods were used in their unmodified forms to characterize the natural aggregates used in this study. The presence of cement paste and especially increased air voids (compared to virgin aggregates) in RCA, however, required modification to the following standard testing methodologies:

Absorption capacity (concrete and mortar mixing) - ASTM C 128;

Mortar mixing - ASTM C 305; and

Alkali-silica reaction testing - ASTM C 1260.

In the following sections, a brief overview of the testing methodology and subsequent modifications that were made when testing RCA will be given. Details about standard testing procedures that were not modified can be referred to in the given standard, and a more in-depth 
report of aggregate characterization techniques used and modifications to those techniques can be found in the Phase I report (Ideker, Tanner et al., 2012).

\subsubsection{Aggregate Preparation}

ASTM C1260 is a mortar bar test and requires the aggregate to be a specific fine aggregate gradation as specified in ASTM C1260 (2007). The RCA must be crushed using mechanical methods to reach this gradation. Gress and Kozikowski speculated that using the ASTM C1260 grading required aggregate crushing that is too aggressive because it can destroy the integrity of the two-phase RCA particle (original natural aggregate and adhered mortar), and thus alter its reactivity (Gress, 2000). Work by Shehata et al. also evaluated this problem by performing ASTM C1260 testing on RCA that had gone through one level of crushing, and then a second set of testing on RCA that had been left over from the first crushing (slightly larger particles) and crushed again. That study found that the amount of crushing can have a significant impact on the reactivity of aggregates (Shehata, Christidis et al., 2010), which was attributed to the loss of adhered mortar during successive crushing (Nagataki, Gokce et al., 2004). To investigate this, material from the crushing facility produced from the four exposure blocks from Ottawa (Alberta, Bernier, Potsdam and Springhill RCAs) that met the ASTM C1260 gradations ( $<4$ $\mathrm{mm})$ was put aside and labeled as "crusher's fines." The larger material $(>4 \mathrm{~mm})$ produced from the pilot scale crushing was then re-crushed using laboratory crushers to the appropriate gradation for the ASTM C1260 and labeled "re-crushed." These two materials were then tested separately as part of the multi-laboratory study. The results of this study will be discussed in Section 3.0. A full review of how the RCAs were crushed is available in the Phase 1 report (Ideker, Tanner et al., 2012). The RCAs used as part of the dual-laboratory study and the mitigation study (Jobe, CalPort, OPP and Steps) were used in a mixed form, incorporating both crusher's fines and re-crushed material.

ASTM C1260 states that aggregates that need to be crushed to meet the gradation requirements must be washed free of dust and fine particles, and then dried prior to use. This is typically done by placing the crushed aggregate over a sieve of a finer mesh size than the gradation, and spraying it with tap water until the water that passes through the aggregate runs clear. It was necessary to modify the aggregate washing procedure prior to incorporating RCA in to sample mixtures because the water never ran clear. Previous researchers have speculated that washing aggregates may result in a reduction in expansion due to washing away available alkalis ( $\mathrm{Li}$ and Gress, 2006; Shehata, Christidis et al., 2010). A prolonged washing period may alter the characteristics of the RCA by eroding away adhered mortar, hydrating unhydrated cement particles in the RCA, or washing away calcium or alkalis from the RCA and existing ASR gel within the RCA. In order to counter these effects, but still provide a basic level of washing for the aggregate, a reduced time for each aggregate size was used.

- Wash aggregate using a rubber hose with a fanned-spray hose nozzle for the following times for each retained on sieve size:

○ \#8 Sieve: 3 minutes 30 seconds

○ \#16 Sieve: 5 minutes

- \#30 Sieve: 6 minutes

○ \#50 Sieve: 7 minutes

- \#100 Sieve: 8 minutes 
A full explanation of the new procedure can be found in the Phase I report (Ideker, Tanner et al., 2012).

\subsubsection{Absorption Capacity}

As noted earlier, RCA's absorption capacity has been shown to be significantly higher than virgin aggregate, depending on the RCA's composition, ranging from 3-12\% (Katz, 2003; Rao, Jha et al., 2007). The standard test method for determining the absorption capacity of aggregates, ASTM C128, is not currently approved for use with RCA (ASTM C128, 2007) because it states a soak time of $24 \pm 4$ hours is required to reach full saturation. This soak time may not be valid for aggregates with high absorption capacities. In order to find the appropriate soak time for RCA, a lab-created RCA was soaked for 24,48 and 72 hours. The absorption capacity was checked for each soak time. It was determined that the RCA reached $95 \%$ of its absorption capacity within 24 hours of soaking, and exhibited minimal gain in water uptake at 48 and 72 hours. Furthermore, a 30-minute soak time was required to reach $85 \%$ of the aggregate's total absorption capacity. It was determined that the ASTM C128 method's 24-hour soak period could be used to determine the RCA's absorption capacity.

\subsubsection{Mortar Bar Mixing Procedure}

Previous work by Scott and Gress using the concrete prism test (ASTM C1293) has shown that using RCA in the oven-dry state in ASR testing could result in early expansion of the test specimens. This is thought to be because the highly absorptive RCA takes in water from the concrete matrix and swells. It was shown that presoaking aggregates prior to running the ASR tests produced less early expansion (Scott and Gress, 2004). Also, the high absorption capacity can result in a significant reduction in workability when using RCA (Poon, Shui et al., 2004). Therefore, it was decided that the RCA should be soaked in the mixing water, with an adjustment to account for the absorption capacity of the aggregates. The RCA was soaked for 30 minutes to allow for $85 \%$ absorption prior to use in the ASTM C1260 test. The presoaking of aggregates necessitated a modification to the order of the addition of material during the mortar mixing procedure (ASTM C305, 2006). The full explanation of the new mortar mixing procedure can be found in the Phase I report (Ideker, Tanner et al., 2012).

\subsection{ASTM C1260 AND ASTM C1567 GENERAL DESCRIPTIONS}

ASTM C 1260 is a rapid test used to assess ASR in mortar specimens, and is often referred to as the accelerated mortar bar test (AMBT). This test involves casting mortar prisms that measure 25 x $25 \times 285 \mathrm{~mm}$. A stainless steel gage stud is cast into both ends of each bar to provide an effective $254 \pm 2.54-\mathrm{mm}$ gage length. After curing for $24 \pm 2$ hours in $95 \%$ or higher relative humidity, $23 \pm 2{ }^{\circ} \mathrm{C}$ moist room, the specimens are submerged in tap water and placed in a $80 \pm$ $2^{\circ} \mathrm{C}$ oven where they equilibrate to that temperature before the next reading. The initial or zero reading of the bars is taken $24 \pm 2$ hours later and the bars are quickly transferred to a solution of $1 \mathrm{~N} \mathrm{NaOH}$, which is already at $80 \pm 2^{\circ} \mathrm{C}$. The bars then remain in $1 \mathrm{~N} \mathrm{NaOH}$ at $80 \pm 2^{\circ} \mathrm{F}$ for 14 days. In this project, readings were taken at 21 and 28 days as well. Several measurements are taken throughout this period at approximately the same time each day. Length change is 
recorded to the nearest 0.0001 inch and results are presented for the average of four prisms to the nearest $0.01 \%$ (ASTM C 1260-07).

It is important to note that this test is only applicable to mortar. Therefore, if the reactivity of a coarse aggregate is to be assessed with this test method, the aggregate must be crushed to meet the gradation standards of the test. As a result, it is possible to expose and remove reactive phases during the crushing, sieving and washing process required by the standard (ASTM C 1260-08). This may lead to inaccurate reactivity predictions when using ASTM C 1260 for field structures containing potentially reactive coarse aggregates (Thomas et al., 2006).

Expansion criteria for this test fall into three categories within ASTM C 1260 based on expansion measured 16 days after casting (14 days after immersion in $1 \mathrm{~N} \mathrm{NaOH}$ ). Expansion of less than $0.10 \%$ is generally considered to be indicative of innocuous behavior. Expansion of more than $0.20 \%$ indicates that the aggregates are potentially deleterious. Expansion that falls between $0.10-0.20 \%$ indicates that the aggregate may exhibit either innocuous or deleterious performance in the field (ASTM C 1260-07). The above expansion criteria, as described in ASTM C 1260, are not actually used by many researchers or agencies. Rather, the consensus among many ASR researchers and engineers is to use an expansion limit of $0.10 \%$ after 14 days of immersion in the soak solution to indicate aggregate reactivity (Thomas et. al, 2007).

By ASTM C 1260 standards, aggregates are classified by day 14 as reactive; however, it has been suggested that researchers continue the test for 28 days for further observation (Fournier, 2006). Because the ASTM C 1260 test conditions are harsh, the rate of expansion can increase between 14 and 28 days. This means a specimen may pass within 14 days and fail within 28 days. Such examples contribute to false negative results that are widely reported in the literature. Although ASTM C 1260 does not provide guidance on 28-day measurements for a classification, this speculation may help engineers recommend conservative treatment options. For example, an engineer may change the aggregate classification if it reached the $0.1-0.2 \%$ expansion limits at the 28-day point. Other researchers have shown the strongest correlation to field exposure (in outdoor exposure blocks and actual structures) to be a 14-day limit at $0.1 \%$ expansion (Thomas et. al, 2007). For this study's purposes, an expansion limit of $0.10 \%$ at 14 days will be used. However, readings will be taken out to 28 days to provide longer-term expansion data, which will be beneficial to more fully characterize RCA reactivity and for future data analysis should different limits be suggested for RCA.

The ASTM C1567 test is also referred to as the AMBT, and is a modification of the ASTM C1260 test that allows the efficacy of SCM to reduce ASR expansion to be tested (ASTM C1567, 2007). The testing procedure is similar to the ASTM C1260 test explained above. Expansion criteria for this test, however, differs from that of the ASTM C1260 test, and falls into two categories within ASTM C1567 based on expansion measured 16 days after casting (14 days after immersion in $1 \mathrm{~N} \mathrm{NaOH}$ ). Expansion of less than $0.10 \%$ is generally considered to be indicative of innocuous behavior. That is, the aggregate's reactivity will likely not be high enough to cause deleterious expansions in concrete in the field. Expansions of more than $0.10 \%$ indicate that the aggregates are potentially deleterious (ASTM C1260, 2007). 


\subsubsection{Discussion of AMBT Testing Methods}

The shortcomings of ASTM C 227 and ASTM C 289 (e.g., excessive leaching in C 227 and aggregate only testing C 289) highlighted the need for and led to the development of ASTM C 1260 (Lane, 1999), also known as the AMBT. In 1986, Oberholster and Davies (1986) developed a test in South Africa that eventually became ASTM C 1260 and was formally adopted in 1994.

ASTM C1260 and ASTM C1567 are preferred to other tests because they are reliable and quick, and the severe testing environment helps to identify more slowly reacting aggregates (ACI, 2008). Unfortunately, the test does have limitations. The harsh testing environment does not represent actual field conditions, and some aggregates that perform well in the field actually fail this test. Therefore, the AMBT should not be solely used to reject aggregate. Other tests such as ASTM C 33 (2003) or ASTM C 1293 are also used (Touma et al., 2001). ASTM C 1293 has been shown, though rarely, to classify an aggregate as nonreactive when it proves to be reactive in the field (Fournier, Nkinamubanzi et al., 2006). Because of the possibility for these tests to register false results, it is recommended that multiple methods be used to characterize aggregate ASR susceptibility, including past field performance (Ideker, Bentivegna et al., 2012). This, however, is a difficult task when using RCA. Currently, there are very few examples of field performance of RCA where ASR is monitored (Gress, Snyder et al., 2009), and very little data has been collected concerning ASTM C1260, ASTM C1293, and outdoor exposure site testing. This difficulty highlights the need for more testing in this area

\subsubsection{Multi-laboratory and Dual-laboratory Studies (ASTM C1260) Testing Program}

The testing program for this work was performed in two phases. Phase I included the fourlaboratory study. This phase of the study used the Alberta, Bernier, Potsdam and Springhill RCA. In order to examine the effects of crushing procedures, different mixtures were cast using the crusher's fines and the re-crushed versions of the RCA. Specimens with $100 \%$ RCA, 50\% RCA and 25\% RCA were cast for both the crusher's fines and re-crushed versions, with the CANMET sand used for the remaining portion of the material required for the mixtures. This phase also provided the data, from the multi-lab study, to assess the test's repeatability and applicability of the precision statements listed in ASTM C1260.

Phase II involved further ASR testing of RCA in a second, two-laboratory study using the CalPort, Steps and OPP RCA, to determine if stockpiled and field-structure sourced RCA produced similar results and repeatability as those produced by the laboratory aggregates. Specimens with 100\% RCA, 50\% RCA and 25\% RCA replacement levels were cast using the CalPort RCA. Specimens with 100\% RCA, 50\% RCA and 20\% RCA replacement levels were cast using the Steps and OPP RCA. Twenty percent replacement using the Steps and OPP RCA were done because there was not enough material available to complete the testing with a $25 \%$ replacement level. The testing carried out in phases I and II is summarized in Table 2-3 below. 
Table 2-3: Multi-laboratory Mortar Bar Sets for Phases I and II

\begin{tabular}{|c|c|c|c|c|}
\hline \multicolumn{5}{|c|}{ Phase I Sets } \\
\hline \multicolumn{5}{|c|}{ Crusher's Fines RCA } \\
\hline Mixture Type $^{a}$ & Potsdam & Springhill & Bernier & Alberta \\
\hline $100 \% \mathrm{RCA}$ & 1 & 2 & 1 & 1 \\
\hline $50 \% \mathrm{RCA}$ & 1 & 1 & 2 & 2 \\
\hline $25 \% \mathrm{RCA}$ & 1 & 1 & 1 & 2 \\
\hline \multicolumn{5}{|c|}{ Re-crushed RCA } \\
\hline Mixture Type $^{a}$ & Potsdam & Springhill & Bernier & Alberta \\
\hline $100 \% \mathrm{RCA}$ & 1 & 3 & 1 & 1 \\
\hline $50 \% \mathrm{RCA}$ & 1 & 1 & 2 & 2 \\
\hline $25 \% \mathrm{RCA}$ & 1 & 1 & 1 & 2 \\
\hline \multicolumn{5}{|c|}{ Phase II Sets } \\
\hline \multicolumn{2}{|c|}{ Mixture Type $^{\mathrm{a}}$} & CalPort & Steps & OPP \\
\hline \multicolumn{2}{|c|}{$100 \%$ RCA } & 2 & 2 & 1 \\
\hline \multicolumn{2}{|c|}{$50 \%$ RCA } & 2 & 2 & 2 \\
\hline \multicolumn{2}{|c|}{$25 \% \mathrm{RCA}$} & 2 & N/A & $\mathrm{N} / \mathrm{A}$ \\
\hline \multicolumn{2}{|c|}{$20 \% \mathrm{RCA}$} & $\mathrm{N} / \mathrm{A}$ & 2 & 2 \\
\hline
\end{tabular}

Note: Each set composed of 3 mortar bars

a Percent replacement of NA by RCA

\subsubsection{Mitigation Study (AMBT C1567) Testing Program}

A study to determine the efficacy of binary and ternary blends of ordinary portland cement and SCM to mitigate ASR in mortar bars made with RCA was undertaken in Phase II. This testing was completed with the Jobe and CalPort RCAs, with the CANMET sand used as the nonreactive portion in mortar bars that were made with less than a 100\% replacement level of RCA. The class F fly ash, metakaolin and silica fume reported in Table 2-2 were used as a part of the mitigation study as well.

The initial level of fly ash replacement for each aggregate was determined using the equation developed by Malvar and Lenke (2006) at a 90\% confidence level. This equation was developed from a study performed to determine the efficiency of fly ash to mitigate ASR expansion. Malvar and Lenke's equation allows the user to input the chemical constituents and receive a result of the mass percent of fly ash needed to replace cement to control the reaction. They divided the chemical constituents of cement and fly ash into two groups: (1) constituents that promoted ASR and (2) constituents that prevent ASR. The constituents that were classified as promoting ASR were calcium oxide $(\mathrm{CaO})$, alkalis $\left(\mathrm{Na}_{2} \mathrm{O}\right.$ and $\mathrm{K}_{2} \mathrm{O}$, expressed as $\left.\mathrm{Na}_{2} \mathrm{O}_{\text {eq }}\right)$, magnesium oxide $(\mathrm{MgO})$ and sulfur trioxide $\left(\mathrm{SO}_{3}\right)$. The constituents that worked to prevent ASR were identified as silicon dioxide $\left(\mathrm{SiO}_{2}\right)$, aluminum trioxide $\left(\mathrm{Al}_{2} \mathrm{O}_{3}\right)$, and iron oxide $\left(\mathrm{Fe}_{2} \mathrm{O}_{3}\right)$. These were then expressed as calcium oxide equivalents $(\mathrm{CaO} e q)$ and silicon dioxide equivalents $\left(\mathrm{SiO}_{2 \mathrm{eq}}\right)$. 
Weighting factors were also developed to account for the difference in reactivity between the various chemical constituents, and were then applied to the calcium oxide and silicon dioxide equivalents. These were determined to be $\alpha=5.64$ and $\beta=1.14$, respectively. Oxide contents were entered as percent mass of total fly ash or portland cement (Malvar and Lenke, 2006). These can be seen in Equation 2-1 and Equation 2-2:

$$
\begin{gathered}
\mathrm{CaO}_{e q \alpha}=\mathrm{CaO}+\alpha\left(0.905 \mathrm{Na}_{2} \mathrm{O}_{e q}+0.595 \mathrm{~K}_{2} \mathrm{O}+1.391 \mathrm{MgO}+0.700 \mathrm{SO}_{3}\right) \\
\mathrm{SiO}_{2 e q \beta}=\mathrm{SiO}_{2}+\beta\left(0.589 \mathrm{Al}_{2} \mathrm{O}_{3}+0.376 \mathrm{Fe}_{2} \mathrm{O}_{3}\right)
\end{gathered}
$$

Equation 2-1

Equation 2-2

A set of constants was also developed that changed depending on the level of reliability required by the user to determine how much fly ash would be needed to reduce ASR expansions. For a 90\% reliability level that ASR would be mitigated, values used by Malvar and Lenke were: $\mathrm{a}_{1}=0$, $\mathrm{a}_{2}=1.0244, \mathrm{a}_{3}=0.6696$ and $\mathrm{a}_{4}=0.1778$. Finally, the percent mass replacement of fly ash required to mitigate ASR using a specific combination of aggregate, cement and fly ash was determined to be (Malvar and Lenke, 2006):

$$
W=\frac{1-g\left(\frac{0.08}{E_{14 c}}\right)}{\left(1-\frac{C a O_{e q \alpha f a}}{C a O_{e q \alpha c}}\right)-\left(1-\frac{S i O_{2 e q \beta f a}}{S i O_{2 e q \beta c}}\right) g\left(\frac{0.08}{E_{14 c}}\right)}
$$

Where:

$\mathrm{W}=$ mass percent replacement of fly ash required to mitigate ASR

$E_{14 c}=$ Percent expansion of mortar bars in the accelerated mortar bar test at 14 days

$$
g=\frac{a_{4}\left(\tanh ^{-1}\left(\frac{2\left(\frac{0.08}{E_{14 c}}\right)-\left(a_{1}+a_{2}\right)}{a_{2}-a_{1}}\right)\right)+a_{3}}{\frac{0.08}{E_{14 c}}}
$$

$\mathrm{CaO}_{\text {equfa }}=$ Calcium oxide equivalent, with the alpha factor applied, for the fly ash $\mathrm{CaO}_{\text {eq } \alpha c}=$ Calcium oxide equivalent, with the alpha factor applied, for the portland cement $\mathrm{SiO}_{2 \text { eq } \beta \mathrm{fa}}=$ Silicon dioxide equivalent, with the beta factor applied, for the fly ash $\mathrm{SiO}_{2 \mathrm{eq} \beta \mathrm{c}}=$ Silicon dioxide equivalent, with the beta factor applied, for the portland cement

It is important to note that this equation was developed empirically based on the evaluation of five studies using 29 fly ashes and five aggregates (ASTM C618, 2012). The chemical index equations may not be accurate for all combinations of materials, and testing should always be performed prior to using the fly ash replacement level stipulated by this formula in field concrete. The equation does, however, provide a starting point for engineers to use to develop the appropriate fly ash replacement dosage to mitigate ASR. 
Using this equation, the predicted amount of the class $\mathrm{F}$ fly ash used in this study required to reduce expansions in mortar bars made with RCA was determined. These amounts can be seen in Table 2-4.

Table 2-4: Fly Ash Mitigation Requirements per Malvar and Lenke Equation

\begin{tabular}{|c|c|c|c|c|}
\hline RCA & $\begin{array}{c}\text { RCA } \\
\text { Replacement } \\
\text { Level (\%) }\end{array}$ & $\begin{array}{c}\text { Expansions at } \\
\text { 14-days in } \\
\text { ASTM } \\
\text { C1260 (\%) }\end{array}$ & $\begin{array}{c}\text { Fly Ash Required to } \\
\text { Reduce Expansions } \\
\text { Below 0.08\% at 14- } \\
\text { day in ASTM C1567 } \\
\text { (\% weight) }\end{array}$ & $\begin{array}{c}\text { Amount } \\
\text { Used in } \\
\text { Testing (\% } \\
\text { weight) }\end{array}$ \\
\hline Jobe & 100 & 0.12 & 17 & 20 \\
\hline CalPort & 100 & 0.51 & 38 & 40 \\
\hline CalPort & 50 & 0.53 & 35 & 35 \\
\hline CalPort & 25 & 0.29 & 30 & 30 \\
\hline
\end{tabular}

${ }^{1}$ Amounts used in testing were rounded up to the nearest $5 \%$

Research by Shehata et al. has shown that when mitigating ASR in concrete containing RCA, it may take more of a particular fly ash to reduce expansions compared to that needed to reduce expansions for natural aggregate concrete made with the same original natural aggregate as in the RCA (Shehata, Christidis et al., 2010). Specimens were also cast using 10-20\% more fly ash than that recommended by Malvar and Lenke to meet an upper bound on the amount of fly ash necessary to reduce expansions to within acceptable limits.

The mitigation study also looked at the ability of ternary blends to mitigate alkali-silica reaction in mortar bars containing RCA. For this study, ternary blends using class F fly ash, silica fume and portland cement, and class F fly ash, metakaolin and portland cement were incorporated into the mortar bar mixtures. These blends were used with both the Jobe and CalPort RCA at the same replacement levels listed above. The full testing matrix can be seen in Table 2-5. 
Table 2-5: Cementitious Material Content by Mixture for Mitigation Study

\begin{tabular}{ccccccc}
\hline Mixture Name & $\begin{array}{c}\text { RCA } \\
\text { Used }\end{array}$ & $\begin{array}{c}\text { Replacement } \\
\text { Level of RCA } \\
(\%)\end{array}$ & $\begin{array}{c}\text { Portland Cement } \\
\text { Content } \% \text { of } \\
\text { Cementitious } \\
\text { Materials) }\end{array}$ & $\begin{array}{c}\text { Class F Fly Ash } \\
\text { Content (\% of } \\
\text { Cementitious } \\
\text { Materials) }\end{array}$ & $\begin{array}{c}\text { Silica Fume } \\
\text { Content (\% of } \\
\text { Cementitious } \\
\text { Materials) }\end{array}$ & $\begin{array}{c}\text { Metakaolin } \\
\text { Content (\% of } \\
\text { Cementitious } \\
\text { Materials) }\end{array}$ \\
\hline Jobe-100 & Jobe & 100 & 100 & - & - & - \\
Jobe-100-20FA & Jobe & 100 & 80 & 20 & - & - \\
Jobe-100-30FA & Jobe & 100 & 70 & 30 & - & - \\
Jobe-100-40FA & Jobe & 100 & 60 & 40 & - & - \\
Jobe-100-25FA_10MK & Jobe & 100 & 65 & 25 & - & 10 \\
Jobe-100-25FA_5SF & Jobe & 100 & 70 & 25 & 5 & - \\
\hline CalPort-100 & CalPort & 100 & 100 & - & - & - \\
CalPort-100-40FA & CalPort & 100 & 60 & 40 & - & - \\
CalPort-100-50FA & CalPort & 100 & 50 & 50 & - & - \\
CalPort-100-25FA_10MK & CalPort & 100 & 65 & 25 & - & 10 \\
CalPort-100-25FA_5SF & CalPort & 100 & 70 & 25 & 5 & - \\
\hline CalPort-50 & CalPort & 50 & 100 & - & - & - \\
CalPort-50-35FA & CalPort & 50 & 65 & 35 & - & - \\
CalPort-50-45FA & CalPort & 50 & 55 & 45 & - & - \\
CalPort-50-25FA_10MK & CalPort & 50 & 65 & 25 & - & 10 \\
\hline CalPort-25 & CalPort & 25 & 100 & - & - & - \\
CalPort-25-30FA & CalPort & 25 & 70 & 30 & - & - \\
CalPort-25-40FA & CalPort & 25 & 60 & 40 & - & - \\
CalPort-25-25FA_10MK & CalPort & 25 & 65 & 25 & - & 10 \\
CalPort-25-25FA_5SF & CalPort & 25 & 70 & 25 & 5 & - \\
\hline
\end{tabular}

\subsection{OUTDOOR EXPOSURE BLOCKS}

A UW exposure site started in 2008, with the current field specimens constructed in 2011. Although large-scale testing is the most accurate reflection of an aggregate's behavior, it often requires up to five years to observe expansion behavior. The authors know of over 25 large-scale field exposure sites (Thomas, Fournier et al., 2006; Ideker, Drimalas et al., 2012) Large-scale field specimens were also cast and exposed to the Wyoming climate for two years (Figure 2-1). 


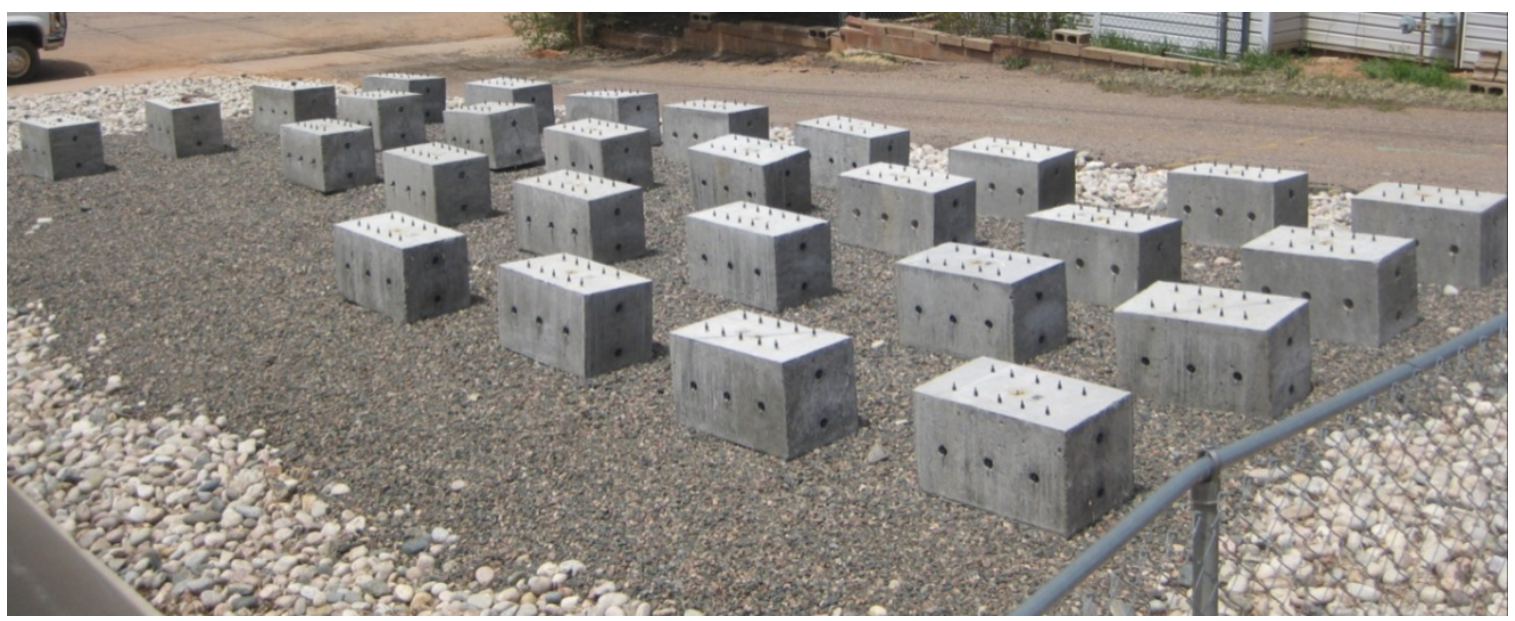

Figure 2-1: Outdoor exposure site

Plywood formwork was constructed to create ( $15 \times 15 \times 26$ in.) specimens. The formwork was then caulked and allowed to cure for 48 hours. Once the caulking was dry, a debonding agent was applied to the formwork and threaded rod assemblies were inserted into predrilled holes for measurement stud installation. To secure the measurement studs into the concrete block, a threaded steel insert assembly (steel insert, a threaded rod, a wooden spacer and a nut) was bolted to the inside of the form, as shown in Figure 2-2.
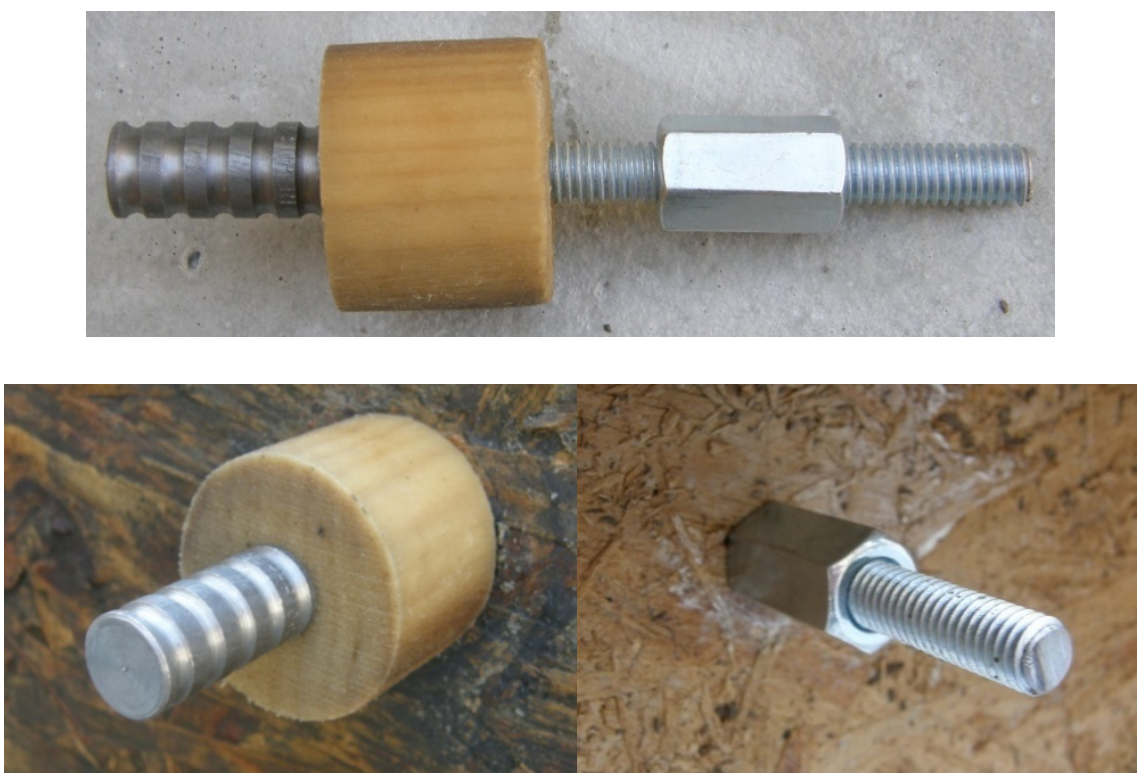

Figure 2-2: A) threaded steel insert assembly b) portion of the insert assembly on the inside of the form (left) and c) portion of the insert assembly on the outside of the form (right)

Ten threaded rod assemblies were installed into the formwork, three on each long side and two on each end, as described in the next section. After curing for 28 days, the formwork was removed. The original threaded rod lengths that were placed in the concrete inserts during 
casting were removed and replaced with the actual measurement stud. Figure 2-3 shows a schematic of the field specimens with associated length measurement locations.

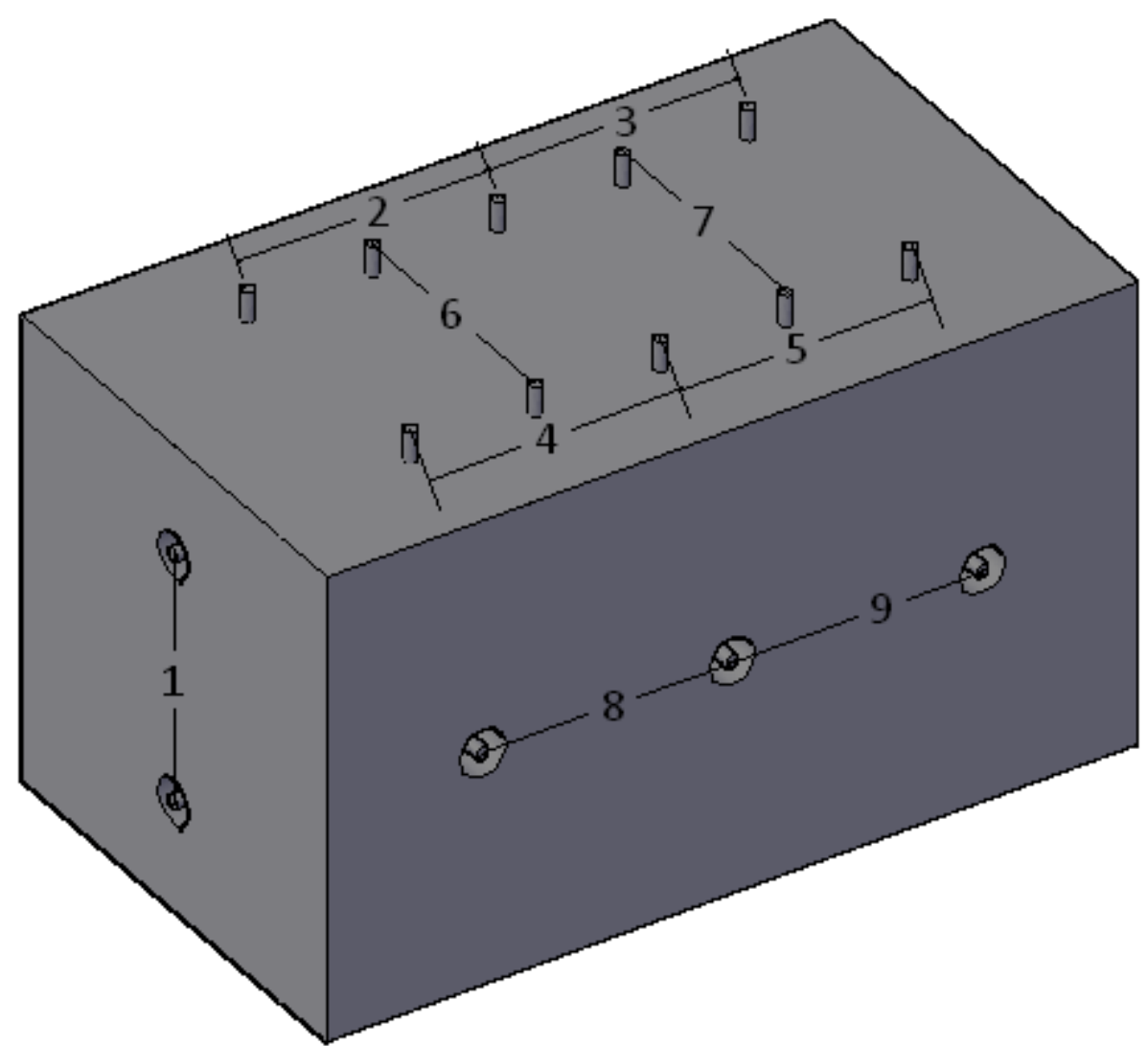

Figure 2-3: Field specimen diagram showing the layout of the measurement locations

Four specimens were cast, including a control specimen and two boosted specimens (Steps and OPP). There was not enough CalR RCA to cast a large-scale block. In addition, the Steps and OPP RCA replacement levels were cut from $25 \%$ to $20 \%$. Brighton aggregate, mined in Colorado, was chosen as a non-reactive aggregate supplement to the blocks due to its extremely low ASR potential. Aggregate Industries, Inc. has extensive data indicating expansion limits are well below the C 1260 limit, and validation studies at UW corroborated their data. RCA field specimens consisted of:

- $1-100 \%$ Brighton - Control

- $1-20 \%$ Steps (Boosted) $/ 80 \%$ Brighton - STEP-B

- $1-20 \%$ Steps $/ 80 \%$ Brighton Block - STEP-U

- $\quad 1-20 \%$ Old Power Plant (Boosted) $/ 80 \%$ Brighton - OPP-B

A "boosted" block includes an addition of sodium hydroxide $(\mathrm{NaOH})$ to the mix water during casting. This pushes the cement alkalinity to $1.25 \% \mathrm{Na}_{2} \mathrm{O}$ and induces an estimate of behavior associated with the same initial alkalinity level as C 1293 tests. Casting both a boosted and an unboosted large-scale block, allows for an aggregate's full range of expansive behavior to be seen. 
All specimens in this study were cast with a target water-to-cement ratio of 0.42 . A polycarboxylate-based superplasticizer was added to the field specimen mix as well to increase workability. Quantities of aggregate and cement are shown in Table 2-6.

Table 2-6: Cement, Coarse and Fine Aggregate Proportions for Large-scale Field Specimens

\begin{tabular}{|c|c|}
\hline Material & Quantity (Ib) \\
\hline Coarse Aggregate & 305 \\
\hline Fine Aggregate & 196 \\
\hline Cement & 124 \\
\hline
\end{tabular}

Overall expansion was evaluated by averaging measurements on 12 locations on each block (Figure 2-3). There were four longitudinal measurements on the top, and two longitudinal measurements along each side. In addition, there were two transverse measurements on top and one vertical measurement on each end. All measurements had an approximate gage length of eight inches.

\subsubsection{Measurement Procedure}

Figure 2-4a shows the measurement studs after installation. Each measurement stud was made from 2-inch lengths of galvanized threaded rod with a preset hole drilled into the very center and a second hole offset by 0.1 inches. Offset holes were placed in each stud to maximize movement measurements, as shown in Figure 2-4b.

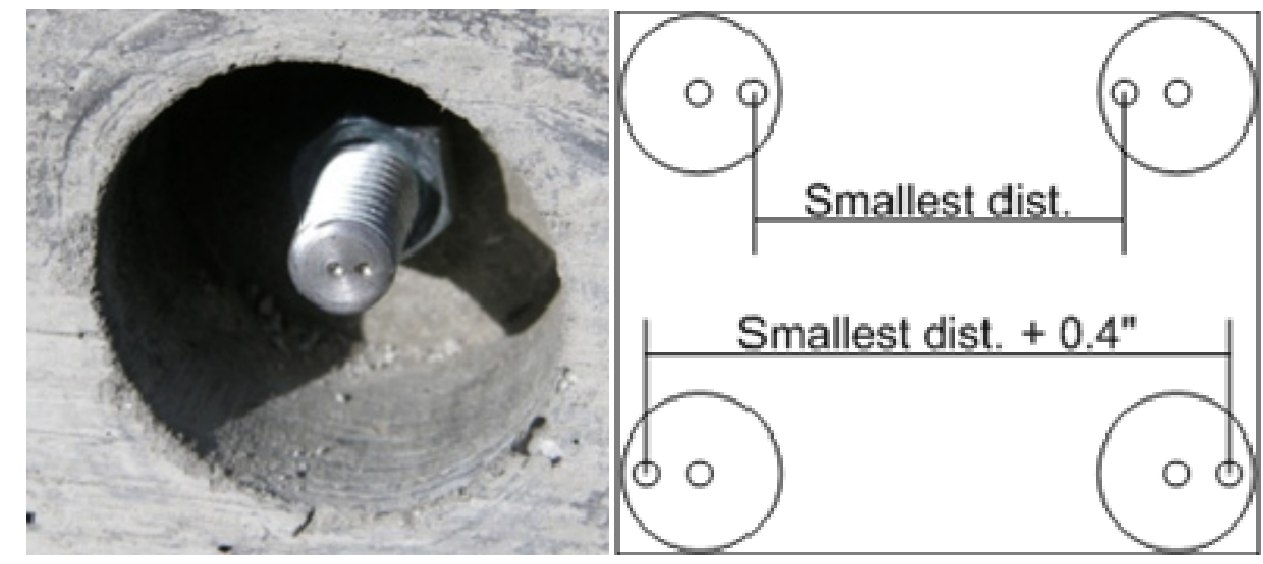

Figure 2-4: A) Measurement studs after installation into large-scale field blocks b) use of offset markings in measurement stud

Gage points were selected so that a single 8-inch Demec instrument could be used. This apparatus is constructed out of invar to reduce measurement variations due to thermal expansions; the gage resolution is 0.0001 inch. Final expansion measurements represent the average of longitudinal strains $(2,3,4,5,8,9)$ and transverse strains $(1,6,7)$ (see Figure 2-3). 


\subsection{PHASE I SUMMARY}

This research project, started in the 2009-2010 funding cycle, had the primary goal of investigating the long-term durability of concrete incorporating recycled concrete aggregate (RCA) through accelerated laboratory testing. Of particular interest was the possibility of pronounced alkali-silica reaction (ASR), an expansive reaction that results in cracking and a reduction in the service life of concrete structures in new concrete incorporating RCA which may have active ASR. This area of concern was identified by several states as a major research need in a recent Federal Highway Administration study (FHWA, 2003).

A unique opportunity arose for the research team on this project to collaborate with two additional universities. Dr. Benoit Fournier (formerly of CANMET-MTL) is an associate professor at Université Laval in Quebec City, and Dr. Medhat Shehata is an assistant professor at Ryerson University in Toronto.Dr. Fournier is a world-renowned ASR researcher with over 25 years of experience focusing on testing methods and characterization of the reaction from a petrographic perspective. He recently has started investigations into RCA as sources of virgin aggregate have decreased and demand for sustainable construction practices in Canada has increased. Dr. Shehata has the longest tenure working on RCA, starting with his dissertation research topic and continuing through his six years as an assistant professor. This collaboration allowed four universities to work on the same sources of RCA.

As a result of the collaboration with research teams at Laval and Ryerson, the scope of the project and objectives for Phase I were modified. All Phase I objectives were still met. However, it was necessary to shift research priorities slightly between the project's two phases. In short, more verification of accelerated testing methods was performed in Phase I, resulting in a larger testing matrix for accelerated testing at both OSU and the UW. The DOT survey and database collection was therefore not started until late in Phase I. The results of the survey are reported here in Section 5.0.

\subsection{MULTI-LABORATORY STUDY}

Overall, the research team found that results from the ASTM C 1260 testing method could be replicated for the RCA sources investigated in this project. The team found that even though the RCA incorporated into ASTM C 1260 specimens had already undergone deleterious ASR in the field, there was still potential for expansion with certain RCA sources. The procedure used to crush the RCA to the appropriate gradation for the ASTM C1260 test can also have an impact on the level of reaction. The variation in multi-laboratory testing was higher than that for virgin reactive aggregate testing. While the four laboratories do not represent a minimum number of laboratories on which to base a precision and bias summary (ASTM recommends a minimum of six for a multi-laboratory precision and bias statement), the COVs for a single group range from $13.6-94.1 \%$. The latter is considerably higher than the multi-lab COV of $43 \%$ as specified by ASTM C 1260. A full set of variation data is available in the Phase I report (Ideker, Tanner et al., 2012). 
Phase I testing also found the following outcomes:

- Modifications to standard aggregate testing and characterization standards are necessary for RCA.

- Absorption capacity testing required at least a 24 -hour soaking period to take up $95 \%$ of the aggregate's total absorption.

- Modifications to ASTM C 305 were required for properly mixing mortars containing RCA, including a soaking period of 30 minutes for all aggregates (including RCA) to ensure proper absorption by dry aggregate and adequate mixing.

- Based on testing in this research project, precision and bias statements in ASTM C 1260 (for virgin aggregate) do not apply to RCA. Additional analysis from at least six laboratories testing the same materials would be needed to properly establish precision and bias statements. 


\subsection{PHASE II TESTING RESULTS AND DISCUSSION}

The testing program for Phase II consisted of three parts: 1) Accelerated mortar bar testing between UW and OSU using three sources of aggregates; 2) Large-scale field blocks with RCA replacement levels; and 3) Detailed study on mitigation effects. Results of each part are presented in the following sections.

\subsection{MULTI-LABORATORY AMBT TESTING}

The Phase I multi-laboratory study focused specifically on RCA that came from lab-created concrete. These RCA sources came from concrete exposure blocks that each had a specific mixture design, and therefore the RCA would be consistent throughout each source. The Phase I study showed that RCA that came from parent concrete that had already undergone deleterious ASR in the field retained the potential for expansion with certain RCA sources. Precision and bias statements in ASTM C 1260 (for virgin aggregate) do not apply to RCA. The Phase II study was performed to understand if these same conclusions could be made when using concrete that came from a stockpiled source or field structures, all of which relatively little is known about the parent concrete. The mixture design may vary throughout each individual source of RCA. Phase II testing was performed only by OSU and UW.

For this study's purposes, an expansion limit of $0.10 \%$ at 14 days will be used for all AMBT results. However, readings will be taken out to 28 days to provide longer-term expansion data, which will be beneficial to more fully characterize RCA reactivity and for future data analysis should different limits be suggested for RCA.

Figure 4-1 shows the expansion from 0 to 28 days of the CalPort, Steps and OPP RCA at a 100\% replacement level for the specimens made only at OSU. 


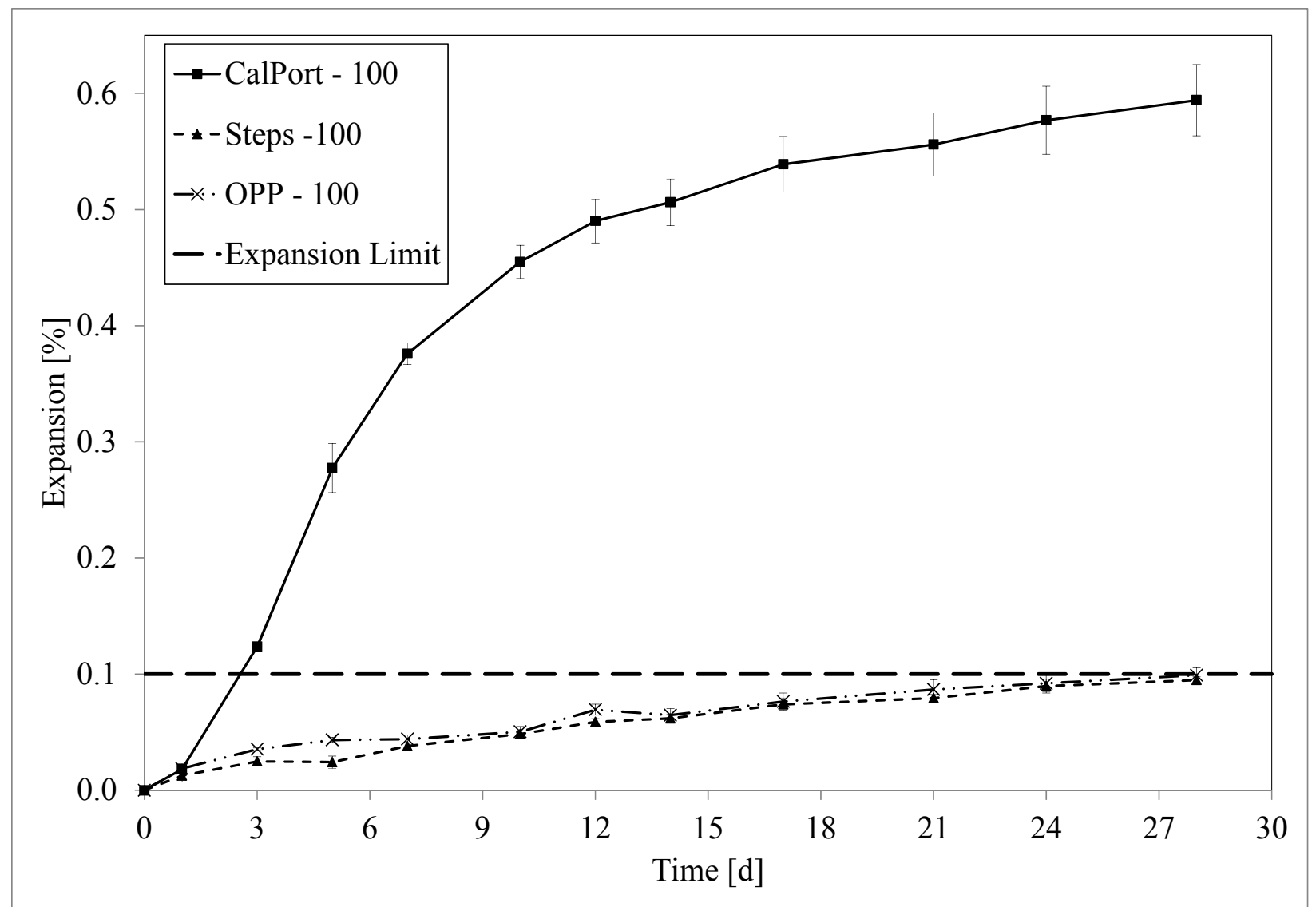

Figure 4-1: Expansion from 0 to 28 days for 100\% CalPort, 100\% Steps and 100\% OPP RCA (OSU Samples Only)

By day three, the mortar bars containing the CalPort RCA exceed the $0.10 \%$ expansion limit. By day 14 , they have reached an average expansion of $0.51 \%$ and an expansion of $0.59 \%$ by day 28 . According to the ASTM C1260 test limits, this aggregate would be classified as reactive. Steps and OPP RCA mortar bars, however, both react similarly. Steps mortar bars have an average expansion of $0.09 \%$ at day 28 , and the OPP mortar bars have an average expansion of $0.10 \%$ at 28 days. Therefore, since neither of the mortar bar sets has reached the expansion limit of $0.10 \%$ at 14 days, according to ASTM C1260 both of these RCAs would be classified as innocuous.

Though the original natural aggregates used in the CalPort, OPP and Steps RCA are different, this may not be the only reason for the major difference in expansion seen between the two RCA from the UW field structures (OPP and Steps) and the returned concrete RCA (CalPort). The three aggregates have significantly different ages. The returned concrete was crushed into RCA and used a relatively short time after the parent concrete was mixed. OPP and Steps material was produced from concrete that had been poured at least 10 year ago. A majority of the reactive material may have been depleted, leading to the lower level of reactivity seen in the OPP and Steps RCAs compared to the CalPort RCA. Additionally, the properties of returned concrete may have led to more original natural aggregate being included in the CalPort RCA compared to the OPP and Steps RCA. Returned concrete typically has water added to it at the job site and during the truck's cleanout. Therefore, the material's water-to-cement ratio may be significantly higher than the design water-to-cement ratio. This can lead to reduced concrete strength. Reduced 
concrete strength means that more of the adhered mortar will be removed during crushing operations and sieved out, leaving an RCA that is composed of relatively more reactive natural aggregate. As discussed in the Phase I report (Ideker, Tanner et al., 2012), this difference in adhered mortar content may cause a significant difference in expansion. This was confirmed in a study of the adhered mortar content performed on two of the RCAs used in Phase I. This study by Beauchemin and Fournier showed that the material that contained more adhered mortar had lower levels of expansions compared to material that contained less adhered mortar (Beauchemin and Fournier, 2012).

The following three figures show the 14-day average expansions for each RCA replacement level for each set of bars at UW and OSU for the CalPort, Steps and OPP RCA mortar bars, respectively.

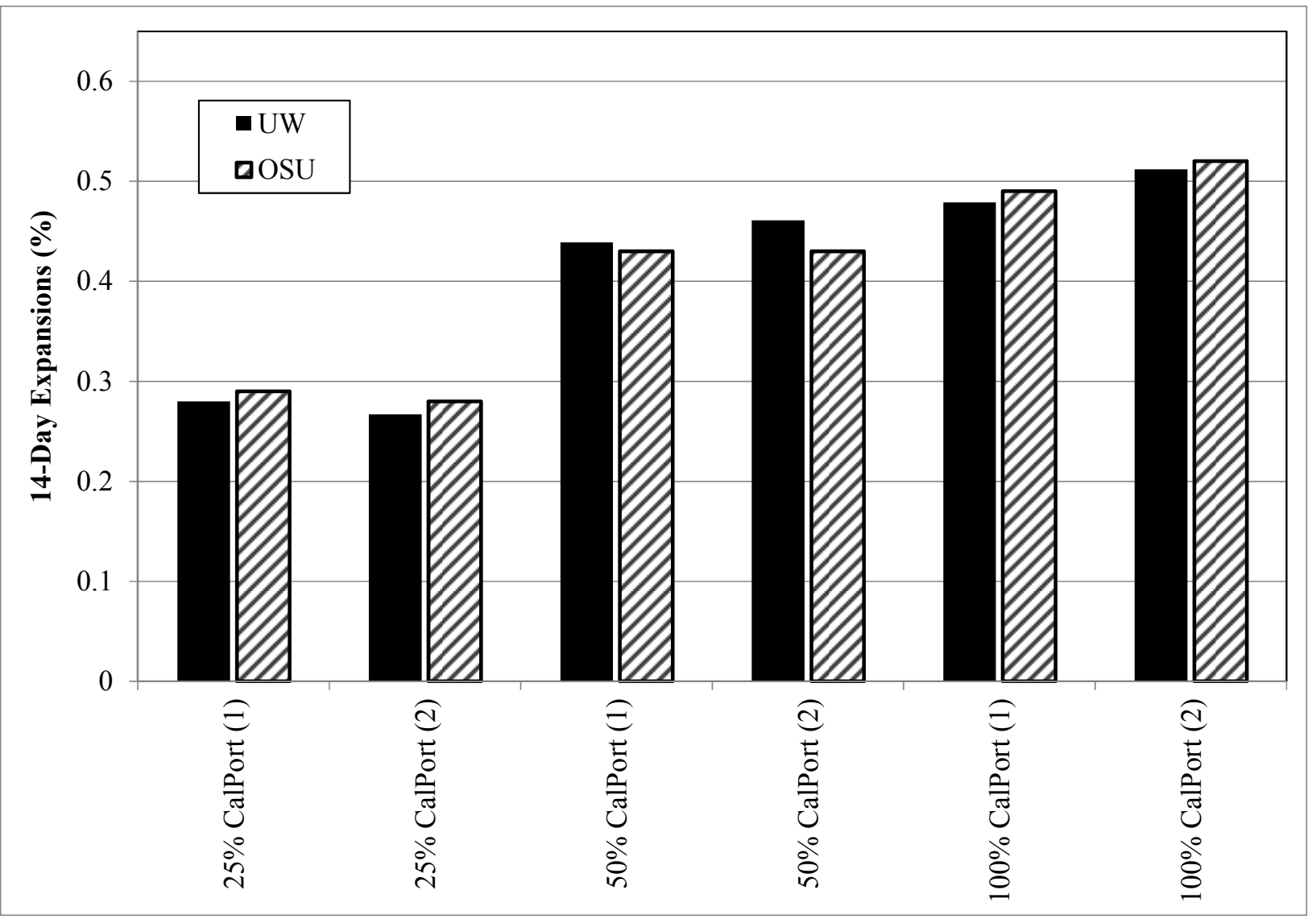

Figure 4-2: Average 14-day results for CalPort RCA sets 


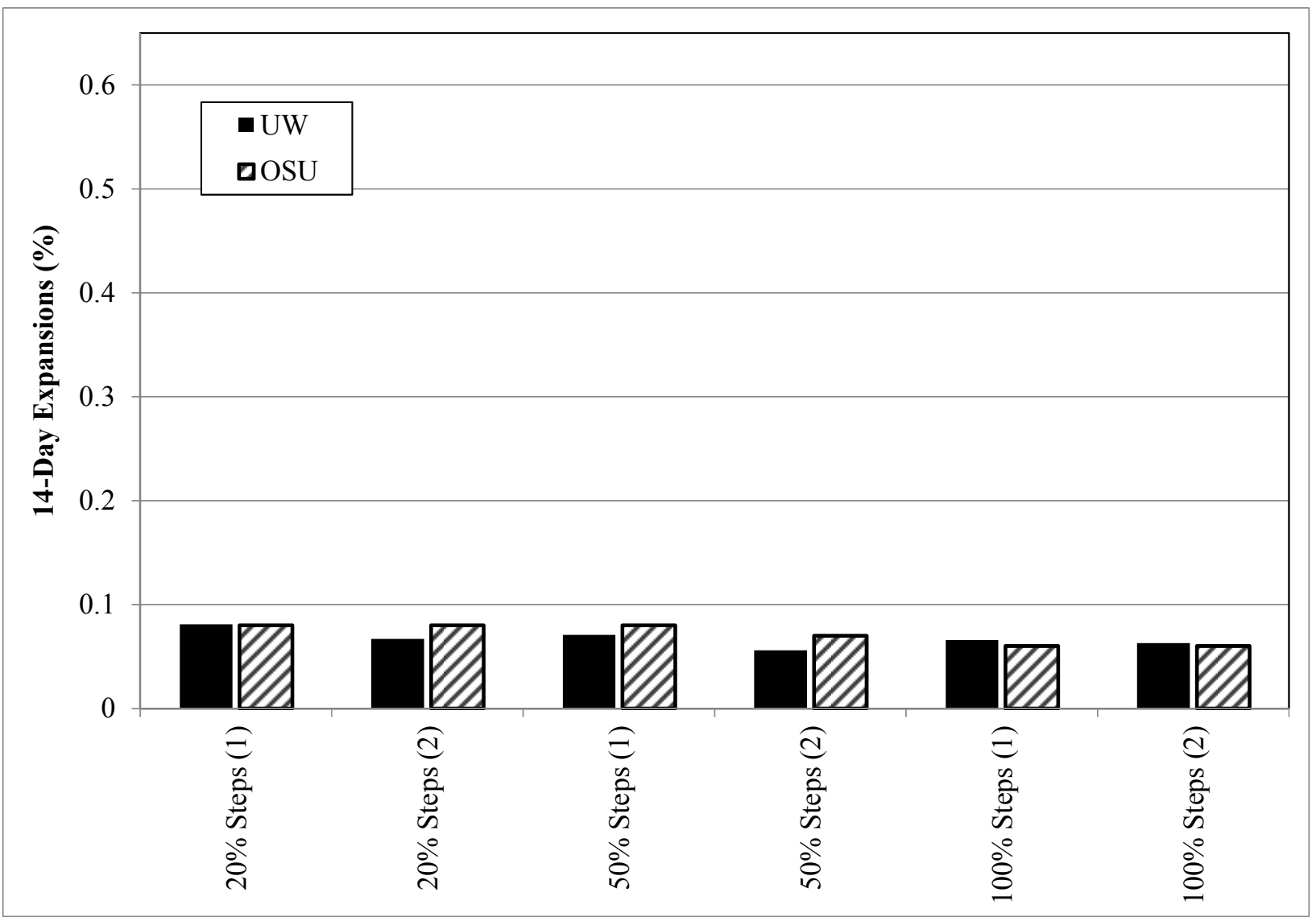

Figure 4-3: Average 14-day results for Steps RCA sets 


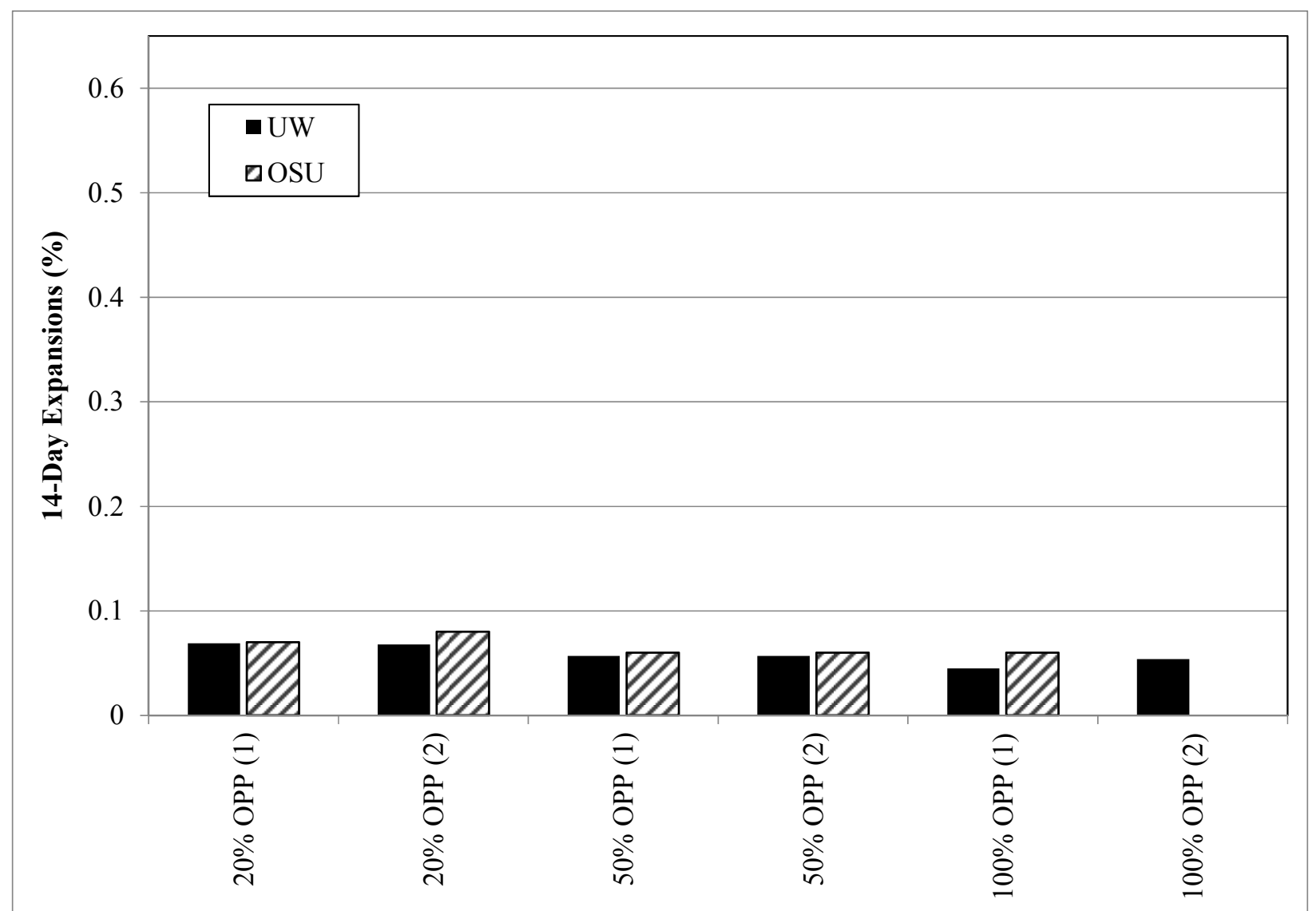

Figure 4-4: Average 14-day results for OPP RCA sets

Mortar bars containing the CalPort RCA show an increase in expansion as the amount of RCA included in the mortar bars increases from $25 \%$ to $50 \%$ and $100 \%$. This supports the results seen in Phase I, where typically the more reactive RCA that was included in a mortar bar, the higher the expansions (Ideker, Tanner et al., 2012). The other two aggregates used in the Phase II duallaboratory study do not follow this trend. The mortar bars containing OPP and Steps RCA show little change in expansion when the replacement level of natural aggregate for RCA is increased.

The reason for this difference could be due to one of the reasons stated above: the age of the Steps and OPP RCAs' parent concrete may have allowed for the depletion of reactive material. Alternatively, the inverse relationship between expansion and RCA replacement level seen in the Steps and OPP could be due to a pessimum effect. Some aggregates are known to have pessimum effects where, up to a certain percentage of reactive material, expansions increase. However, beyond that level expansions decrease (Hobbs, 1988; Bektas, Turanli et al., 2004; Garcia-Diaz, Bulteel et al., 2010). The pessimum proportion is an ideal balance between reactive silica and available alkali that will produce the highest expansion. These aggregates may exhibit higher expansions at lower replacement levels, or between replacement levels, than those tested. Additionally, the CalPort RCA was made from both a reactive natural coarse aggregate and a reactive natural fine aggregate. Therefore, the CalPort RCA would contain comparatively more reactive material compared to the other RCAs used in this study because not only is the original natural coarse aggregate reactive, but the adhered mortar also contains reactive material. 
These results confirm what was shown in the Phase I report: that different RCA sources can have significantly different ASR levels (Ideker and Tanner et al., 2012). The difference in trends seen between these three aggregates, and those in Phase I, exhibits the need to require testing at all replacement levels prior to using RCA that may have the potential to be ASR.

Table 4-1 shows the mean expansions; the coefficients of variation (COV); the precision boundary ( $43 \%$ above or below the mean expansions according to ASTM C1260); and the number of bars whose expansion was outside the precision boundary for all RCA replacement levels and RCAs used in Phase II.

Table 4-1: Dual-laboratory Expansion Averages, Coefficients of Variation, and Precision Limits for Phase II RCA

\begin{tabular}{|c|c|c|c|c|c|c|}
\hline \multirow{2}{*}{$\begin{array}{c}\text { RCA Aggregate } \\
\text { Type and } \\
\text { Replacement } \\
\text { Level }\end{array}$} & \multirow[b]{2}{*}{$\begin{array}{c}\text { Number of } \\
\text { Samples } \\
\text { (Bars) }\end{array}$} & \multirow[b]{2}{*}{$\begin{array}{l}\text { Average 14-Day } \\
\text { Expansion (\%) }\end{array}$} & \multirow[b]{2}{*}{$\begin{array}{l}\text { Coefficient of } \\
\text { Variation (\%) }\end{array}$} & \multicolumn{3}{|c|}{$\begin{array}{c}\text { Precision Boundary Limits (21.5\% Above or } \\
\text { Below Mean Expansion) }\end{array}$} \\
\hline & & & & $\begin{array}{c}\text { Lower } \\
\text { Expansion } \\
\text { Boundary (\%) }\end{array}$ & \begin{tabular}{|c|} 
Upper \\
Expansion \\
Boundary (\%)
\end{tabular} & $\begin{array}{l}\text { Outside of } \\
\text { Precision } \\
\text { Boundary }\end{array}$ \\
\hline $\mathrm{OPP}-20 \%$ & 12 & 0.072 & 7.75 & 0.056 & 0.087 & 0 \\
\hline OPP - 50\% & 12 & 0.059 & 2.96 & 0.046 & 0.071 & 0 \\
\hline OPP - $100 \%$ & 9 & 0.053 & 14.2 & 0.042 & 0.064 & 0 \\
\hline Steps - 20\% & 12 & 0.077 & 8.68 & 0.060 & 0.094 & 0 \\
\hline Steps - 50\% & 12 & 0.069 & 14.3 & 0.054 & 0.084 & 0 \\
\hline Steps - 100\% & 12 & 0.062 & 4.61 & 0.049 & 0.076 & 0 \\
\hline CalPort - 25\% & 12 & 0.279 & 3.38 & 0.22 & 0.34 & 0 \\
\hline CalPort - 50\% & 12 & 0.440 & 3.32 & 0.35 & 0.53 & 0 \\
\hline CalPort - 100\% & 12 & 0.500 & 3.80 & 0.39 & 0.61 & 0 \\
\hline
\end{tabular}

The COVs for the Steps, OPP and CalPort aggregates ranged from 2.96-14.3\%, which is within the $15.2 \%$ COV limit for the ASTM C1260 test. Also, all sample sets fell within the precision boundary limits (21.5\% above or below mean expansion in ASTM C1260) for their respective aggregate type and replacement levels. This data is shown in a graphical representation in Figure 4-5. This graph shows the 14-day expansion averages and ASTM precision limits (horizontal dash). It also shows the lowest expansion reported for that set of bars (square), and the highest expansion reported for that set of bars (triangle). 


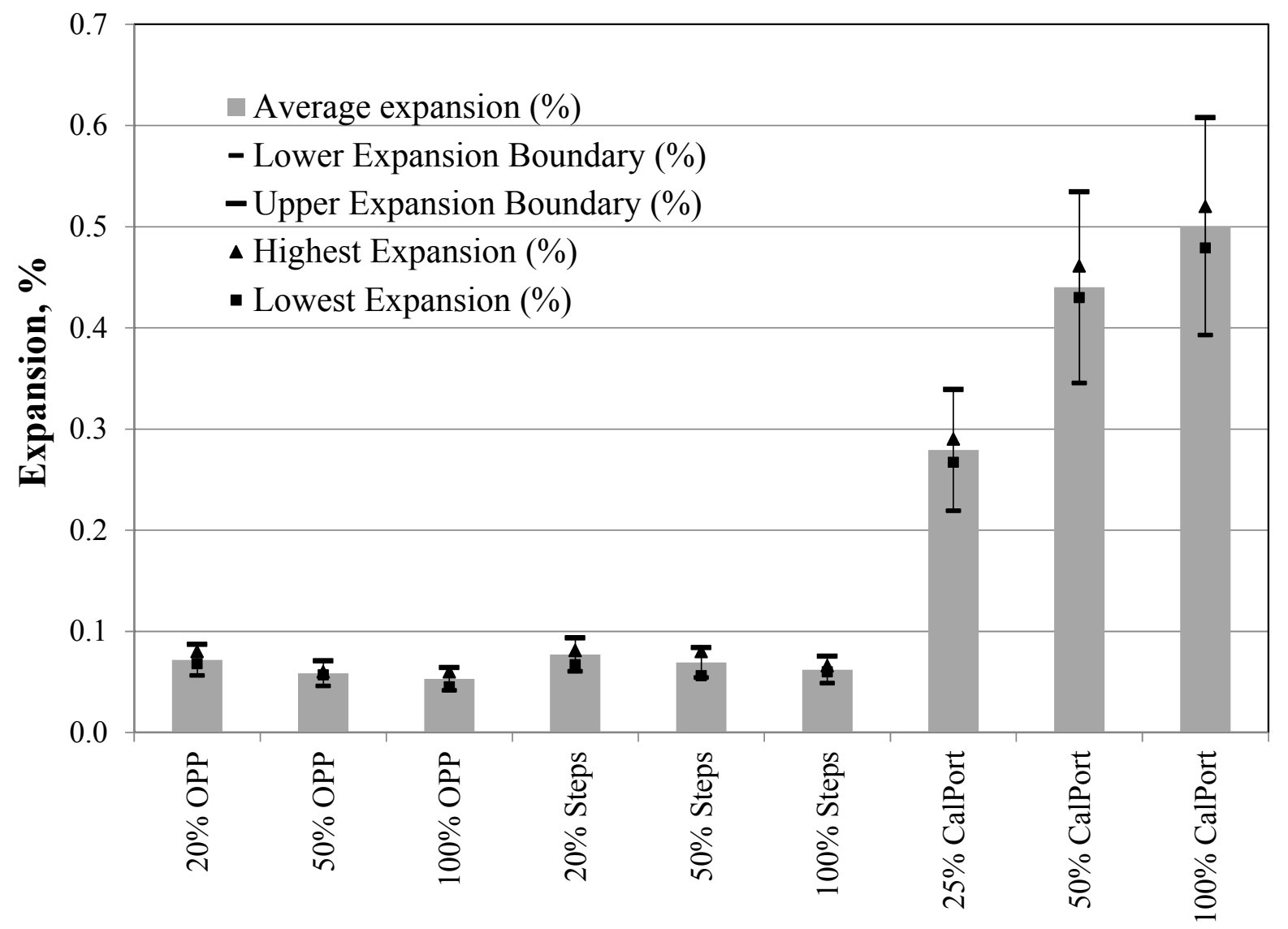

Figure 4-5: ASTM C1260 precision limits vs. dual-laboratory study data for Phase II RCA

None of the CalPort, Steps or OPP sets exceeded the precision boundary limits prescribed by the ASTM C1260 test. They also were all within the $15.2 \%$ COV limits. This may be because these were only tested in two laboratories whereas the sets tested in Phase I were tested in four laboratories, which allowed room for further variation. From these results it can be concluded that the precision boundary limits for multi-lab testing are acceptable for testing RCA based on the results of this study. However, the COV needs to be broadened due to the nature of RCA. Further testing using different RCA and more laboratories should be performed to confirm these results.

Table 4-2 displays the number of specimens, the averages, and within-laboratory ASTM precision for each RCA type and proportion of each RCA mixture type at each school. 
Table 4-2: ASTM C 1260 Within-laboratory Averages and Coefficients of Variation for Both UW and OSU Specimens for Each Mixture Type

\begin{tabular}{|c|c|c|c|c|}
\hline University & \multicolumn{2}{|c|}{ UW } & \multicolumn{2}{|c|}{ OSU } \\
\hline Specimen Type & $\begin{array}{l}\text { Average 14-day } \\
\text { Expansion (\%) }\end{array}$ & $\begin{array}{l}\text { Coefficient of } \\
\text { Variation (\%) }\end{array}$ & $\begin{array}{l}\text { Average 14-day } \\
\text { Expansion (\%) }\end{array}$ & $\begin{array}{l}\text { Coefficient of } \\
\text { Variation (\%) }\end{array}$ \\
\hline $\begin{array}{l}20 \% \text { Old Power } \\
\text { Plant } 1 \\
\end{array}$ & 0.069 & 6.5 & 0.07 & 0.84 \\
\hline $\begin{array}{c}20 \% \text { Old Power } \\
\text { Plant } 2 \\
\end{array}$ & 0.068 & 3.72 & 0.08 & 3.24 \\
\hline $\begin{array}{c}50 \% \text { Old Power } \\
\text { Plant } 1 \\
\end{array}$ & 0.057 & 1.01 & 0.06 & 2.53 \\
\hline $\begin{array}{c}50 \% \text { Old Power } \\
\text { Plant } 2 \\
\end{array}$ & 0.057 & 4.08 & 0.06 & 5.16 \\
\hline $\begin{array}{c}100 \% \text { Old } \\
\text { Power Plant } 1 \\
\end{array}$ & 0.045 & 11.76 & 0.06 & 8.52 \\
\hline $\begin{array}{c}100 \% \text { Old } \\
\text { Power Plant } 2\end{array}$ & 0.054 & 1.85 & NA & NA \\
\hline $20 \%$ Steps 1 & 0.081 & 2.47 & 0.08 & 2.76 \\
\hline $20 \%$ Steps 2 & 0.067 & 1.05 & 0.08 & 4.96 \\
\hline $50 \%$ Steps 1 & 0.071 & 4.88 & 0.08 & 5.19 \\
\hline $50 \%$ Steps 2 & 0.056 & 2.07 & 0.07 & 2.66 \\
\hline $100 \%$ Steps 1 & 0.066 & 2.33 & 0.06 & 3.45 \\
\hline $100 \%$ Steps 2 & 0.063 & 11.96 & 0.06 & 6.57 \\
\hline $25 \%$ CalR 1 & 0.28 & 4.91 & 0.29 & 3.69 \\
\hline $25 \%$ CalR 2 & 0.267 & 0.57 & 0.28 & 5.43 \\
\hline $50 \%$ CalR 1 & 0.439 & 0.92 & 0.43 & 3.31 \\
\hline $50 \%$ CalR 2 & 0.461 & 2.63 & 0.43 & 1.64 \\
\hline $100 \%$ CalR 1 & 0.479 & 4.76 & 0.49 & 1.23 \\
\hline $100 \%$ CalR 2 & 0.512 & 1.58 & 0.52 & 1.86 \\
\hline
\end{tabular}

ASTM precision recommends a within-laboratory COV of $2.94 \%$. This COV limit is exceeded by 18 sets of bars, or $50 \%$ of the tests completed, and these COV are marked in italic font. This data matches data seen in Phase I, which showed that when using the ASTM C1260 test to examine RCA the COV limit may need to be modified. Further testing, using different RCA and more laboratories that have experience running the ASTM C1260 test, should be performed to confirm this study's results. This may be best established through a larger multi-lab study than that conducted for this study. 


\subsection{OUTDOOR EXPOSURE BLOCKS}

Figure 4-6 below displays the observed expansion for the four large-scale blocks that were cast for this project.

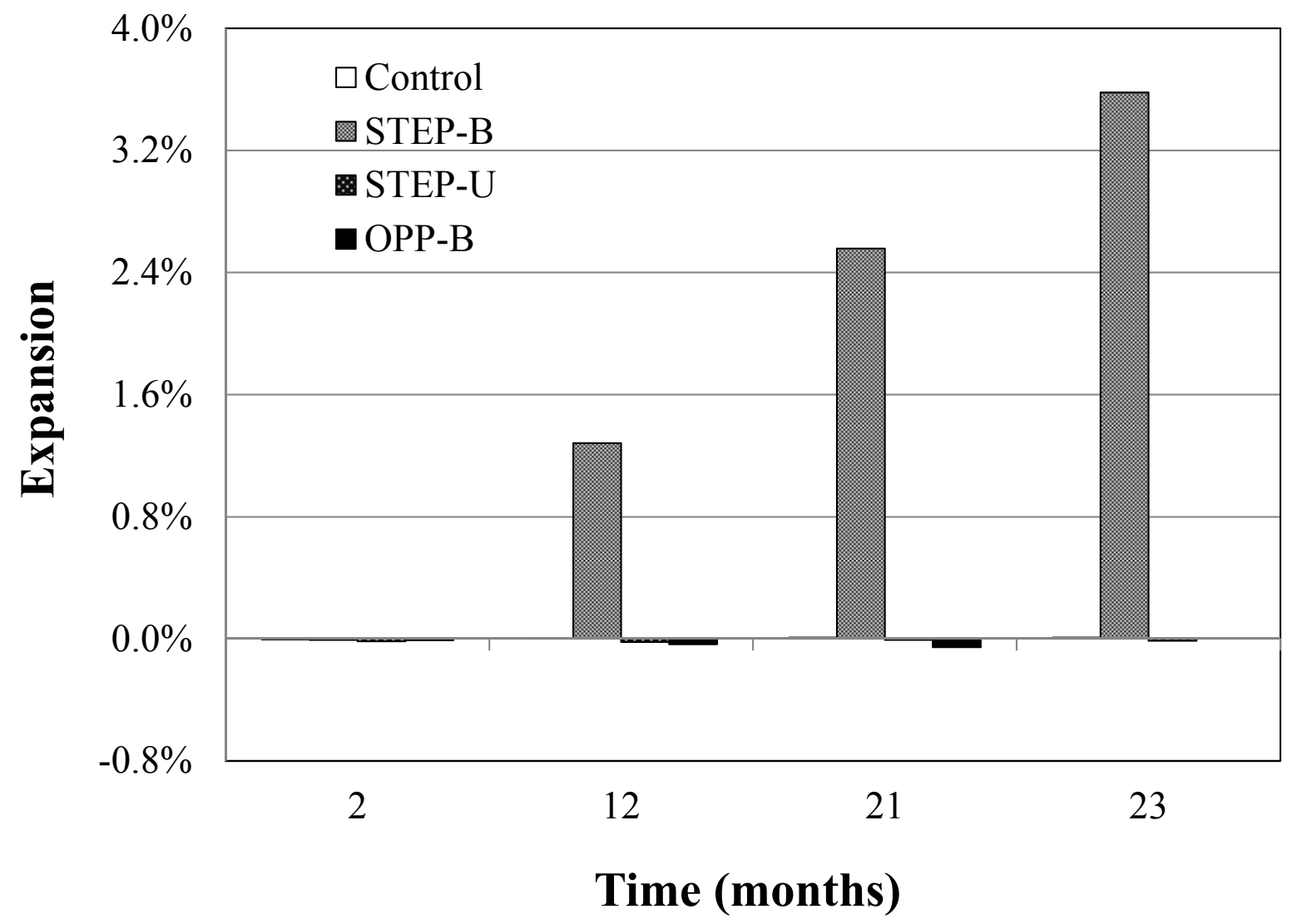

Figure 4-6: Twenty-three month data from large-scale field specimens

Specimen STEP-B has an expansion of $1.3 \%$ at one year and $2.6 \%$ at 21 months, and the remaining three specimens have nearly zero expansion. The OPP-B specimen is less likely to expand because the level of expansion in this RCA was significantly lower than that of the Steps RCA. All RCA and control specimens will be monitored for the next three years.

\subsection{MITIGATION STUDY}

This section provides the results of investigations into mitigating concrete mortar bars with RCA susceptible to ASR. One economical method for mitigating ASR is to include fly ash in new concrete mixtures. Replacement levels of $10 \%, 20 \%, 30 \%$ and $40 \%$ fly ash were conducted, and results for Jobe RCA can be seen in Figure 4-7 and Figure 4-8. 


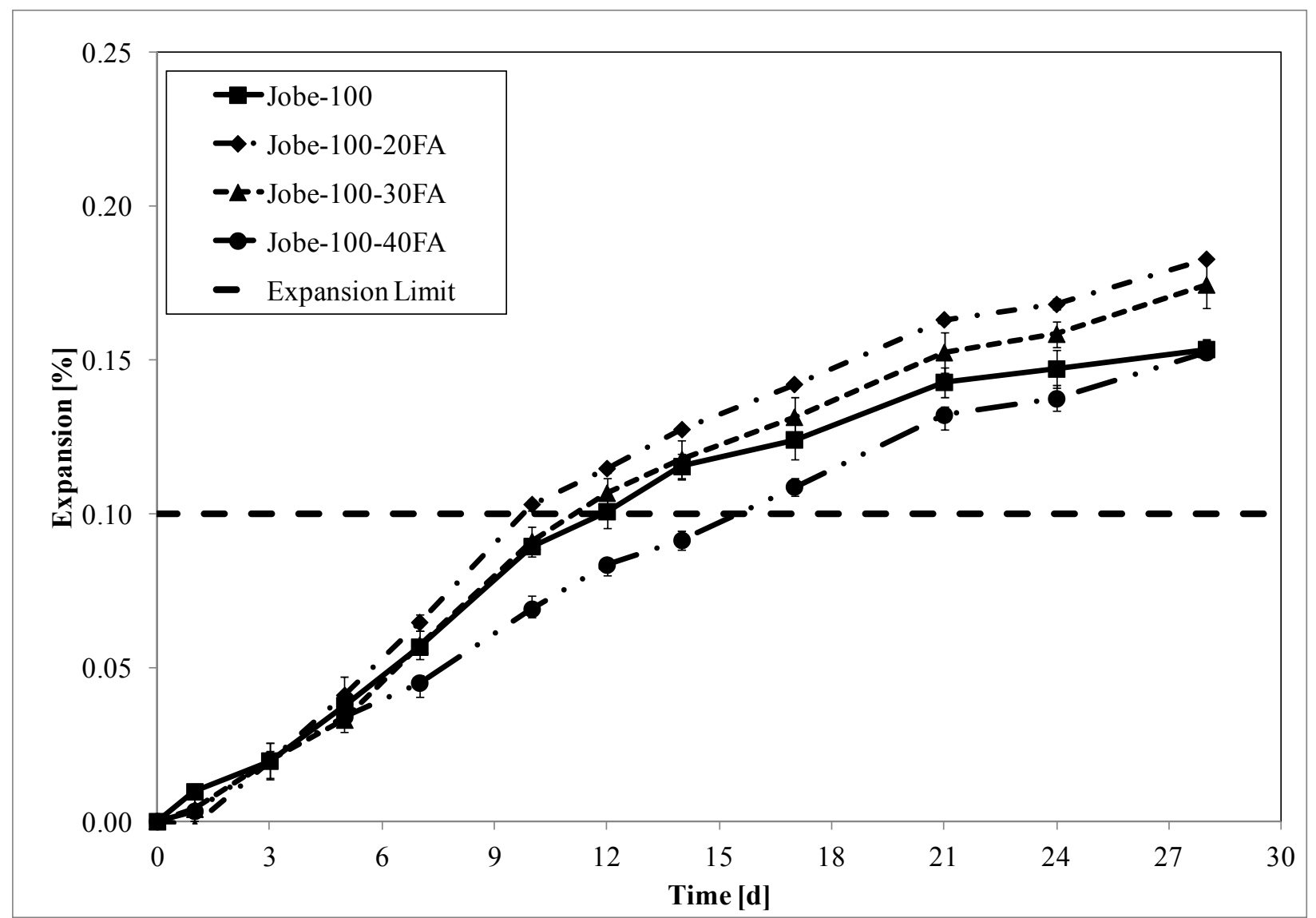

Figure 4-7: Expansion from 0 to 28 days for the Jobe-R RCA mortar bars and various replacement levels of class F fly ash 


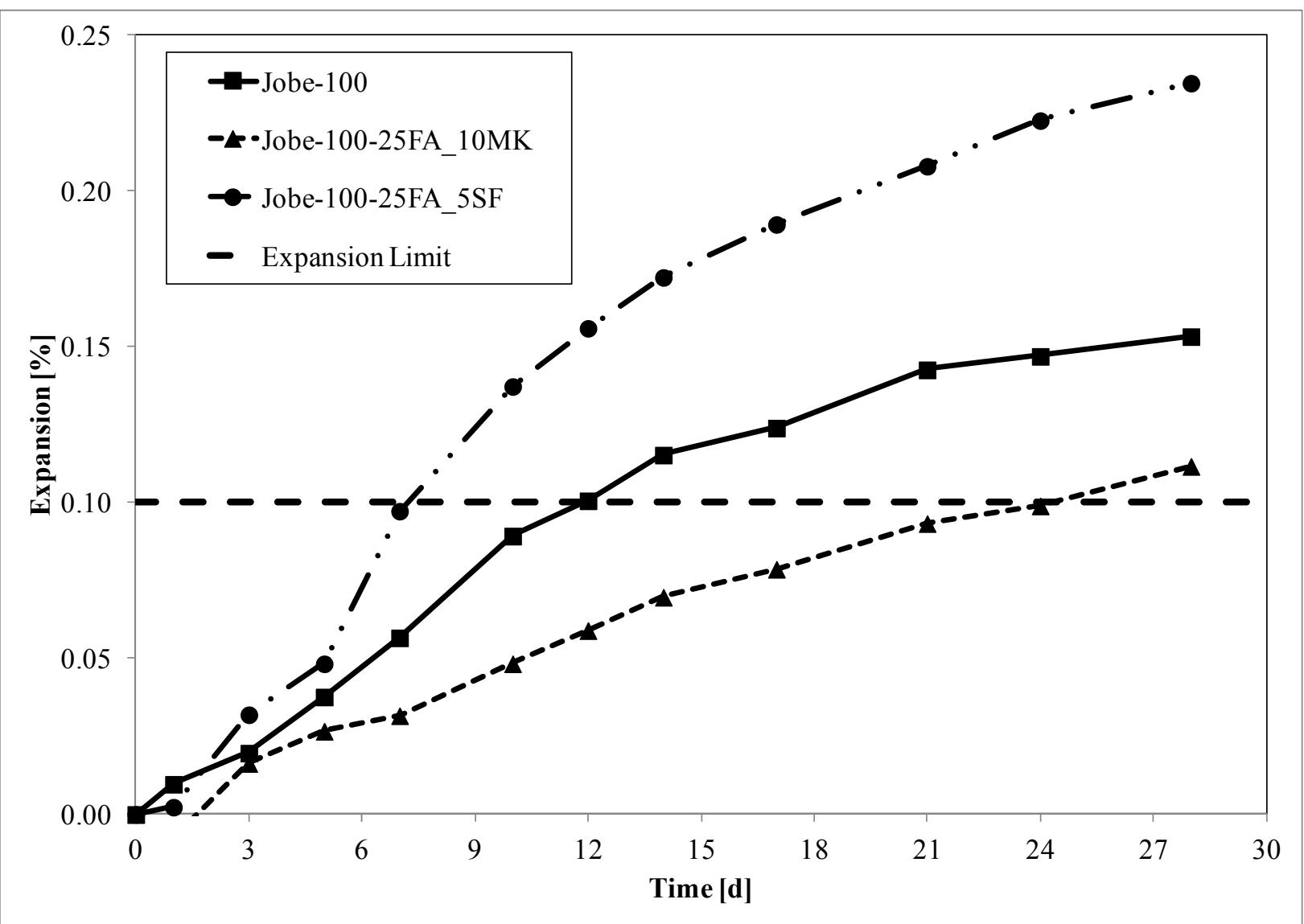

Figure 4-8: Expansion from 0 to 28 days for the Jo-R RCA mortar bars with ternary blends

At the fly ash replacement level suggested by the chemical index equation developed by Malvar and Lenke, $20 \%$ for Jobe-100, expansions due to ASR actually increase. The $30 \%$ fly ash replacement level reaches the same expansion as the control at day 14 . A $40 \%$ fly ash replacement in the Jobe mixture resulted in a decrease in expansion. The $40 \%$ fly ash replacement reduced expansions to below the $0.10 \%$ expansion limit that indicates the mixture will likely not cause deleterious expansions in concrete. The ternary blend with portland cement, fly ash and metakaolin, 14-day expansions of the mortar bars constructed with Jobe, reduced results below the $0.10 \%$ expansion limit.

The expansion of the CalPort mortar bars with 100\% RCA replacement and various mitigation techniques is shown in Figure 4-9. 


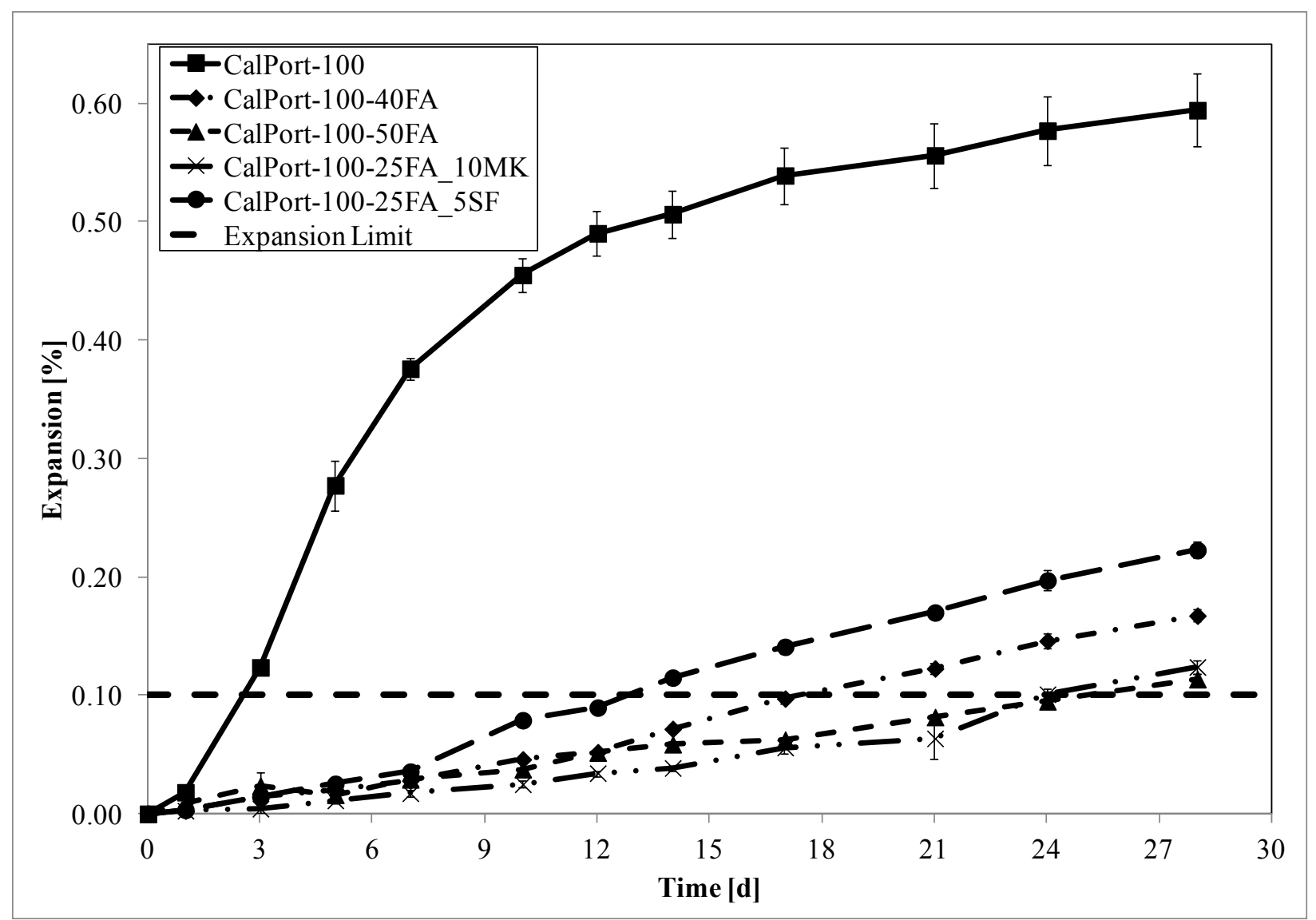

Figure 4-9: Expansion from 0 to 28 days of Ca-R mortar bars with various replacements of fly ash and ternary blends

All mitigation techniques, except for the ternary blend with portland cement, silica fume and fly ash, were able to decrease the expansion of the mortar bars to below the $0.10 \%$ expansion limit at 14 days. The ternary blend containing silica fume, CalPort-100-25FA_5SF, did significantly decrease expansion compared to the mortar bars made with just portland cement (the control), CalPort-100; though the expansion was still above the $0.10 \%$ limit at 14 days. The ternary blend containing metakaolin, CalPort-100-25FA_10MK, was able to reduce the ASR-induced expansions at 14 days by the most significant amount.

A summary of 14-day and 28-day expansions for all mortar bar sets from the mitigation study can be seen in Table 4-3. 
Table 4-3: Summary of Mitigation Study Mortar Bar Expansions at 14 and 28 Days

\begin{tabular}{ccc}
\hline Mixture Name & $\begin{array}{c}\text { 14-day } \\
\text { expansions } \\
(\%)\end{array}$ & $\begin{array}{c}\text { 28-day } \\
\text { expansions } \\
(\%)\end{array}$ \\
\hline Jobe-100 & 0.12 & 0.15 \\
Jobe-100-20FA & 0.13 & 0.18 \\
Jobe-100-30FA & 0.12 & 0.17 \\
Jobe-100-40FA & 0.09 & 0.15 \\
Jobe-100-25FA_10MK & 0.07 & 0.11 \\
Jobe-100-25FA_5SF & 0.17 & 0.23 \\
\hline CalPort-100 & 0.51 & 0.59 \\
CalPort-100-40FA & 0.07 & 0.17 \\
CalPort-100-50FA & 0.06 & 0.11 \\
CalPort-100-25FA_10MK & 0.04 & 0.12 \\
CalPort-100-25FA_5SF & 0.12 & 0.22 \\
\hline CalPort-50 & 0.43 & 0.51 \\
CalPort-50-35FA & 0.09 & 0.18 \\
CalPort-50-45FA & 0.05 & 0.12 \\
CalPort-50-25FA_10MK & 0.04 & 0.12 \\
\hline CalPort-25 & 0.29 & 0.35 \\
CalPort-25-30FA & 0.1 & 0.17 \\
CalPort-25-40FA & 0.06 & 0.13 \\
CalPort-25-25FA_10MK & 0.03 & 0.07 \\
CalPort-25-25FA_5SF & 0.09 & 0.17 \\
\hline
\end{tabular}

At all replacement levels it can be seen that the blends containing metakaolin reduced 14-day expansions the most compared to all other SCM blends used. The blends using the silica fume typically performed the worst, though at lower replacement levels of the CalPort RCA (50\% and $25 \%$ ) they were able to reduce expansions below the 14-day expansion limit of $0.10 \%$.

Results show that SCM can reduce expansions in concrete made with RCA. Fly ash replacement levels at $40 \%$ were able to reduce expansions to within acceptable levels for a $100 \%$ replacement level of both the CalPort and Jobe aggregates. Ternary blends containing $25 \%$ class F fly ash, $10 \%$ metakaolin and $65 \%$ portland cement exhibited the best performance in reducing the expansions seen in the ASTM C1567 test when using RCA for all aggregates and RCA replacement levels. The results also show that the chemical index equation developed by Malvar and Lenke was unable to properly predict the amount of fly ash required to reduce expansions in the mortar bars created using the Jobe aggregate. In fact, the recommended fly ash replacement level actually caused an increase in expansion. An additional $20 \%$ increase over the recommended amount of fly ash replacement to reduce expansions calculated through the chemical index equation was required to reduce expansions to below $0.10 \%$ in the ASTM C1567 test using the Jobe aggregates. However, the fly ash replacement level calculated using the equation did reduce the expansions in the mortar bars made with the CalPort aggregate. These 
conflicting results show that the chemical index equation may be capable of predicting the required amount of fly ash to reduce expansions for some RCA and fly ash combinations, but not necessarily for all cases. Further research needs to be conducted to better understand whether the chemical index equation can be used with RCA.

For both the Jobe and CalPort RCA, the ternary blends containing metakaolin resulted in the most significant decrease in expansions compared to the mixtures with no SCM. The Jobe-100 expansion was reduced by $0.05 \%$, and the CalPort-100, CalPort-50 and CalPort-25 expansions were reduced by $0.47 \%, 0.39 \%$, and $0.26 \%$, respectively. The ability of metakaolin to work effectively in a ternary blend has been attributed to its small particle size and chemical composition. During hydration, the pozzolan effectively binds alkalis without adding more reactive constituents to the system (Moser, Jayapalan et al., 2010). Metakaolin has a high aluminum oxide content (typically around 45\%) (Kosmatka, Kerkhoff et al., 2008). The introduction of alumina causes the C-S-H structure to form C-A-S-H (calcium alumino silicate hydrate), which has an even greater capacity to bind alkalis than C-S-H (Ramlochan, Thomas et al., 2000; Thomas, 2011). C-S-H is formed during cement hydration and C-A-S-H can be formed as a result of the pozzolonic reaction produced using fly ash provided sufficient alumina is present in the fly ash (Thomas, 2011), thus further reducing alkali-silica reactivity. The silica fume ternary blend was less effective than the other SCM combinations used to reduce expansions in the mortar bars made with the CalPort aggregate, though a reduction in expansion was observed. It has been shown that higher levels of silica fume may decrease expansions further to acceptable levels (Thomas, 2011); however, higher dosages of silica fume can have negative impacts on the workability of concrete. This is a particularly acute concern when using RCA which, due to its high absorption capacity, already decreases workability in concrete mixtures. Therefore, higher replacement levels of silica fume would not be recommended.

It was observed that as the replacement level of RCA decreases (from $100 \%$ to $50 \%$ to $25 \%$ ), the amount of fly ash required to mitigate the ASR-induced expansions also decreases. The trend is also seen in the ternary blends, with the same ternary blend exhibiting more significant decreases in expansion at lower RCA replacement levels. This is likely due to the decrease in reactive material in the system, and thus a decrease in overall reactivity in the mortar bars. Current codes for structural concrete limit the amount of fly ash in a mixture to $25 \%$, and the overall amount of SCM in a ternary blend containing fly ash or other pozzolans and silica fume to $50 \%$ (ACI 318 , 2008). Therefore, effective ways to limit the amount of SCM needed to control expansions can be to limit the amount of RCA used in a mixture, or carefully evaluate ternary blends. However, it is recommended that all replacement levels and SCM combinations be tested prior to being used in the field, as higher expansions have been noted at lower RCA replacement levels.

The results of the CalPort aggregate's mitigation contradict previous results that have said that higher levels of mitigation are required to reduce expansions in mortar bars made with RCA, compared to those made with natural aggregates (Li and Gress, 2006; Shehata, Christidis et al., 2010). The CalPort original natural aggregates were a reactive siliceous river gravel and reactive siliceous river sand. These natural aggregates produced expansions of $0.59 \%$ and $0.81 \%$ for the coarse and fine natural aggregates, respectively, in the ASTM C1260 test. ASTM C1567 testing with this natural aggregate showed that a $40 \%$ fly ash replacement was able to reduce expansions to acceptable levels $(0.07 \%)$ in mortar bars created with the coarse natural aggregate, and $45 \%$ 
fly ash replacement was able to reduce expansions to acceptable levels $(0.04 \%)$ in mortar bars containing the fine natural aggregate. A $40 \%$ fly ash replacement level was able to reduce the expansions to within acceptable limits $(0.07 \%)$ in mortar bars created with the RCA. This may be due to the makeup of the RCA, however.

During visual examination of the CalPort RCA it was noted that there was a relatively small amount of adhered mortar on the particles, particularly when compared to the Jobe RCA. This indicates that the ability of SCM to mitigate ASR in aggregates may depend on the ratio of adhered mortar to original natural coarse aggregate. However, the quantity of adhered mortar was not quantified as a part of this study. A method to determine the adhered mortar content of an RCA was developed by Abbas et al. However, this method is only applicable for use with aggregates larger than 0.187 inch $(4.75 \mathrm{~mm})$ (Abbas, Fathifazl et al., 2008). This method involves removing the adhered mortar by placing the aggregate in a sodium sulfate solution and then subjecting the submerged aggregate to five freeze/thaw cycles. The aggregate is then washed over a sieve and the adhered mortar, which was broken down during the freeze/thaw cycling, is washed away (Abbas, Fathifazl et al., 2008). The gradation of aggregate required for use in the ASTM C1567 test may be too small for this test method to work. Previous work has shown that the amount of crushing performed on an RCA can affect its reactivity (Shehata, Christidis et al., 2010; Adams, Ideker et al., 2012). This was attributed to the amount of adhered mortar on the aggregate (Shehata, Christidis et al., 2010; Adams, Ideker et al., 2012), which is reduced as the level of crushing is increased (Nagataki, Gokce et al., 2004). These past results show that the amount of adhered mortar can affect the level of reactivity in an aggregate, and subsequently may affect the efficacy of an SCM to mitigate ASR. Further testing needs to be completed to understand how the amount of adhered mortar affects the ability of SCM to mitigate ASR in mortar bars made with RCA.

The effectiveness of the SCM to mitigate ASR for the mixtures with the Jobe aggregate is less than that for the CalPort aggregates. Comparison of the ASTM C1567 tests shows that the same mitigation techniques (40\% fly ash replacement, or 25\% fly ash with $10 \%$ metakaolin replacement, or $25 \%$ fly ash with $5 \%$ silica fume replacement) had less of an effect of reducing expansion for the mortar bars created with the Jobe RCA than on mortar bars created with the CalPort RCA. This may be due to two different factors: the physical characteristics of the RCA and the age of the RCA or the level of reaction in the original natural aggregate. The RCA is a two-phase system. The Jobe's reactive constituent was a fine aggregate that, in the RCA, is contained in the adhered mortar. The CalPort consisted of a reactive fine and coarse aggregate, and, through visual examination, was observed to contain less adhered mortar than the Jobe $\mathrm{RCA}$. The reactive component of the RCA for the Jobe particle is the original natural fine aggregate embedded in the adhered mortar. The SCM, therefore, may not have as much free access to the matrix surrounding Jobe aggregate to prevent ASR from occurring. The age of the RCA's parent concrete may also have had an impact on the ability of SCM to mitigate expansion. Jobe RCA was produced from an expansion block that was six years old, whereas the CalPort was produced from returned concrete at a ready-mix facility and is relatively young. This could have affected the SCM's effectiveness because the overall reactivity was due less to the original natural aggregate having had the ability to react significantly prior to being recycled into an RCA. 


\subsection{TRANSPORTATION AGENCY SURVEY}

\subsection{SURVEY}

A survey of state DOTs was conducted in both Phase I and Phase II of the project to assess the current use, perception, barriers and needs for using recycled concrete aggregates (RCA) in new concrete. While the majority of participants included state DOTs, federal agencies and the Canadian Ministries of Transportation also responded. This section will outline the participants in the survey, the survey questions, an overview of the results and main findings, and recommendations from the survey. Appendix A contains all of the raw data for reference.

\subsubsection{Participants}

Survey participants included 26 different agencies and are shown in Table 5-1.

Table 5-1: Participating Agencies in RCA Survey

\begin{tabular}{|l|l|l|}
\hline DOT 1 & FHWA-TFHRC & New York State \\
\hline DOT 2 & Georgia & Oklahoma \\
\hline DOT 3 & Idaho & Ontario MTO \\
\hline DOT 4 & Illinois & Oregon 1 \\
\hline Alabama & Louisiana & Oregon 2 \\
\hline California & Maryland & South Carolina \\
\hline Colorado & Minnesota & Utah \\
\hline Delaware & Mississippi & Washington \\
\hline FHWA Research & Nevada & \\
\hline
\end{tabular}

Four of the state DOTs chose to not self-identify when filling out the survey, and those are represented as DOTs 1-4. For the results in Section 5.2, responses are not attributed to specific agencies to ensure their responses are confidential. While the agencies responded to $95 \%$ of all questions, some agencies did not respond to every single question. Additionally, some questions had multiple possible answers and, as a result, most of the responses in the bar charts are for frequency of answer or response type, not by overall percentage. These discrepancies will be noted specifically with the type of response.

\subsection{SURVEY QUESTIONS}

The form below shows a summary of the survey that was sent out to state DOTs. The survey also may be accessed at: http://gbml.oregonstate.edu/OTREC/. However, this site will likely be taken down shortly after approval of this report. 


\subsubsection{Start of Letter to DOTs}

\section{O T R E C - Project 339}

Durability Assessment of Recycled Concrete Aggregate

Dear Department of Transportation Representative, You have been selected based on your expertise related to sustainability and the use of recycled concrete as aggregate (RCA) in your organization. We are hopeful that you will help us by participating in a survey related to how your organization uses and assesses RCA. The feedback that you provide will be used to develop a free information technology systems (such as an online tool, database etc.) that will enable the industry to have easy access to the specific information enabling the cost-effective and safe use of recycled concrete aggregate across transportation related construction projects. If you are willing to participate in this survey please click this link: http://gbml.oregonstate.edu/OTREC/

You will be prompted to consent to Oregon State University and the Oregon Transportation Research and Education Consortium's use and publishing of the information you provide. After you affirm your consent you will be able to move on to take the survey.

There are three sections in this survey. The first section asks questions related to sustainability and the use of RCA within your DOT. The second section is specifically directed toward determining the type of information that a database or online tool would contain to be most useful for improving the usage of RCA in new construction. The final section allows you to provide direct feedback, suggestions and comments. The estimated time to complete this survey is approximately 30 minutes or less.

Thank you for your time.

Sincerely,

OSU Concrete team 
<Introduction Placed on Website>

Department of Transportation Representative,

Thank you very much for agreeing to take this survey on the use of recycled concrete as aggregate in your organization. Below is the consent paragraph, please read it and enter your name in the signature box; and then continue on to the survey by pressing the NEXT button.

Thank you for your time.

Sincerely,

OSU Concrete team

By entering your name in the signature box below you hereby consent to Oregon State University and the Oregon Transportation Research and Education Consortium using and publishing the information you provide in response to the following survey.

Name:

Date: 


\section{SECTION 1: Sustainability and Use of RCA}

\section{General Questions about RCA and Sustainability}

Please answer the following questions about your DOT's use of and perception of RCA and sustainability in general.

Please rank the following:

1 -strongly disagree (or no)

2 -Disagree

$\underline{3-\text { Neutral }}$

$\underline{4-\text { Agree }}$

5 -Strongly Agree (or yes)

1) Sustainability is important to your DOT.

C Strongly Disagree

C Disagree

C Neutral

C Agree

C Strongly Agree

2) Sustainability is addressed within our DOT in a clear, meaningful way.
C Strongly Disagree
C Disagree
C Neutral
C Agree
C Strongly Agree

3) Using materials, such as recycled concrete aggregates, that would otherwise be landfilled is viewed as an important part of sustainability measures to our DOT.

C Strongly Disagree

C Disagree

C Neutral

C Agree 
C Strongly Agree

4) Our DOT has specific guidelines for the use of RCA in new construction.

C Strongly Disagree

C Disagree

C Neutral

C Agree

C Strongly Agree

5) There is strong information from the federal level about the use of recycled concrete aggregate in new concrete construction.

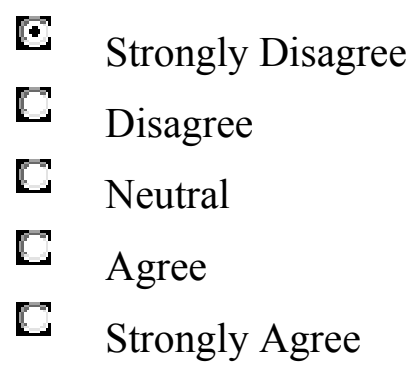

Please select the letters associated with the answers that best represent the stance of your DOT:

6) Which of the following are the biggest barriers to the use of recycled concrete aggregate?
$\ulcorner$ Economics
$\ulcorner\quad$ Social issues
$\ulcorner\quad$ Initial construction costs
$\ulcorner\quad$ Life cycle analysis (LCA)
$\ulcorner\quad$ Standards
$\ulcorner\quad$ Testing 
Г

Quality

$\Gamma$

Specifications

$\Gamma$

Perception

7) Which of the following characteristics of an RCA source would enable you to use it most beneficially?

(Enter your rank 1 - 5 in each box)

Strength

Durability

Mixture design

Presence of epoxy

Source

8) The use of RCA in new concrete will negatively affect the economics of transportation related construction projects.
C Strongly Disagree
C Disagree
C Neutral
C Agree
C Strongly Agree

9) When determining whether or not to use RCA, our DOT considers both cost and embodied energy to assess the benefits.
C Strongly Disagree
C Disagree
C Neutral 


\section{Agree \\ C Strongly Agree}

10) When determining whether or not to use recycled concrete aggregates, our DOT considers sustainability (e.g. environmental benefits of not landfilling) as the most important factor determining usage.

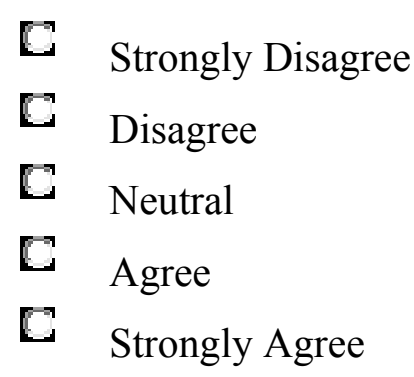

11) Our DOT believes that government incentives such as tax credits, funding incentives or credits in green building programs (e.g. Green Highways or LEED) could effectively promote the use of RCA.

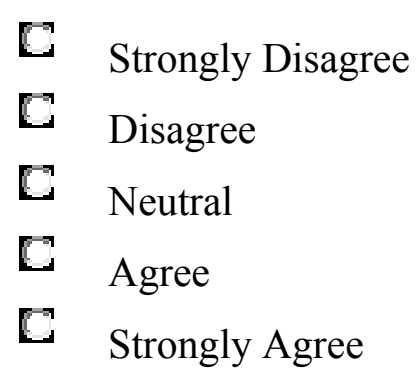

12) Environmental issues related to a specific source of RCA in order of importance to your DOT's decision making strategy: (Enter your rank $1-7$ in each box)

Environmental location (i.e. inside or outside)

Why it was taken out of service

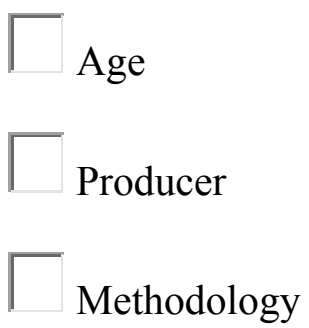


Were repairs performed and if so in what volume

Existing condition

1) Alkali-silica reaction in concrete is of concern to our DOT.

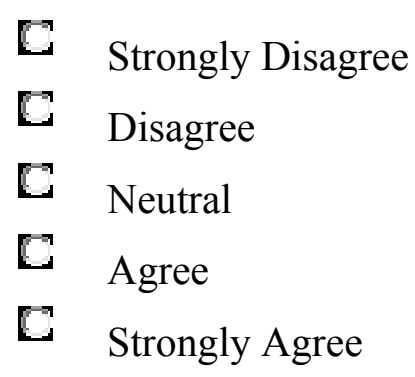

2) Our DOT has known cases of alkali-silica reactivity in our transportation infrastructure (e.g. bridges, pavements, retaining walls, cross-over barriers, etc.)

\section{Yes \\ C No}

If you answered yes to Question 2 above please indicate the APPROXIMATE percentage of your transportation related infrastructure that is affected by ASR. If not known please check the box for "not known".

$\ulcorner\quad$ Not Known

$\%$ Affected by ASR

3) Our DOT is concerned with using RCA in new concrete construction because of the potential for:

(Check all that apply)

ᄃ Alkali-silica reactivity

$\lceil\quad$ Residual chlorides 

$\ulcorner$ Carbonation
$\ulcorner\quad$ Sulfate attack
$\ulcorner$ Lower strengths
$\ulcorner\quad$ Increased shrinkage
$\ulcorner$ Other:

4) Our DOT is most interested in using RCA in new construction for the following use (s): (Check all that apply)

Fill Material

\ulcorner

Base Material

Sub-base Material

Pavements

Sidewalks

Structural Concrete

Other:

Other:

\section{Database Questions}

We are considering the development of a web-based tracking tool/database to store information about recycled concrete aggregate sources that may be available in your state. This would be a free online tool to enable DOTs (and other potential users) to more effectively use RCA in a 
wide variety of construction projects. Your answers to the following questions will help us determine if this is a desired tool and how we can best customize it for use.

1) Our DOT would use a database containing information regarding recycled concrete aggregate sources, material properties, and performance history.

C Yes

C No

2) Such a database would be beneficial and increase the use of RCA throughout our construction projects.

C Yes

C No

3) The following types of information are under consideration as fields or input values in the new online

database tool. Please check all that you think are relevant. You may select as many as possible.

You

may also provide additional suggestions in the following questions.

Coarse aggregate type

Coarse aggregate volume/mass

Fine aggregate type

Fine aggregate volume/mass

Cement type

Cement type volume/mass

Water to cement ratio $(\mathrm{w} / \mathrm{cm})$

SCM type

SCM type volume/mass 
Structural element RCA derived from

Volume of RCA and/or mass of RCA

Reason taken out of service

Existing deterioration

Air entrainment and dosage rate

Condition of RCA (rebar, wire mesh, fibers, etc.)

Years in service (for RCA)

Other:

Other:

4) Please describe what software or internet format you believe would be the most successful way for users to access the program's information. Please offer the names of specific software that you would like to use such a program with, or a format of internet access that would most suit your needs. (Eg. A website, a Microsoft Access program, Microsoft Excel etc. )

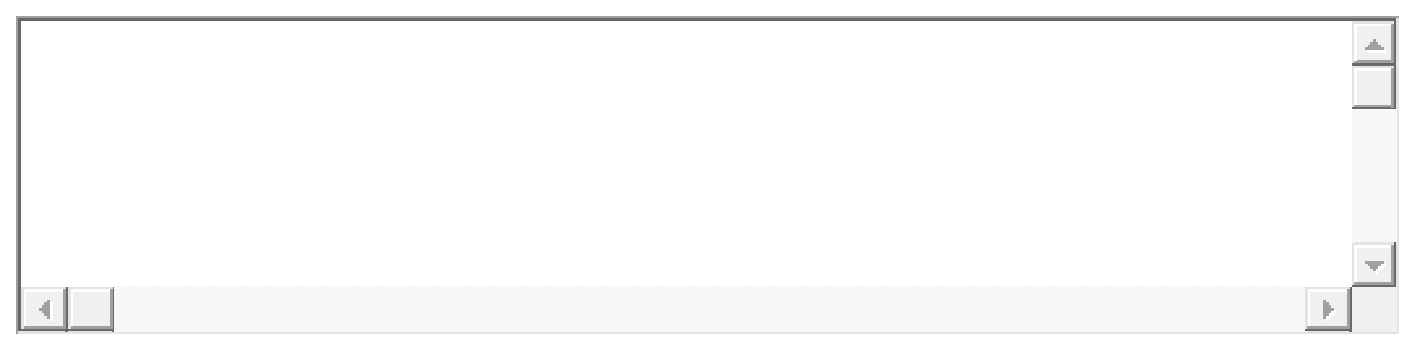

5) What ways of searching would be most useful for you? (Eg. by location, by mix design etc. ) 


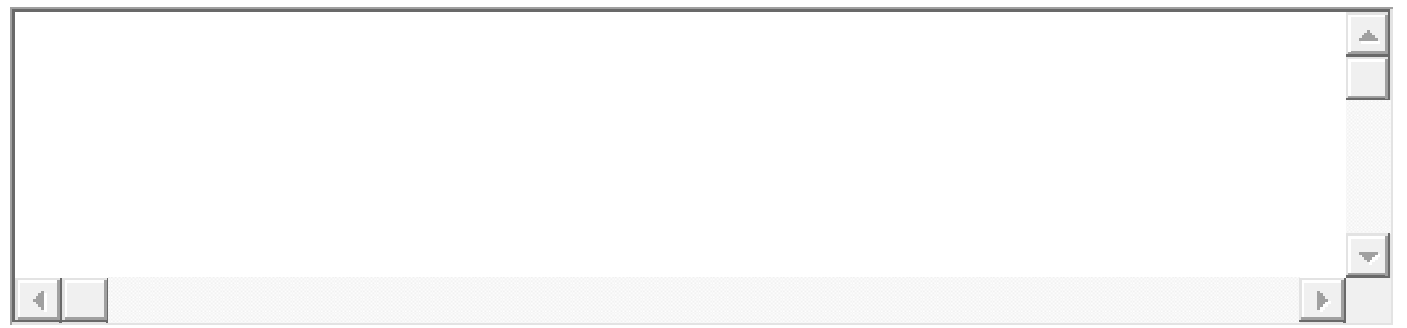

6) Please use the area below if you would like to expand on your ideas or offer other suggestions for the development of such an online database to house information about RCA specific to your state.

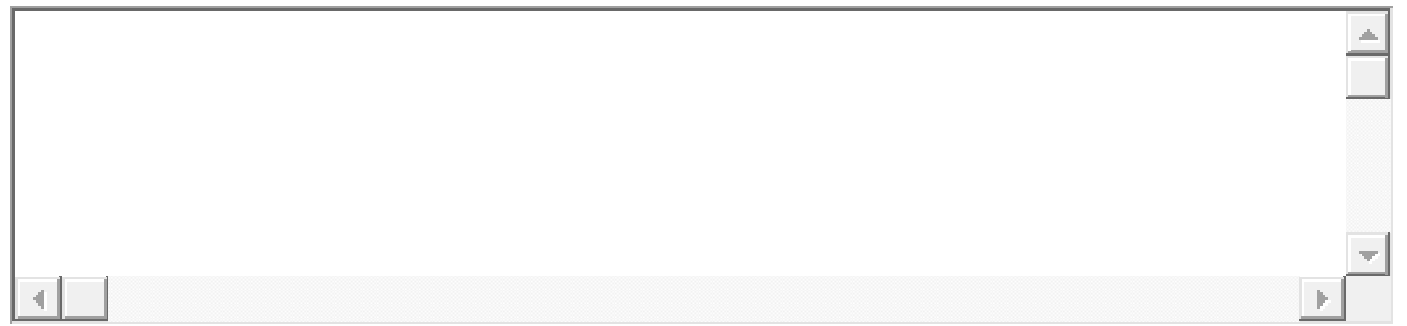

Thank you for completing the survey.

Sincerely,

OSU Concrete team

\subsection{SURVEY RESULTS AND DISCUSSION}

\subsubsection{General Questions about RCA and Sustainability}

This section provides an overview of the participant's feedback in relation to RCA and sustainability. The results of the first two questions in the survey, "Sustainability is Important to Your DOT" and "Sustainability is Addressed in Clear and Meaningful Way within your DOT," are shown below in and Figure 5-1 and Figure 5-2. 


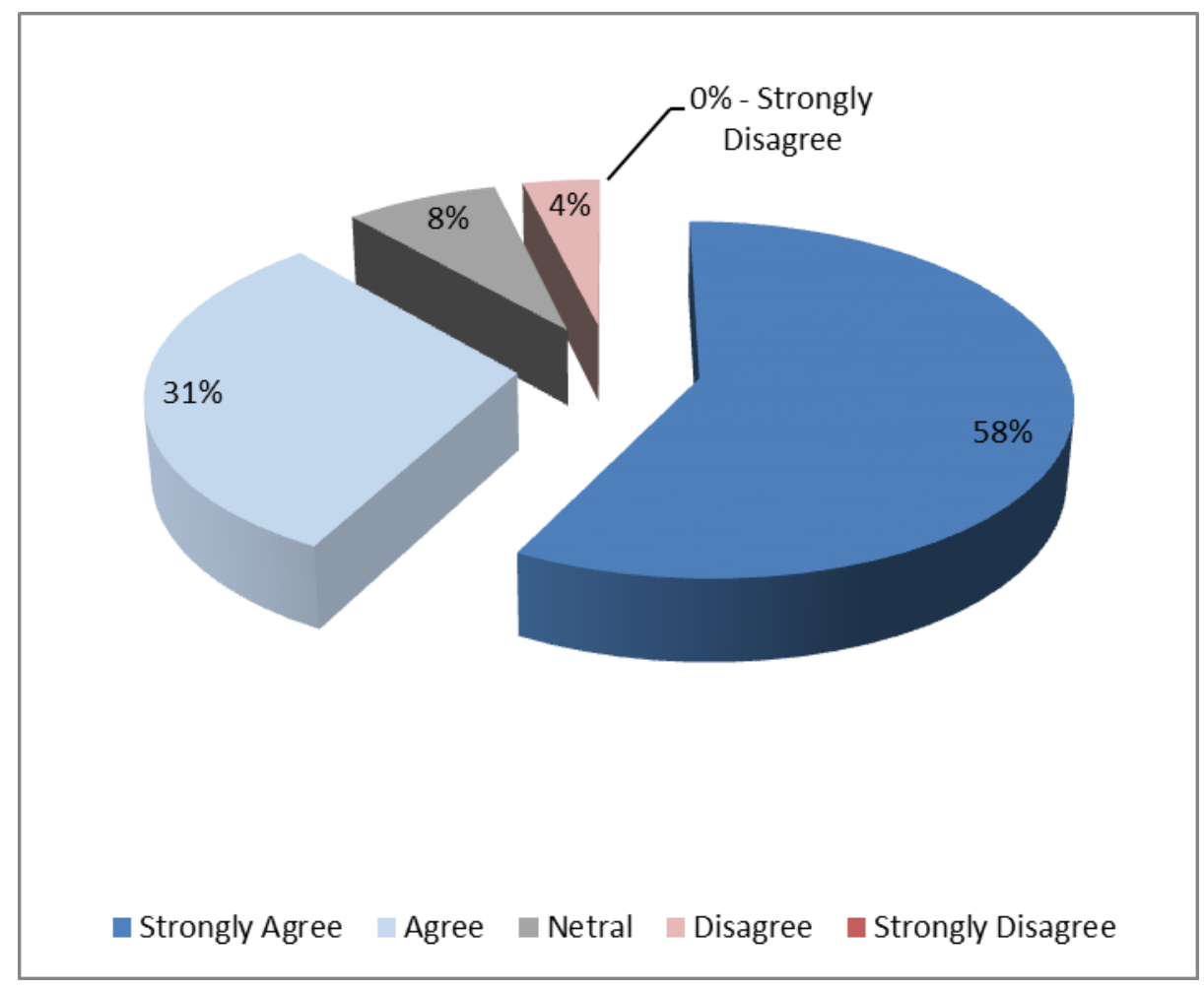

Figure 5-1: Importance of sustainability to survey participants

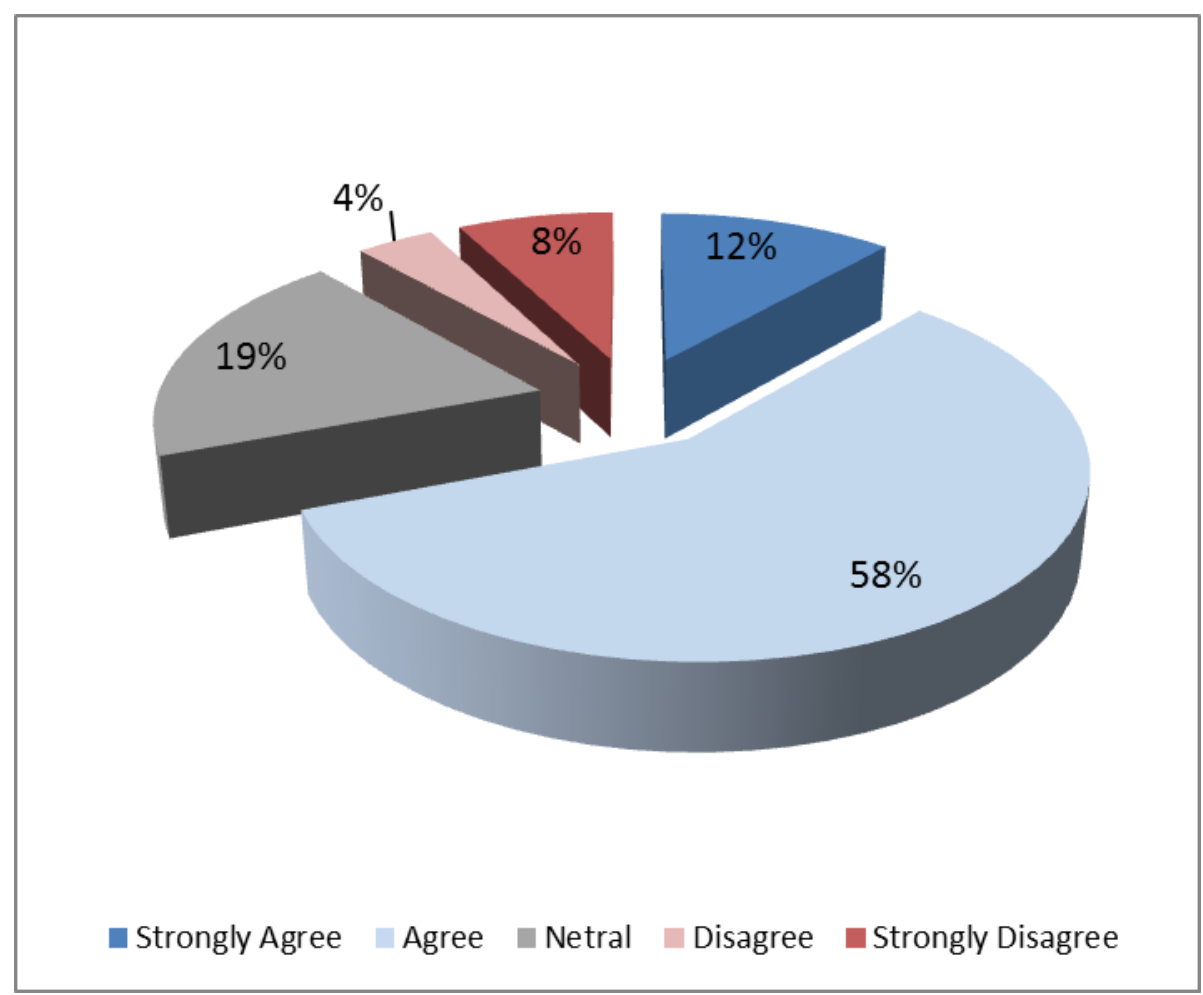

Figure 5-2: Sustainability is addressed within participants' agencies in a clear and meaningful way 
While the majority (89\%) of participants chose "strongly agree" or "agree" when asked if sustainability was viewed as important to their agency, only $12 \%$ also "strongly agreed" that sustainability was addressed within their agency in a clear and meaningful way. Another 58\% did agree that sustainability was addressed in a clear and meaningful way within their agency, for a total of $70 \%$ choosing "strongly agree or agree," Only $8 \%$ "strongly disagreed" with the statement that sustainability was addressed in a clear and meaningful way.

Participants were then asked their viewpoint on using RCA versus landfilling it, and how that related to sustainability. These results can be seen in Figure 5-3.

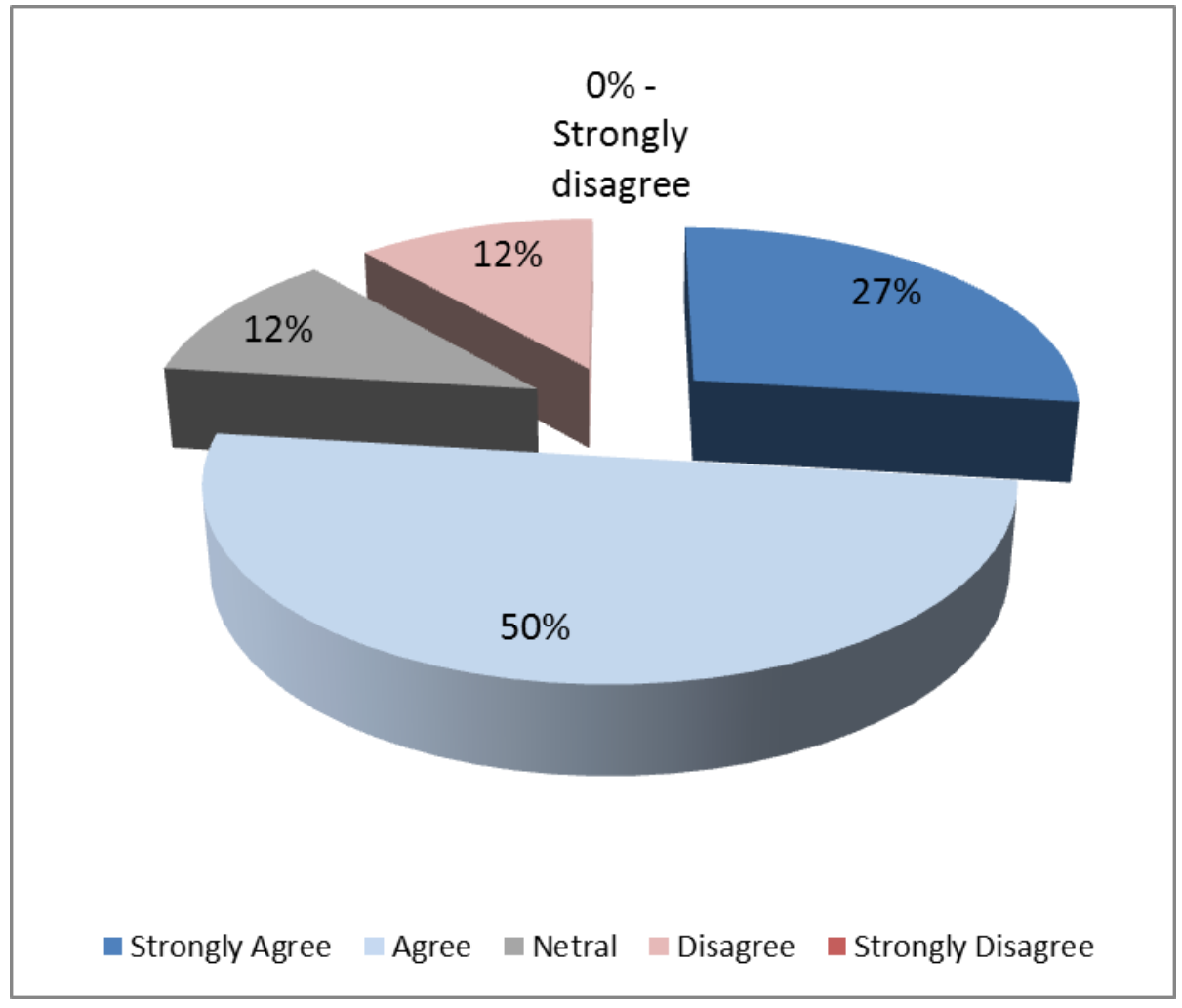

Figure 5-3: Using RCA instead of landfilling is viewed as an important part of sustainability to your agency

When asked their viewpoint if using RCA instead of landfilling it was an important part of sustainability, $27 \%$ of the respondents chose "strongly agree" and 50\% chose "agree," with no response registering "strongly disagree." Responses for "neutral" and "disagree" accounted for $12 \%$ of the responses.

Survey participants were asked about guidance on RCA use within their agency (Figure 5-4) and at the federal level (Figure 5-5). 


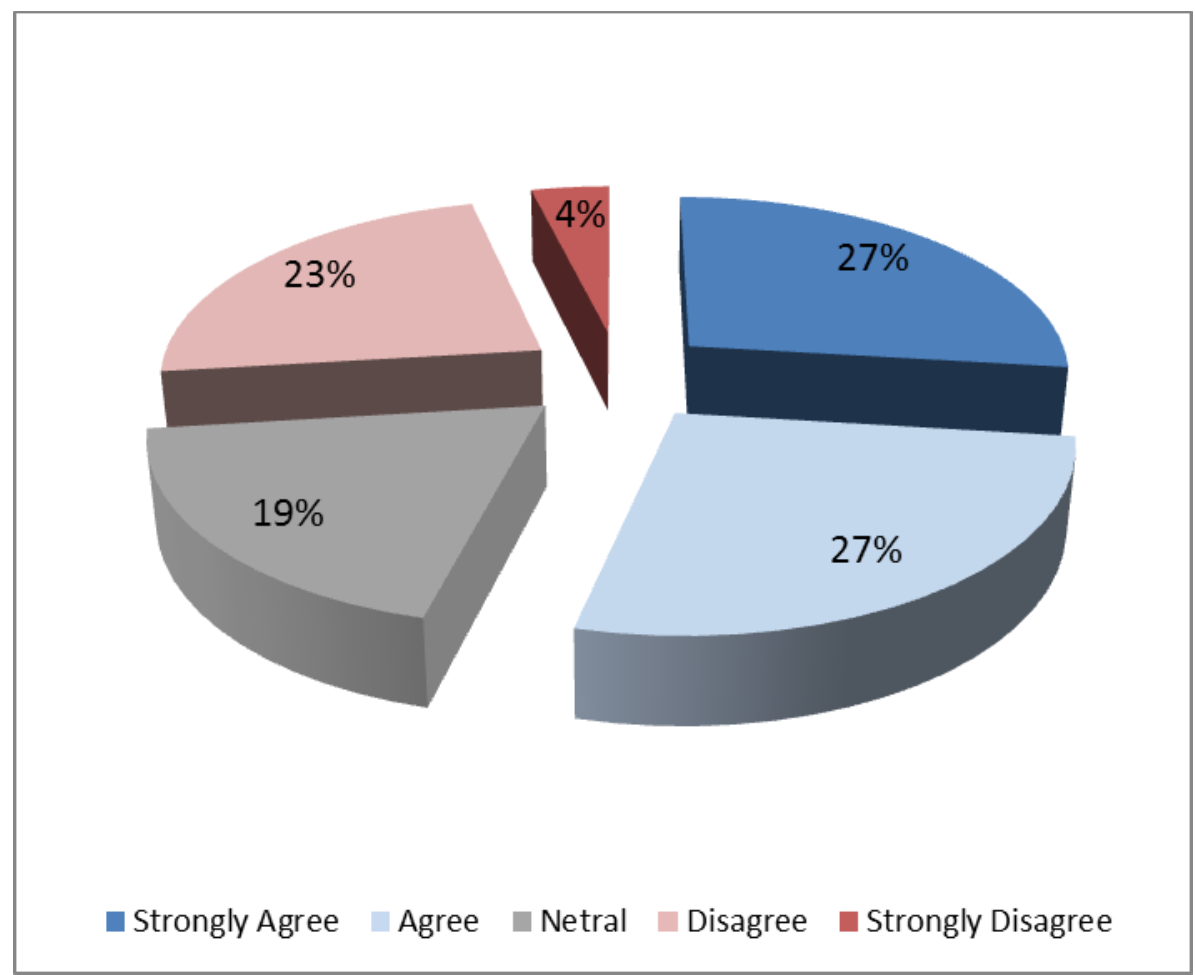

Figure 5-4: Agency has specific guidance for the use of RCA in new concrete

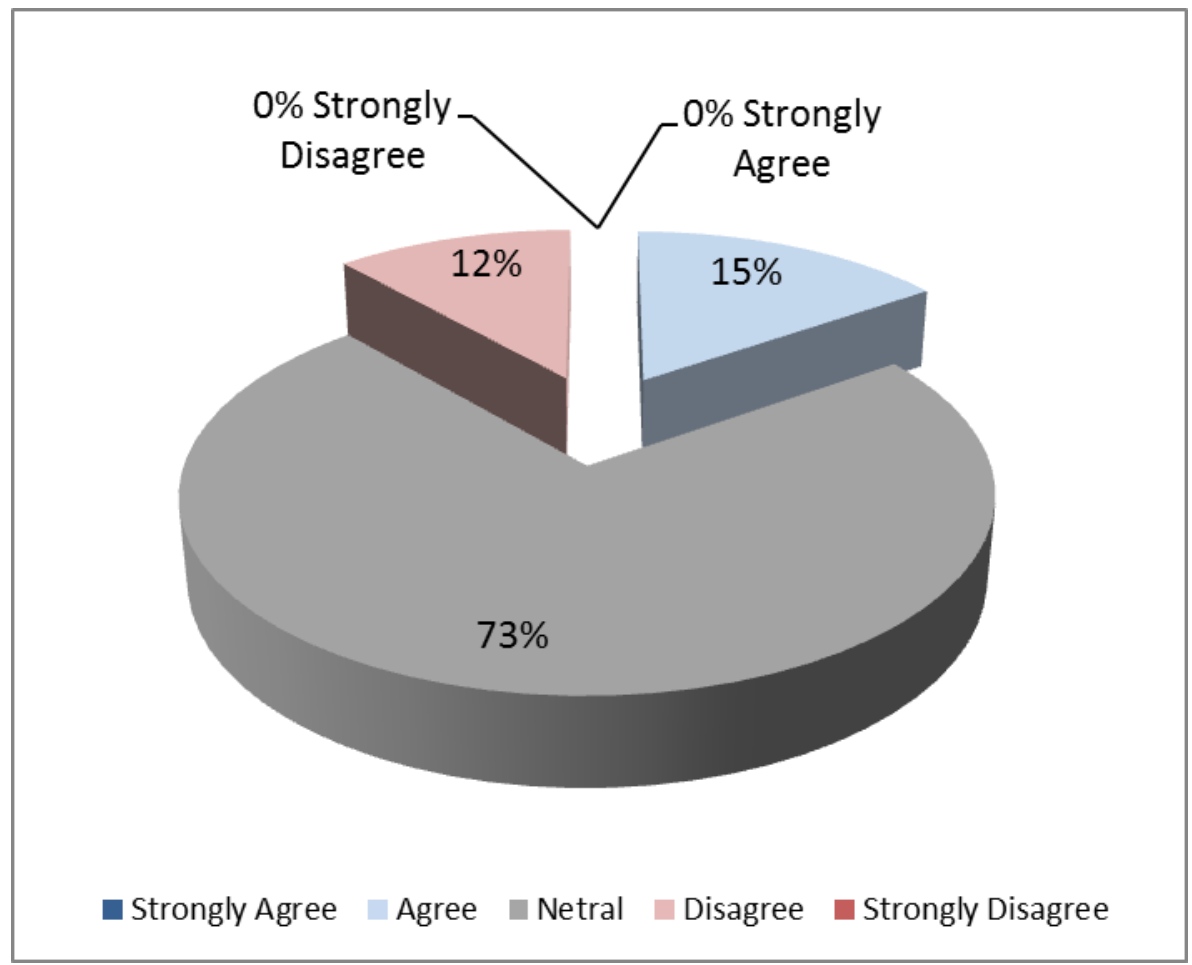

Figure 5-5: There is strong information from the federal level for the use of RCA in new construction 
Figure 5-4 and Figure 5-5 depict differing views on guidance for RCA use at the state level versus the federal level. While $54 \%$ of respondents either "agreed" or "strongly agreed" that their agency had specific guidance, none "agreed or "strongly agreed" that there was strong information at the federal level about RCA use in new construction. In fact, $73 \%$ of respondents were "neutral" on this question, whereas $27 \%$ either "disagreed" or "strongly disagreed" that there was strong guidance about RCA at the federal level.

Figure 5-6 shows the respondents views on economics of RCA.

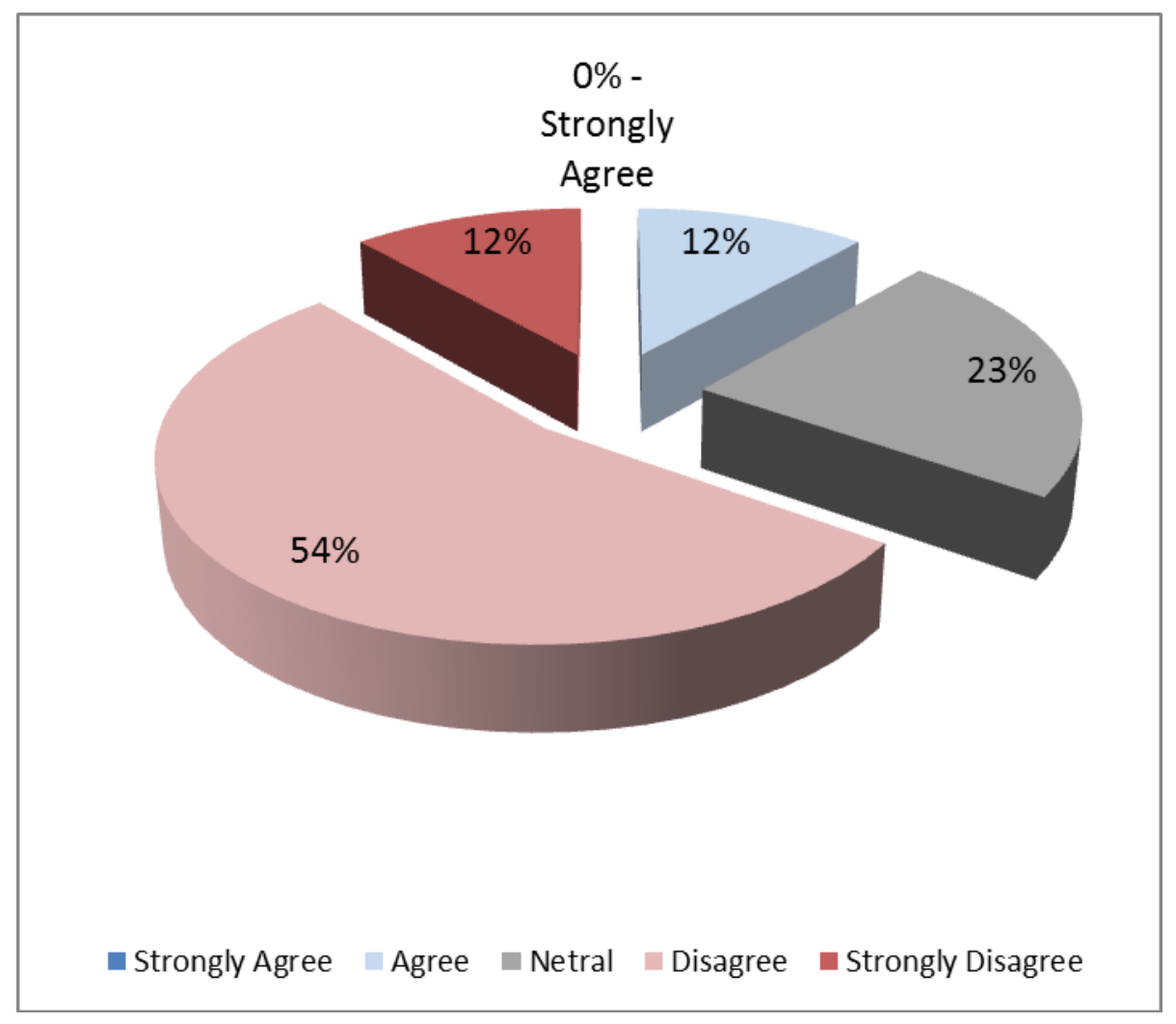

Figure 5-6: The use of RCA will negatively affect economics of transportation-related construction

When the statement was made that "use of RCA will negatively affect economics of transportation-related construction," the majority of participants $(66 \%)$ "disagreed" or "strongly disagreed" with the statement. In fact only $12 \%$ "agreed" that it would negatively affect the economics of transportation-related construction and none "strongly agreed."

Participants were also asked about what considerations are taken into account when considering the use of RCA. Those results are shown in Figure 5-7 and Figure 5-8. 


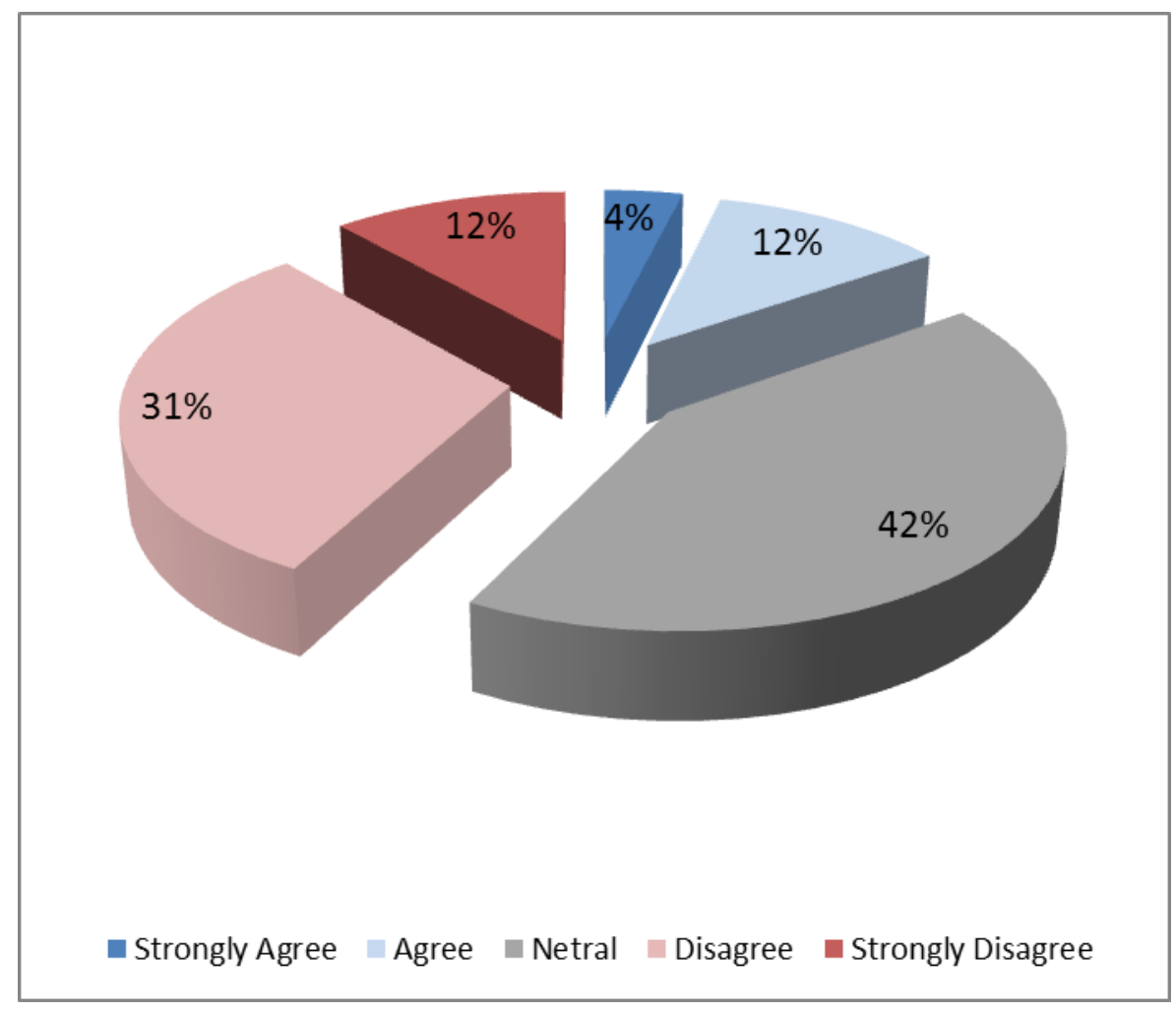

Figure 5-7: Agency considers both cost and embodied energy to assess benefits when considering RCA 


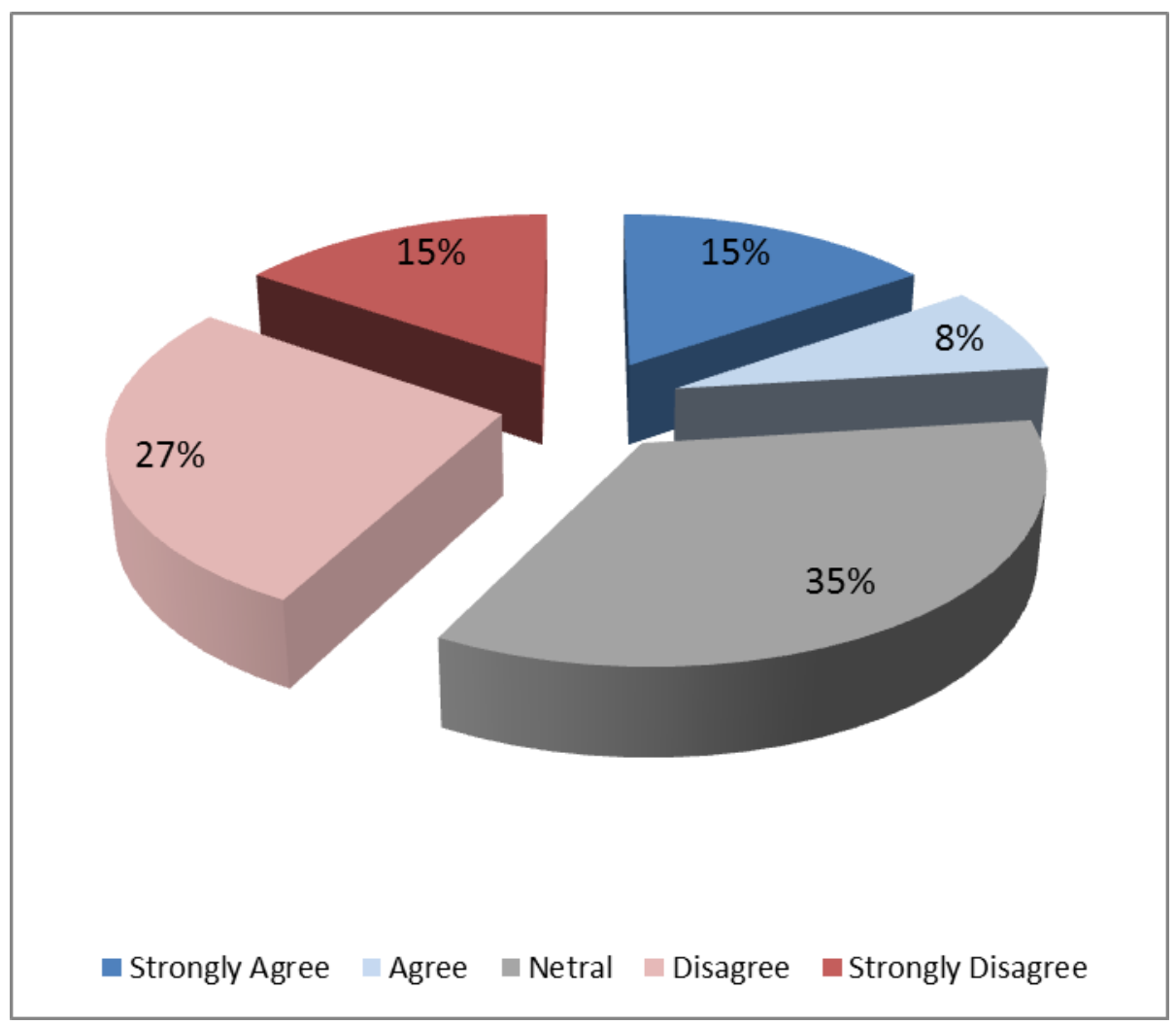

Figure 5-8: When determining whether to use RCA, our DOT considers sustainability as the most important factor

When asked if cost and embodied energy were considered in relation to benefits when assessing RCA, $42 \%$ of the respondents were "neutral." A total of $43 \%$ either "disagreed" or "strongly disagreed." This also may have been the result of considering two factors in the question that was asked, and thus may not be one of the most conclusive results from the field survey. It can be inferred, though, that only a small percentage (16\%) agreed with this statement, and it is reasonable to conclude that embodied energy and cost may not be considered together when assessing RCA. When asked if sustainabilty was the most important factor when considering whether to use RCA, 42\% chose either "strongly disagree" or "disagree." Of the respondents, $35 \%$ were "neutral," and only 23\% either "agreed" or "disagreed." This shows that other considerations may be more important than sustainabilty when considering RCA use.

Figure 5-9 shows what participants' viewpoints were regarding government incentives to promote RCA use. 


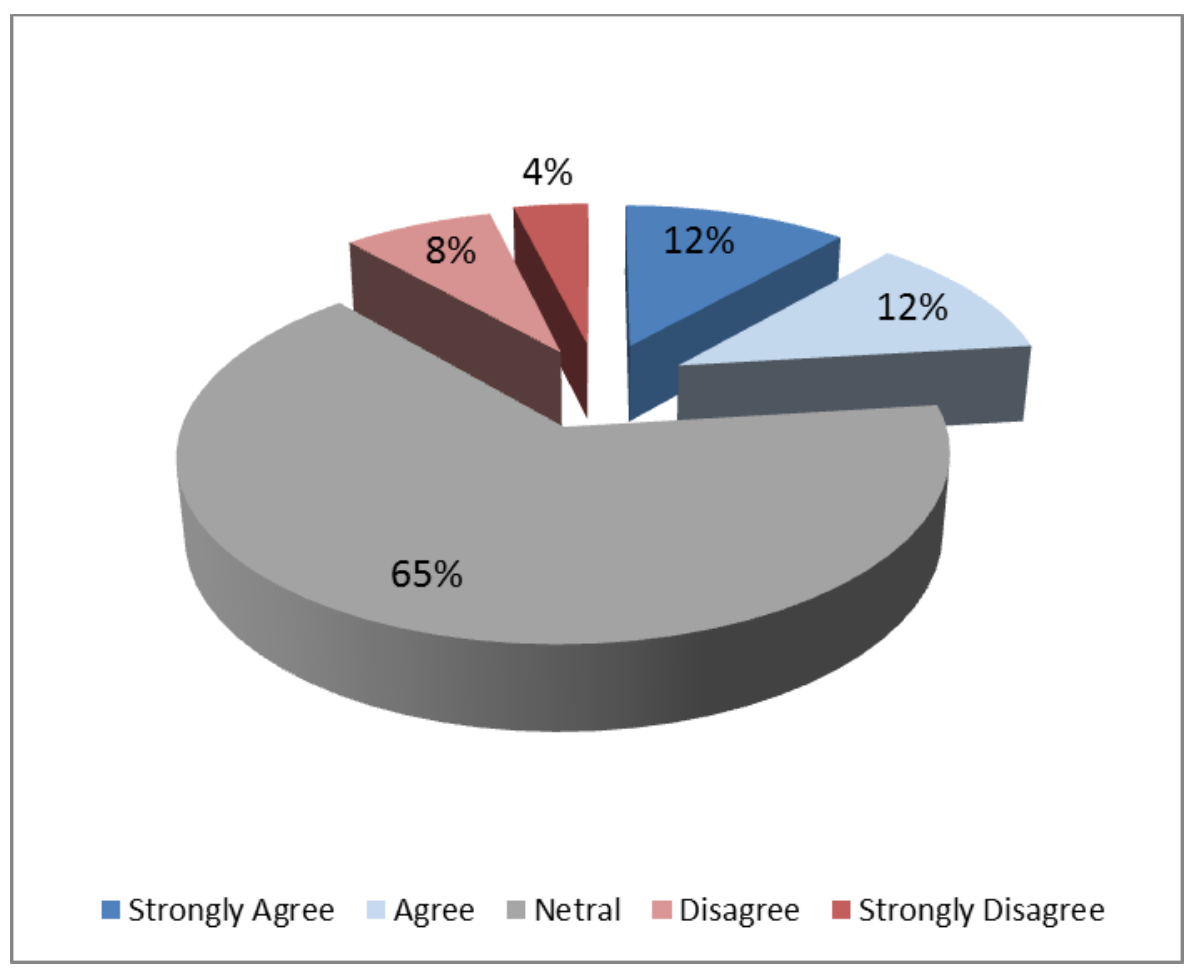

Figure 5-9: Agency believes that government incentives could effectively promote the use of RCA

The majority of respondents $(65 \%)$ were "neutral" in regard to government incentives being used to effectively promote RCA use. Only $12 \%$ of respondents either "disagreed" or "strongly disagreed," whereas $24 \%$ either "agreed" or "strongly agreed." It appears that the driving force for using RCA may not come in the form of incentives, or that such programs may not be viewed as positive channels for increasing its use. Further information may be necessary to make a better interpretation of these results.

\subsubsection{Durability and Long-Term Performance of RCA in New Concrete}

One of the central concerns of this research project was assessing the potential for ASR in new concrete when RCA undergoing ASR was used. Therefore, the research team asked participants their views on ASR within their agency, and specifically if ASR was viewed as a concern to their agency. Figure 5-10 shows the results specific to ASR concerns within the responding agencies. 


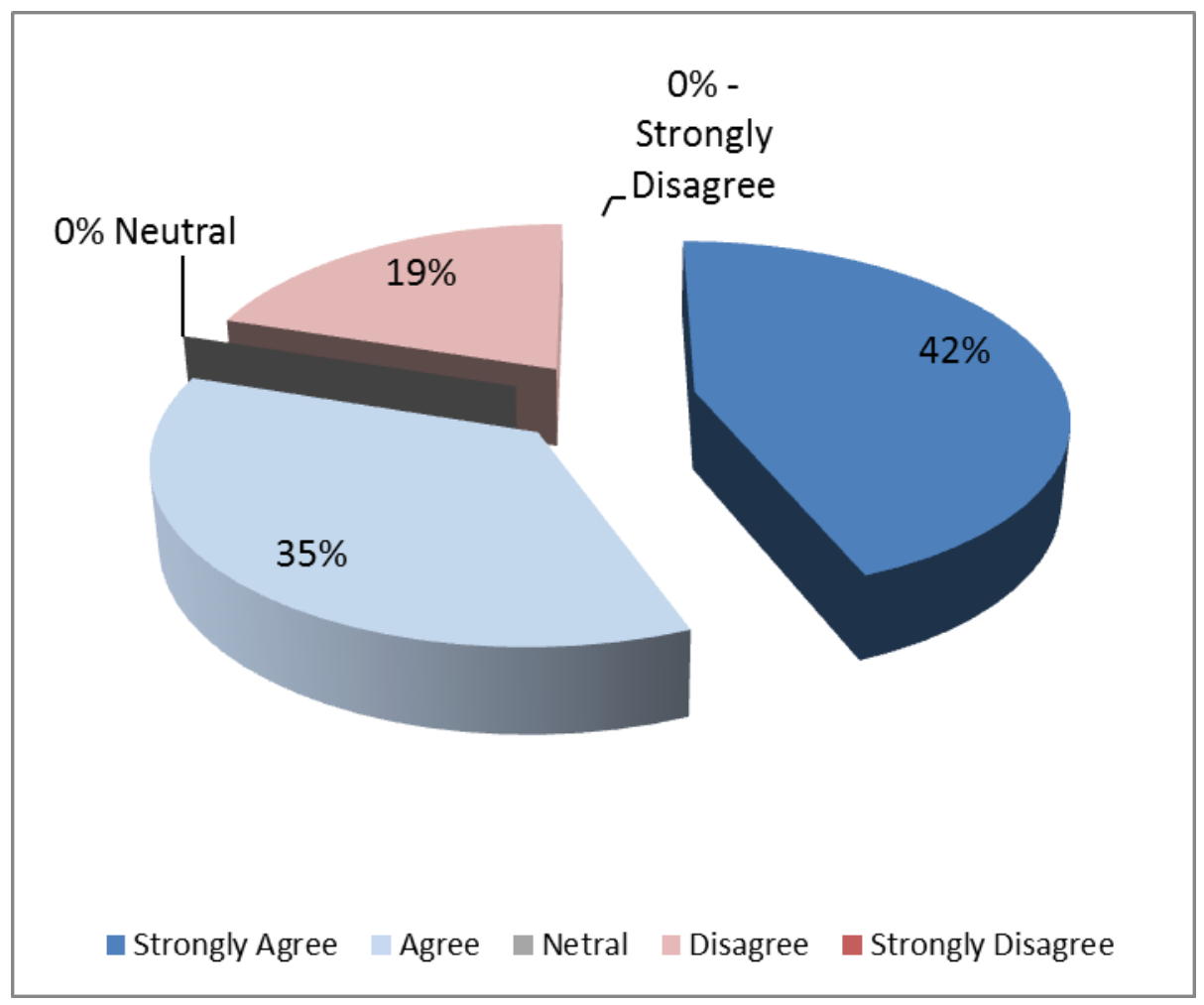

Figure 5-10 ASR is a concern to our DOT

From Figure 5-10 it can be seen that a large majority (77\%) of respondents either "agreed" or "strongly agreed" that ASR was a concern to their agency. Interestingly, in a separate question rspondents were asked if their agency had known instances of ASR in concrete structures. An overwhelming majority (72\%) said "yes," and only 28\% said "no." This was in strong agreement with the $77 \%$ of respondents that said their agency had concerns about ASR. Of those respondants that answered "yes," they were further asked to estimate the number or percentage of structures affected by ASR. Eight respondants replied "unknown" while three respondants provided numbers, but the values were not in a consistent format that were reportable. Seven other respondants did not answer the follow-up question.

One of the most important questions from the survey asked respondents what the biggest barriers were to using RCA. Respondents were given a list of choices from which to choose. They could choose multiple answers for this question, which is why the results in Figure 5-11 are given in a bar graph in terms of frequency of response. 


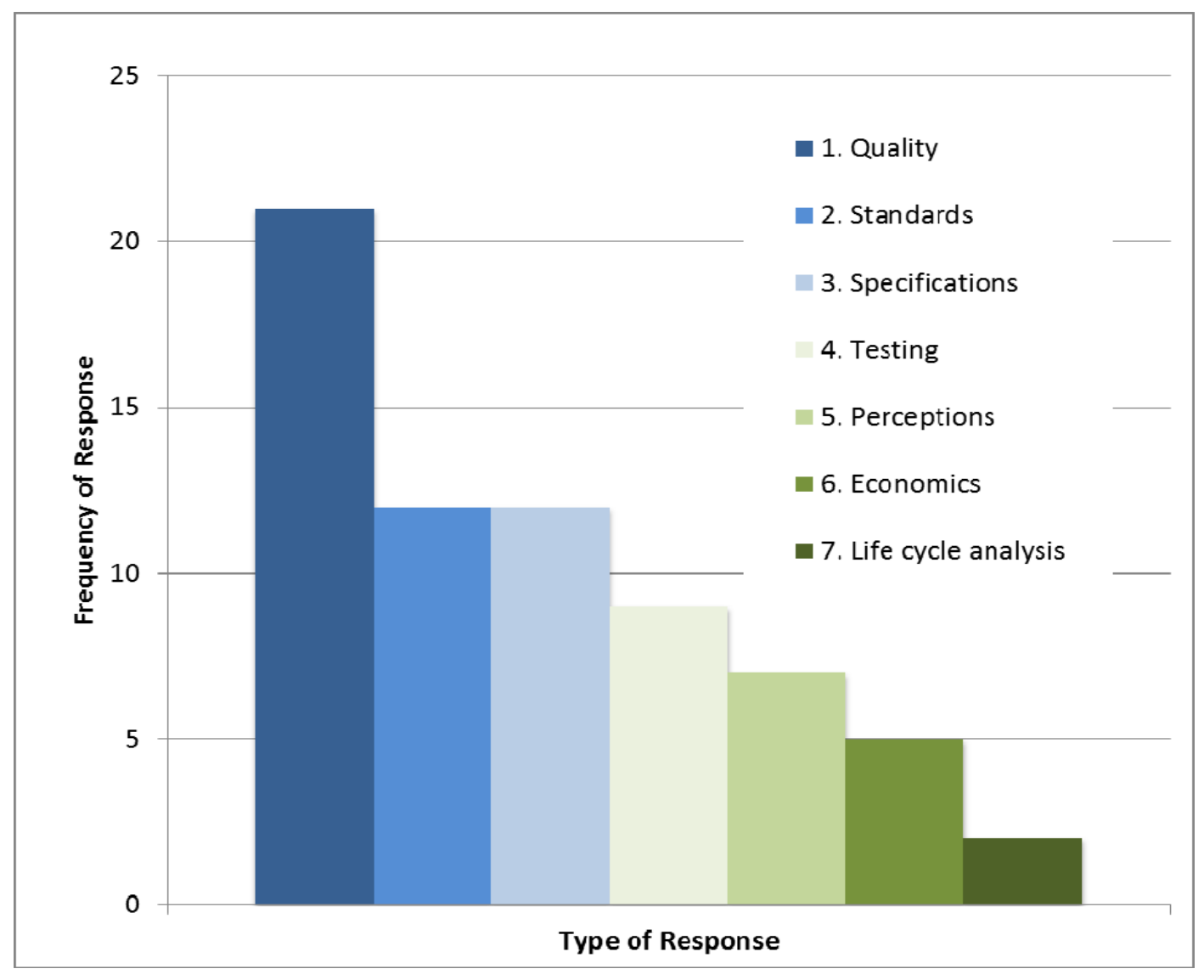

Figure 5-11: Most significant barriers to using RCA in new concrete

By far the biggest barrier identified in using RCA was concern about the quality of the RCA, with 21 of 27 respondents citing this barrier. The next most-frequent responses (12 each) were concerns with standards and specifications related to RCA. There was also concern with the type of testing to be performed to qualify an RCA source, with nine selections for this barrier. Perceptions, economics and life-cycle analysis received only seven, five and three responses, respectively. Social issues (not shown as no one selected this) were not viewed as barriers to using RCA based on this survey.

As a follow-up question to the results shown in Figure 5-11, respondents were asked what known characteristics would enable the use of RCA in the most beneficial manner. Figure 5-12 shows the results of that question. 


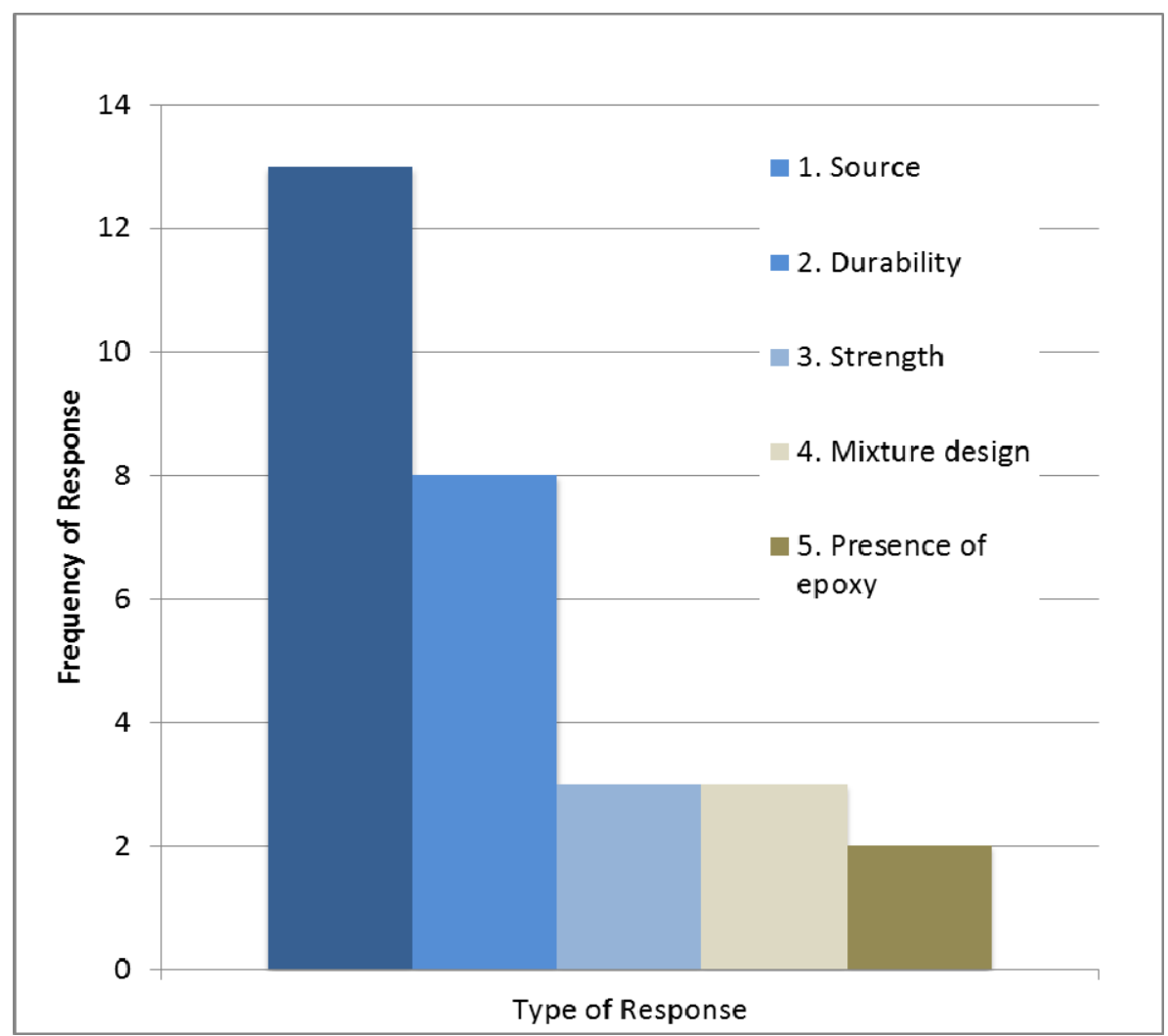

Figure 5-12: Knowing these characteristics would most beneficially enable RCA usage

The most frequent response was knowing the source (13) followed by durability (eight) and then strength (three) and mixture design (three). The presence of epoxy in the concrete was of little concern, with only two responses. This indicates that knowing the source of the RCA provides confidence and the type of information needed to most beneficially use RCA in new concrete. Participants also placed a strong emphasis on knowing about the durability of an RCA source in order to use it most beneficially. It is interesting that strength of the RCA was not noted as a significant characteristic in leading to beneficial use of RCA.

As a corollary, respondents were then asked to rank from 1-7 (1 being most important to 7 being least important) the specific RCA attributes to be known for making a decision about its use. These results are shown in Figure 5-13. 


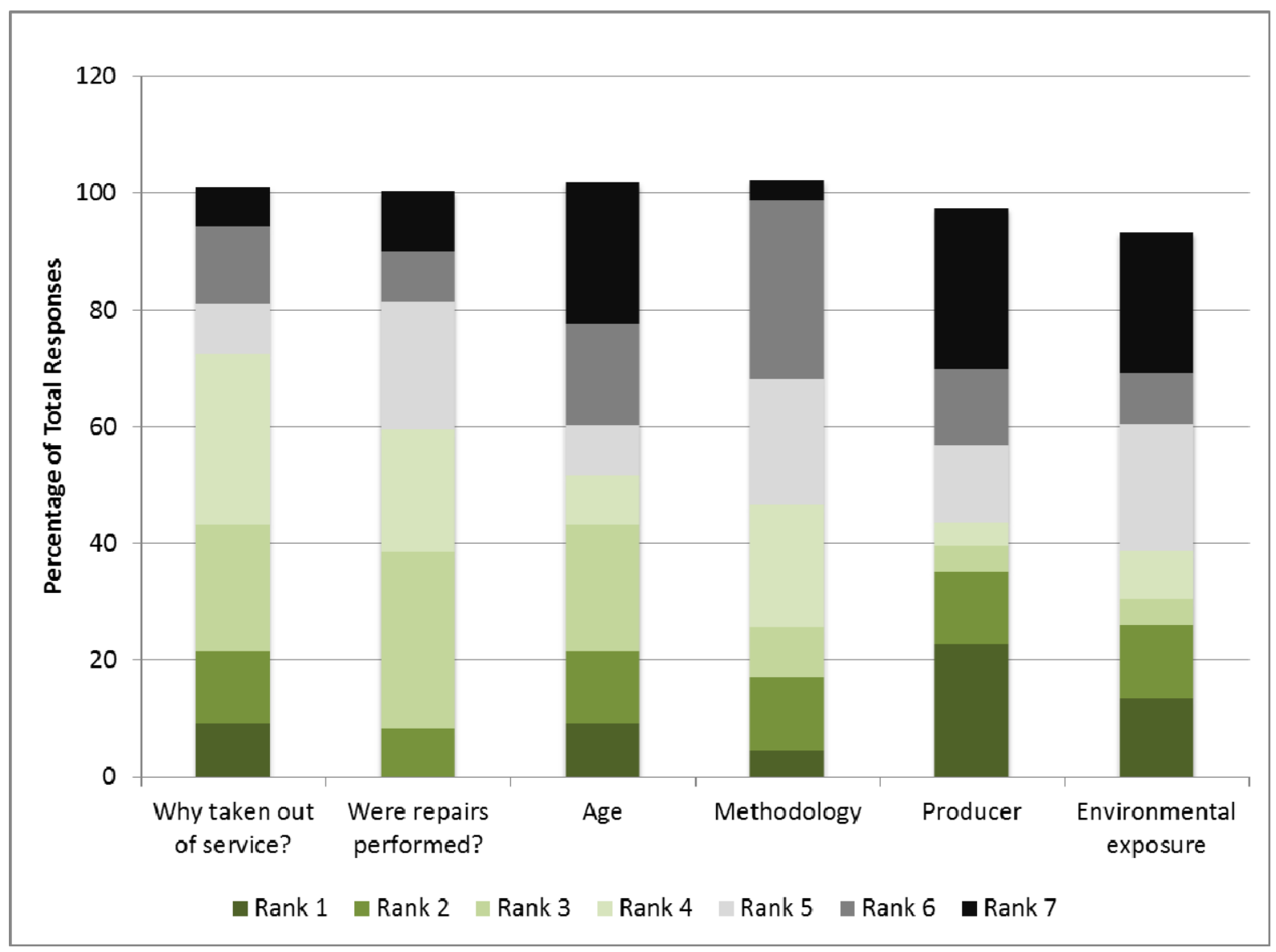

Figure 5-13: RCA attributes most important to making decisions for usage

In Figure 5-13, the green shaded bars represent those attributes that received a rank in the range of more important, whereas gray/black shaded areas indicate those areas of lower importance. The two most highly ranked attributes about RCA were 1) why the RCA source was taken out of service and 2) knowing if repairs had been performed on the parent concrete. The RCA's age and methodology of demolition/processing were ranked near or at $50 \%$ of total responses. Attributes that ranked of lower importance included 1) the RCA's producer and 2) environmental exposure. These responses indicate concerns about the quality of the RCA source material, durability and age, and reflect a similar response to that seen in Figure 5-12.

Respondents were then asked to identify specific concrete deterioration mechanisms that may be going on in an RCA source that were of concern for use of that RCA in new concrete. They were asked to choose from the major factors influencing concrete performance and included corrosion of reinforcing steel (residual chloride or carbonation); sulfate attack; ASR; shrinkage concerns; or "other," where they were asked to list other concerns. These results are shown in Figure 5-14. 


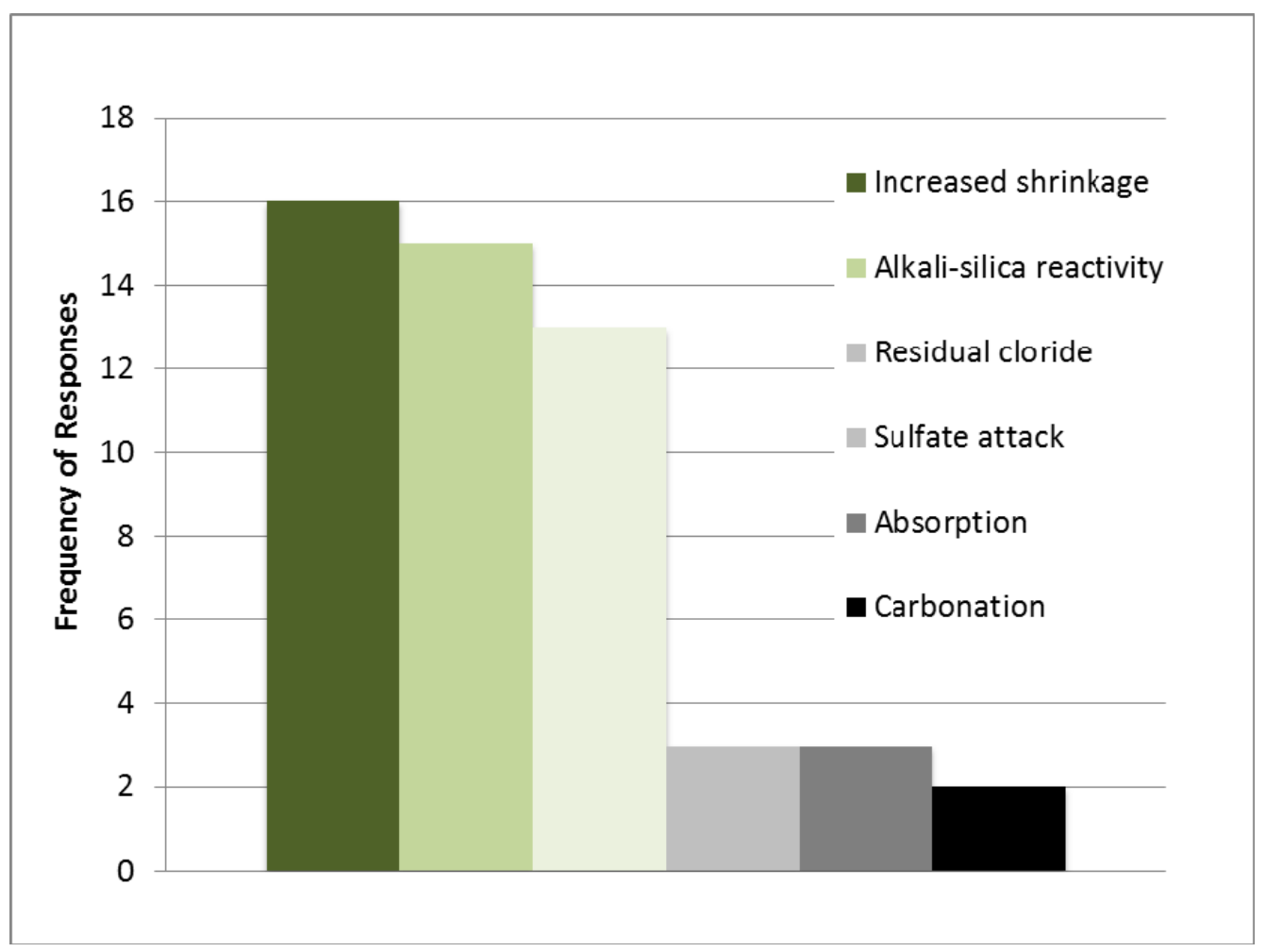

Figure 5-14: Potential attributes of RCA that cause concern for usage

The three most commonly cited concerns, in order of frequency of response, were:

- Increased shrinkage

- ASR

- Residual chlorides

Concerns with sulfate attack, absorption and carbonation were noted to be of little concern, with three or less responses for each. This provides good information when considering what testing mechanisms/approaches may be most needed for qualifying an RCA source.

Respondents were also asked what application was of most interest for incorporating RCA. Those responses can be seen in Figure 5-15. 


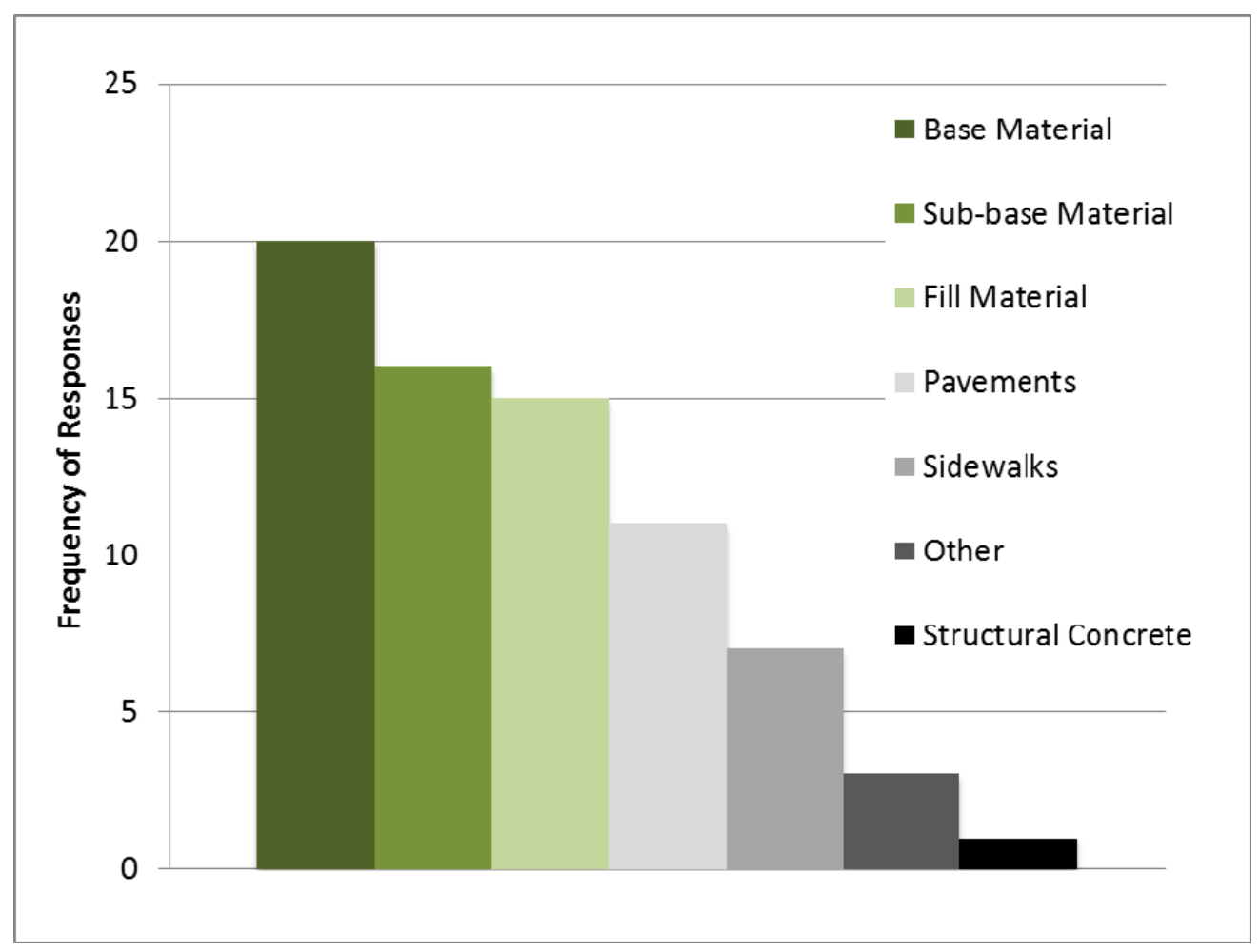

Figure 5-15: Most interest in using RCA for particular applications

The majority of respondents were most interested in using RCA in fairly "benign" applications including base material, subbase material and fill material. These comprised 20, 16 and 15 responses, respectively. Pavements were of interest as a potential application in using RCA and garnered 11 responses. Sidewalks were also of interest, with seven responses. However, usage of RCA in structural concrete was not an interest by the vast majority of survey participants.

\subsubsection{Database Creation}

When participants were asked if a database for tracking RCA would be used by their agency, $87 \%$ responded "yes" whereas only $13 \%$ responded "no." When further asked if such a database would increase the benefcial usage of RCA, $100 \%$ of the previous respondents who said, "yes, the database would be useful" also stated that the database would increase the beneficial usage of RCA. Respondents were then asked what type of information (database fields) should be included. They were given a list of potential fields where they could choose as many as were pertinent to the database in their opinion. There were also options for "other" free response type fields. These responses are compiled in Figure 5-16 and Figure 5-17. 


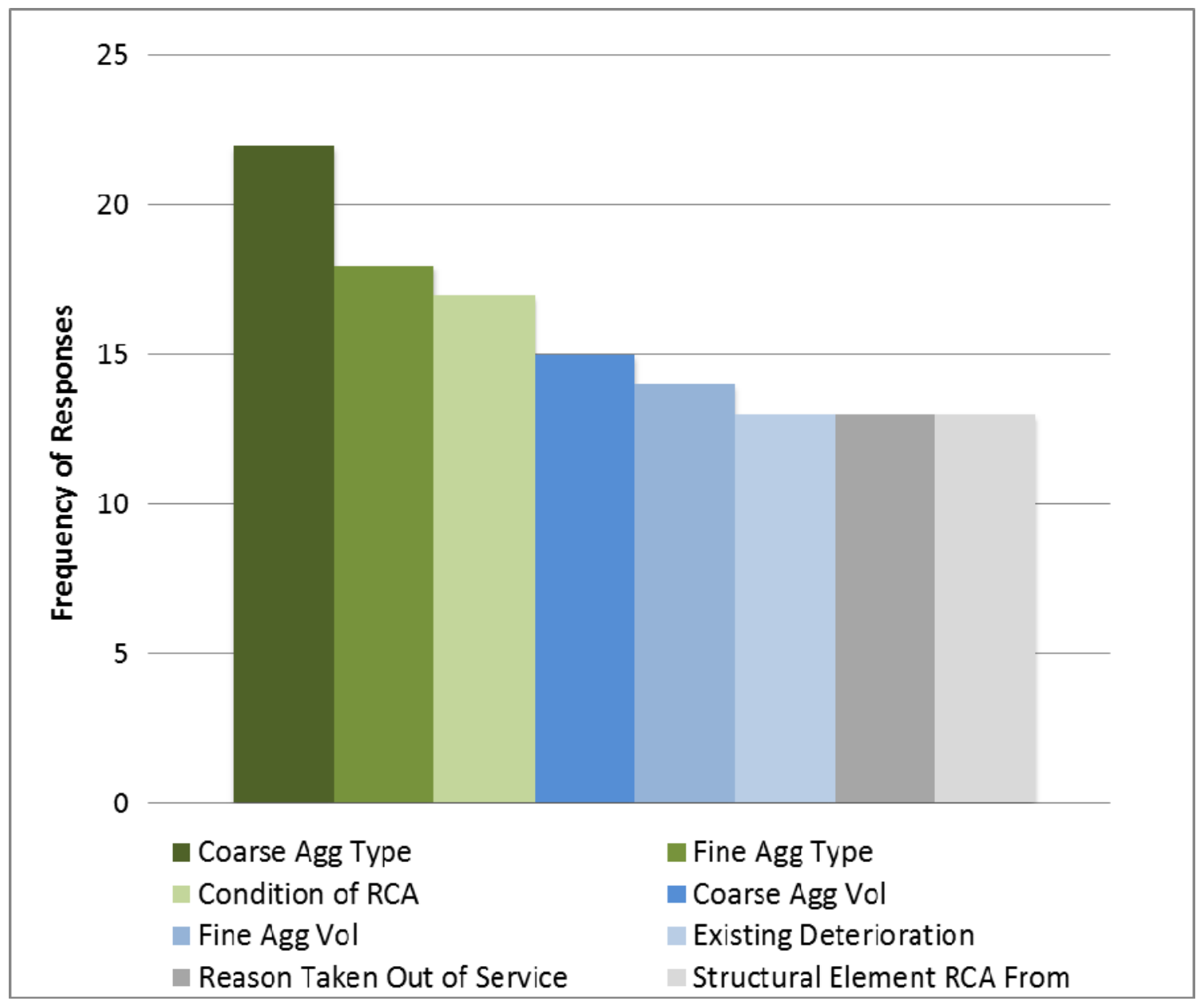

Figure 5-16: If a database was provided to track RCA sources, what are the most desired fields for input? 


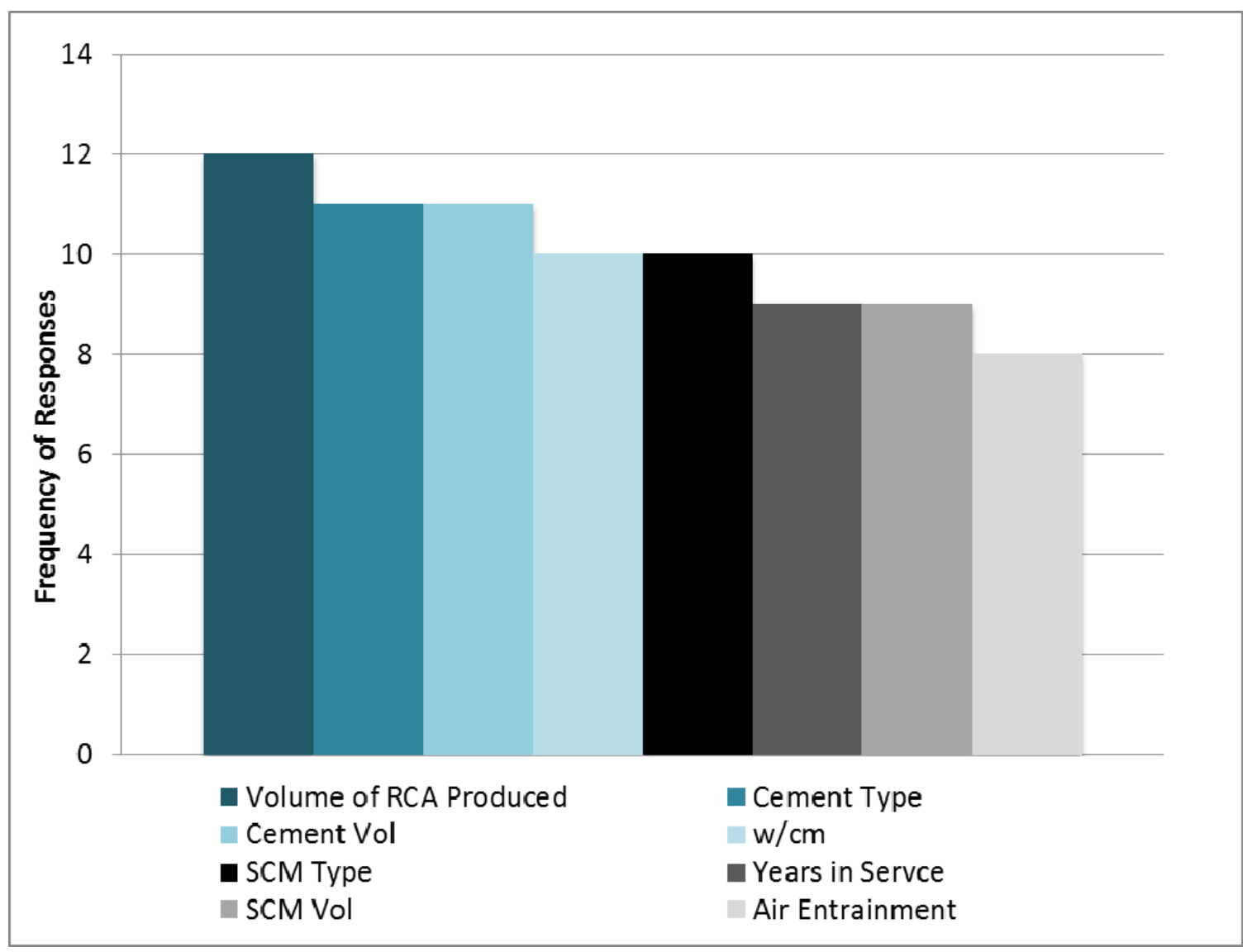

Figure 5-17: If a database was provided to track RCA sources, what are the most desired fields for input (Part 2)?

In general, the respondents typically agreed with the list of potential database fields where at least half of the respondents (13 or more) cited that having entries for the following information were important:

- Coarse aggregate type

- Fine aggregate type

- Coarse aggregate volume

- Fine aggregate volume

- Existing deterioration

- Reason taken out of service

- Structural element from where the RCA was taken

Respondents cited the remaining categories less than half of the time (half of the respondents). However, even the least-cited field for the database, "air entrainment," still received eight responses. It is likely that all of these fields will be included in the development of a database to track RCA sources. Some of the other fields requested included:

- Chloride content

- Testing standards 
- Whether it was a fine or a coarse RCA

- Gradation of fine and/or coarse aggregate

While all of these fields will likely be included in the future development of such a database, there will also be some customizable fields for individual users to add their own tracking mechanisms.

Respondents were also asked to provide guidance on what type of software or Internet form would be most useful. The responses were varied, but many participants indicated a web-based format would be the most useful. Others said that Excel or MS Access were familiar tools and would be useful. Interestingly, a number of respondents indicated that a GIS-based system would be useful. Several respondents also suggested that GIS information, combined with a website where a source could be identified on a map with a clickable link that provided specifics about the source, would be desirable.

Respondents were also asked what way of searching would be the most useful to them and a variety of responses were given. However, the majority of responses were given as "location." Other responses said to be able to search by "all input fields" and by "performance parameters as noted in the list from the previous question."

At the end of the survey, the question was posed for any other suggestions, ideas or comments specific to RCA and the use of the database. Most of the respondents provided additional information and several put specific contact information for follow-up. The names and contact numbers will not be given out in this report. However, all of the individual responses can be found in Appendix A. 


\subsection{CONCLUSIONS AND RECOMMENDATIONS}

This Phase II investigation into durability of new concrete incorporating recycled concrete aggregates (RCA) focused on several goals: 1) Provide corroboration of results obtained in Phase I for a multi-laboratory study related to assessing alkali-silica reactivity (ASR) of RCA in accelerated laboratory tests; 2) Investigate the efficacy of mitigation methods to control ASR in concrete containing potentially reactive RCA; 3) Establish long-term data through placement of concrete blocks containing RCA in an outdoor exposure site in Laramie, WY; and 4) Survey state DOTs and other transportation agencies about their perceptions and use of RCA, ASR in concrete within their agency, and how that may be improved through a database tracking tool. Overall conclusions and recommendations for future work are provided below. A brief summary of Phase I results also is included.

\subsection{PHASE I CONCLUSIONS}

- Modifications to standard aggregate testing and characterization standards are necessary for RCA.

- Absorption capacity testing required at least a 24 -hour soaking period to take up $95 \%$ of the aggregate's total absorption.

- Modifications to ASTM C 305 were required for properly mixing mortars containing RCA, including a soaking period of 30 minutes for all aggregate (including RCA) to ensure proper absorption by dry aggregate and adequate mixing.

- Based on testing in this research project, precision and bias statements in ASTM C 1260 (for virgin aggregate) do not apply to RCA. Additional testing from at least six laboratories analyzing the same materials would be needed to properly establish precision and bias statements.

\subsection{PHASE II CONCLUSIONS}

Phase II involved further ASR testing of RCA in a second, two-laboratory investigation of three different stockpiled RCA sources to determine if stockpiled and field-structure sourced RCA produced similar results and repeatability as those produced by the lab-created RCA specimens investigated in Phase I. The results of this study showed:

- ASTM C 1260-07 currently recommends a within-laboratory COV of 2.94\%. This COV limit was exceeded by 18 sets of bars, or $50 \%$ of the tests completed in Phase II research. This data matches data seen in Phase I that showed that when using the ASTM C1260 test to examine RCA, the COV limit may need to be modified. It is recommended that further testing, using different RCA and more laboratories (at least six), should be performed to confirm the results shown in this study. This must be completed before a 
new standard for RCA and/or incorporation of RCA into the current ASTM C 1260 test may be allowed.

Exposure blocks were cast and placed in an outdoor exposure site for realistic exposure to environmental fluctuations in Laramie, WY. While these blocks are still fairly new (cast in 2011) one of the exposure blocks incorporating RCA from a set of steps on the University of Wyoming campus is showing significant deterioration (Expansion $>1.2 \%$ ) after only one year of outdoor exposure. Continued monitoring over the next 5-10 years will provide invaluable data about the reliability of accelerated laboratory tests compared to more reliable field testing.

Phase II also investigated the efficacy of SCM to control ASR in new concrete incorporating potentially reactive RCA. The initial level of fly ash replacement for each aggregate was determined using the equation developed by Malvar and Lenke (2006) at a 90\% confidence level. The results show the following:

- SCM can reduce expansions in concrete made with potentially reactive RCA.

- Generally, as the replacement level of RCA was reduced the amount of SCM needed to control deleterious ASR was also reduced for the RCA sources investigated in this study. However, it is recommended that all replacement levels and SCM combinations be tested prior to being used in the field, as higher expansions have been noted at lower RCA replacement levels.

- The specific amounts of fly ash predicted by the Malvar and Lenke equation needed to control deleterious ASR in concrete incorporating RCA produced conflicting results. In about half of the cases, the chemical index equation was capable of predicting the required amount of fly ash to reduce expansions for RCA and fly ash combinations. However, not all RCA followed this trend. Further research needs to be conducted to better understand whether the chemical index equation can be used with RCA and what modifications may be needed for better assessment.

- The amount of adhered mortar can affect the level of reactivity in an aggregate, and subsequently may affect the efficacy of a SCM to mitigate ASR. Further testing needs to be completed to understand how the amount of adhered mortar affects the ability of SCM to mitigate ASR in mortar bars made with RCA.

- For both the Jobe and CalPort RCA, the ternary blends containing metakaolin resulted in the most significant decrease in expansions compared to the mixtures with no SCM. This may also be linked to the fact that metakaolin has a high aluminum oxide content, which has been shown recently to be an important parameter for a SCM to control ASR.

- The silica fume ternary blends was less effective than the other SCM combinations used to reduce expansions in the mortar bars made with the CalPort aggregate, though a reduction in expansion was observed.

A survey of all state DOTs and several other transportation agencies (FHWA and Canada's Ministries of Transportation) was conducted to determine current perceptions and use of RCA and concerns with ASR, and to gauge what information would be most useful in a database tracking tool for RCA sources. The survey drew 27 responses, viewed as a strong response rate. The following main conclusions were drawn: 
- A vast majority of agencies believed that sustainability was important and that it was addressed in a clear and meaningful way.

- The majority (54\%) believed they had specific guidance for the use of RCA in new concrete. However, only $15 \%$ believed that there was strong information from the federal level about the use of RCA in new construction.

- The use of RCA in new construction is viewed as an important sustainability measure; however, there are other benefits of using RCA as well.

- Most (77\%) of respondents indicated that their agency was concerned about ASR in concrete.

- The biggest barriers to using RCA were noted as concerns about quality, a lack of standards and specifications, and unclear guidance on RCA testing.

- The biggest concerns specific to a source of RCA when considering it for use in new construction were increased shrinkage, ASR and residual chlorides.

- The most sought-after information about a potential RCA source when considering it for use were the RCA's existing condition when it was taken out of service, the reason it was taken out of service, whether repairs were performed to the structural element taken out of service, and the RCA's age.

- The applications of interest for using RCA in decreasing rank (from most interest to least interest) included base material, subbase material, fill material, pavements, sidewalks and structural concrete.

The results from this research project and from the survey will provide valuable information as the research team moves forward to provide documents, papers and presentations about the use of RCA in new concrete. It has also clearly established the following research needs related to RCA:

- Development of standards/specifications for use of RCA in new concrete, with a particular focus on qualifying/testing a potential source of RCA. This is needed at both the state and federal levels.

- Research related to the shrinkage potential of new concrete incorporating RCA and associated cracking risk is an area for future investigations.

- Assessing durability concerns continues to be a significant need, with a focus on shrinkage, ASR and residual chlorides. This information is particularly beneficial when considering testing methods for qualifying a source of RCA for new construction.

- The development of a database is of considerable interest for tracking RCA sources and enabling better usage.

- Multi-laboratory investigations utilizing more sources of RCA (e.g., at least six labs and 6-10 RCA sources) are necessary to provide appropriate information to ASTM and other standards organizations for modifying current or developing new testing methods related to assessing ASR of RCA.

- Further work into the efficacy of SCM to control ASR when new concrete incorporates potentially reactive sources of RCA. 


\subsection{REFERENCES}

Abbas, A., G. Fathifazl, et al. (2008). "Proposed method for determining the residual mortar content of recycled concrete aggregates." Journal of ASTM International 5.

ACI 318 (2008). Building code requirements for structural concrete (ACI 318-08) and commentary. American Concrete Institute. Farmington Hills, Michigan, American Concrete Insitute.

ACI (2008). State-of-the-Art Report on Alkali-Aggregate Reactivity-ACI 221.1R-98(2008). ACI manual of concrete practice. Detroit, Mich.: 221.

Adams, M. P., J. H. Ideker, et al. (2012). "Applicability of the ASTM C1260 mortar bar test for alkali-silica reactivity testing with recycled concrete aggregates." in preparation for submittal to Journal of ASTM International.

American Concrete Institute (2001). Removal and reuse of hardened concrete. American Concrete Institute. Farmington Hills, MI, American Concrete Institute. ACI 555R-01.

ASTM C128 (2007). "Standard test method for density, relative density (specific gravity), and absorption of fine aggregate". ASTM International. West Conshohocken, PA, ASTM International.

ASTM C305 (2006). "Standard practice for mechanical mixing of hydraulic cement pastes and mortars of plastic consistency". ASTM International. West Conshocken, PA, ASTM International.

ASTM C618 (2012). "Standard Specification for Coal Fly Ash and Raw or Calcined Natural Pozzolan for Use in Concrete". ASTM International. West Conshohocken, PA, ASTM International.

ASTM C1260 (2007). "Standard Test Method for Potential Alkali Reactivity of Aggregates (Mortar-Bar Method)". ASTM International. West Conshohocken, PA, ASTM International.

ASTM C1293 (2008b). Standard Test Method for Determination of Length Change of Concrete Due to Alkali-Silica Reaction. ASTM International. West Conshohocken, PA, ASTM International: 6 .

ASTM C1567 (2007). "Standard Test Method for Determining the Potential Alkali-Silica Reactivity of Combinations of Cementitious Materials and Aggregate (Accelerated Mortar-Bar Method)". ASTM International. West Conshohocken, Pa.

Beauchemin, S. and B. Fournier (2012). Petrographic analysis of aggregate particles used in the accelerated mortar bar test for evaluating the potential alkali-reactivity of recycled concrete aggregates (RCA). 14th International Conference on Alkali-Aggregate Reactivity, Austin, Texas (USA).

Bektas, F., L. Turanli, et al. (2004). "Alkali reactivity of mortars containing chert and incorporating moderate-calcium fly ash." Cement and Concrete Research 34(12): 22092214.

Berube, M. A. and B. Fournier (2000). "Alkali-aggregate reaction in concrete: a review of concepts and engineering implications." Canadian Journal of Civil Engineering 27(2): 167-191. 
Fathifazl, G., A. Abbas, et al. (2009). "New mixture proportioning method for concrete made with coarse recycled concrete aggregate." Journal of Materials in Civil Engineering 21(10): 601-611.

Fathifazl, G., A. G. Razaqpur, et al. (2010). Proportioning concrete mixtures with recycled concrete aggregate: A novel method. Concrete International Farmington Hills, MI, American Concrete Institute: 37-43.

FHWA. (2003, 04/07/2011). "Recycled Concrete Aggregate." Retrieved 11/27, 2011, from http://www.fhwa.dot.gov/pavement/recycling/rca.cfm.

Folliard, K. J., M. D. A. Thomas, et al. (2006). Interim recommendations for the use of lithium to mitigate or prevent alkali-silica reaction (ASR). U. S. Department of Transportation: Federal Highway Association. McLean, Virginia, USA, U.S. DoT.

Fournier, B., J. H. Ideker, et al. (2009). "Effect of environmental conditions on expansion in concrete due to alkali-silica reaction." Materials Characterization 60(7): 669-679.

Fournier, B. and V. M. Malhotra (1996). Reducing expansion due to alkali-silica reactivity. Concrete International, American Concrete Institute. 18: 55-59.

Fournier, B., P.-C. Nkinamubanzi, et al. (2006). "Evaluating potential alkali-reactivity of concrete aggregates - How reliable are the current and new test methods?" IberoAmerican Sobre "Concreto Estrutural".

Fournier, B., P.-C. Nkinamubanzi, et al. (2006). Evaluating potential alkali-reactivity of concrete aggregates, how reliable are the current and new test methods. Marc-Andre Berube Symposium on Alkali-Aggregate Reactivity in Concrete, CANMET, Ottowa.

Froundistou-Yannis, S. (1977). "Waste concrete as aggregate for new concrete." ACI Journal 74(8): 373-376.

Garcia-Diaz, E., D. Bulteel, et al. (2010). "ASR pessimum behaviour of siliceous limestone aggregates." Cement and Concrete Research 40(4): 546-549.

Gress, D. L. (2000). Accelerated ASR Testing of concrete prisms incorporating recycled concrete aggregates. 11th International Conference on Alkali-Aggregate Reaction, Québec City, QC, Canada, Centre de Recherche Interuniversitaire sur le Béton.

Gress, D. L., M. B. Snyder, et al. (2009). "Performance of rigid pavements containing recycled concrete aggregate: update for 2006." Transportation Research Recod: Journal of the Transportation Research Board 2113: 99-107.

Hobbs, D. W. (1988). Alkali-silica reaction in concrete. London, Thomas Telford Ltd.

Ideker, J. H., A. F. Bentivegna, et al. (2012). "Do current laboratory test methods accurately predict alkali-silica reactivity." ACI Materials Journal 109(4): 395-402.

Ideker, J. H., T. Drimalas, et al. (2012). The Importance of Outdoor Exposure Site Testing. 12th International Conference on Alkali-Aggregate Reactivity in Concrete, Austin, Texas, USA.

Ideker, J. H., J. E. Tanner, et al. (2012). Durability asessment of recycled concrete aggregates for use in new concrete - Phase I Report. Portland, OR, Oregon Transportation and Education Consortium: 60.

Katz, A. (2003). "Properties of concrete made with recycled aggregate from partially hydrated old concrete." Cement and Concrete Research 33(5): 703-711.

Kosmatka, S. H., B. Kerkhoff, et al. (2008). Design and control of concrete mixtures. Skokie, Illinois, Portland Cement Association. 
Kou, S.-C., C.-S. Poon, et al. (2011). "Influence of recycled aggregates on long term mechanical properties and pore size distribution of concrete." Cement and Concrete Composites 33(2): 286-291.

Lane, D. S. (1999). "Comparison of Results from C 441 and C 1293 with Implications for Establishing Criteria for ASR-Resistant Concrete." Cement, Concrete, and Aggregates, CCAGDP 21(2): 149-156.

Lauritzen, E. K. (2004). Recycling concrete - an overview of challenges and opportunities. ACI SP-219: Recycling concrete and other materials for sustainable development. T. C. Liu and C. Meyer. Farmington Hills, Mich, American Concrete Institute: 1-10.

Li, X. and D. L. Gress (2006). "Mitigating alkali-silica reaction in concrete containing recycled concrete aggregate." Transportation research record: journal of the transportation research board 1979: 30-35.

Malvar, L. J. and L. R. Lenke (2006). "Efficiency of fly ash in mitigating alkali-silica reaction based on chemical composition." ACI Materials Journal 103(5): 319-326.

Melton, J. S. (2004). Guidance for recycled concrete aggregate use in the highway environment. ACI SP-219: Recycling concrete and other materials for sustainable development. T. C. Liu and C. Meyer. Farmington Hills, Mich, American Concrete Institute: 47-60.

Mirdamadi, A., H. Layssi, et al. (2008). Comparative study of metakaolin and silica fume to prevent alkali-silica reaction in concrete. 13th International Conference on AlkaliAggregate Reaction, Trondheim, Norway.

Moser, R. D., A. R. Jayapalan, et al. (2010). "Assessment of binary and ternary blends of metakaolin and Class $\mathrm{C}$ fly ash for alkali-silica reaction mitigation in concrete." Cement and Concrete Research 40(12): 1664-1672.

Nagataki, S., A. Gokce, et al. (2004). "Assessment of recycling process induced damage sensitivity of recycled concrete aggregates." Cement and Concrete Research 34(6): 965 971.

Oberholster, R. E. and G. Davies (1986). "An accelerated method for testing the potential alkali reactivity of siliceous aggregates." Cement and Concrete Research 16(2): 181-189.

Poon, C. S., Z. H. Shui, et al. (2004). "Influence of moisture states of natural and recycled aggregates on the slump and compressive strength of concrete." Cement and Concrete Research 34(1): 31-36.

Quanlin, N. and F. Naiqian (2004). Inhibiting effect of superfine mineral powders on alkali aggregate reactions. 12th International Conference on Alkali-Aggregate Reaction in Concrete, Beijing, China, International Academic Publishers World Publishing Corporation.

Ramlochan, T., M. Thomas, et al. (2000). "The effect of metakaolin on alkali-silica reaction in concrete." Cement and Concrete Research 30(3): 339-344.

Rao, A., K. N. Jha, et al. (2007). "Use of aggregates from recycled construction and demolition waste in concrete." Resources, Conservation and Recycling 50(1): 71-81.

Sagoe-Crentsil, K. K., T. Brown, et al. (2001). "Performance of concrete made with commercially produced coarse recycled concrete aggregate." Cement and Concrete Research 31(5): 707-712.

Scott, H. C., IV and D. L. Gress (2004). Mitigating alkali silica reaction in recycled concrete. ACI SP-219: Recycling concrete and other materials for sustainable development. T. C. Liu and C. Meyer. Farmington Hills, Mich, American Concrete Institute: 61-76. 
Shayan, A. and A. Xu (2003). "Performance and properties of structural concrete made with recycled concrete aggregate." ACI Materials Journal 100(5): 371-380.

Shehata, M. H., C. Christidis, et al. (2010). "Reactivity of reclaimed concrete aggregate produced from concrete affected by alkali-silica reaction." Cement and Concrete Research 40(4): 575-582.

Shehata, M. H. and M. D. A. Thomas (2000). "The effect of fly ash composition on the expansion of concrete due to alkali-silica reaction." Cement and Concrete Research 30(7): 1063-1072.

Thomas, M. (2011). "The effect of supplementary cementing materials on alkali-silica reaction: A review." Cement and Concrete Research 41(12): 1224-1231.

Thomas, M., B. Fournier, et al. (2006). "Test methods for evaluating preventive measures for controlling expansion due to alkali-silica reaction in concrete." Cement and Concrete Research 36(10): 1842-1856.

Thomas, M. D. A., B. Fournier, et al. (2006). "Test methods for evaluating preventive measures for controlling expansion due to alkali-silica reaction in concrete." Cement and Concrete

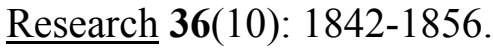




\subsection{APPENDIX A - TABULATED RESULTS OF TRANSPORTATION AGENCY SURVEY}

This Appendix contains the raw tabulated data from the Department of Transportation Survey outlined in Section 5.0 of this report. The Section number and Question number are provided in the first cell. For Question 1 from Section 1 the designation is thus "S1Q1."

\begin{tabular}{|c|c|c|c|c|c|}
\hline S1O1 & Strongly Agree & Agree & Neutral & Disagree & $\begin{array}{l}\text { Strongly } \\
\text { Disagree }\end{array}$ \\
\hline Agency 1 & 1 & & & & \\
\hline Agency 2 & 1 & & & & \\
\hline Agency 3 & & 1 & & & \\
\hline Agency 4 & 1 & & & & \\
\hline Agency 5 & & 1 & & & \\
\hline Agency 6 & & 1 & & & \\
\hline Agency 7 & & & 1 & & \\
\hline Agency 8 & 1 & & & & \\
\hline Agency 9 & 1 & & & & \\
\hline Agency 10 & & 1 & & & \\
\hline Agency 11 & & 1 & & & \\
\hline Agency 12 & & & & 1 & \\
\hline Agency 13 & & 1 & & & \\
\hline Agency 14 & 1 & & & & \\
\hline Agency 15 & 1 & & & & \\
\hline Agency 16 & 1 & & & & \\
\hline Agency 17 & 1 & & & & \\
\hline Agency 18 & 1 & & & & \\
\hline Agency 19 & & & 1 & & \\
\hline Agency 20 & 1 & & & & \\
\hline Agency 21 & & 1 & & & \\
\hline Agency 22 & 1 & & & & \\
\hline Agency 23 & 1 & & & & \\
\hline Agency 24 & & 1 & & & \\
\hline Agency 25 & 1 & & & & \\
\hline Agency 26 & 1 & & & & \\
\hline
\end{tabular}




\begin{tabular}{|c|c|c|c|c|c|}
\hline S1Q2 & Strongly Agree & Agree & Neutral & Disagree & $\begin{array}{l}\text { Strongly } \\
\text { Disagree }\end{array}$ \\
\hline Agency 1 & 1 & & & & \\
\hline Agency 2 & & 1 & & & \\
\hline Agency 3 & & 1 & & & \\
\hline Agency 4 & & 1 & & & \\
\hline Agency 5 & & 1 & & & \\
\hline Agency 6 & & & 1 & & \\
\hline Agency 7 & & & & & 1 \\
\hline Agency 8 & & 1 & & & \\
\hline Agency 9 & & 1 & & & \\
\hline Agency 10 & & 1 & & & \\
\hline Agency 11 & & & 1 & & \\
\hline Agency 12 & & & & & 1 \\
\hline Agency 13 & & 1 & & & \\
\hline Agency 14 & & & 1 & & \\
\hline Agency 15 & & 1 & & & \\
\hline Agency 16 & & 1 & & & \\
\hline Agency 17 & & 1 & & & \\
\hline Agency 18 & & 1 & & & \\
\hline Agency 19 & & & & 1 & \\
\hline Agency 20 & & & 1 & & \\
\hline Agency 21 & & & 1 & & \\
\hline Agency 22 & 1 & & & & \\
\hline Agency 23 & & 1 & & & \\
\hline Agency 24 & & 1 & & & \\
\hline Agency 25 & & 1 & & & \\
\hline Agency 26 & 1 & & & & \\
\hline
\end{tabular}




\begin{tabular}{|c|c|c|c|c|c|}
\hline S1Q3 & Strongly Agree & Agree & Neutral & Disagree & $\begin{array}{l}\text { Strongly } \\
\text { Disagree }\end{array}$ \\
\hline Agency 1 & 1 & & & & \\
\hline Agency 2 & & 1 & & & \\
\hline Agency 3 & & & 1 & & \\
\hline Agency 4 & 1 & & & & \\
\hline Agency 5 & & 1 & & & \\
\hline Agency 6 & & 1 & & & \\
\hline Agency 7 & & & & 1 & \\
\hline Agency 8 & & 1 & & & \\
\hline Agency 9 & & 1 & & & \\
\hline Agency 10 & & 1 & & & \\
\hline Agency 11 & & & 1 & & \\
\hline Agency 12 & & & & 1 & \\
\hline Agency 13 & & 1 & & & \\
\hline Agency 14 & & & & 1 & \\
\hline Agency 15 & & 1 & & & \\
\hline Agency 16 & & 1 & & & \\
\hline Agency 17 & 1 & & & & \\
\hline Agency 18 & 1 & & & & \\
\hline Agency 19 & & & 1 & & \\
\hline Agency 20 & & 1 & & & \\
\hline Agency 21 & & 1 & & & \\
\hline Agency 22 & & 1 & & & \\
\hline Agency 23 & 1 & & & & \\
\hline Agency 24 & & 1 & & & \\
\hline Agency 25 & 1 & & & & \\
\hline Agency 26 & 1 & & & & \\
\hline
\end{tabular}




\begin{tabular}{|c|c|c|c|c|c|}
\hline S1Q4 & Strongly Agree & Agree & Neutral & Disagree & $\begin{array}{l}\text { Strongly } \\
\text { Disagree }\end{array}$ \\
\hline Agency 1 & 1 & & & & \\
\hline Agency 2 & & & 1 & & \\
\hline Agency 3 & & & & 1 & \\
\hline Agency 4 & & 1 & & & \\
\hline Agency 5 & & 1 & & & \\
\hline Agency 6 & 1 & & & & \\
\hline Agency 7 & & & 1 & & \\
\hline Agency 8 & & & & 1 & \\
\hline Agency 9 & & 1 & & & \\
\hline Agency 10 & & 1 & & & \\
\hline Agency 11 & & & 1 & & \\
\hline Agency 12 & & 1 & & & \\
\hline Agency 13 & 1 & & & & \\
\hline Agency 14 & & & 1 & & \\
\hline Agency 15 & & & & 1 & \\
\hline Agency 16 & 1 & & & & \\
\hline Agency 17 & 1 & & & & \\
\hline Agency 18 & 1 & & & & \\
\hline Agency 19 & & & & 1 & \\
\hline Agency 20 & & & 1 & & \\
\hline Agency 21 & & 1 & & & \\
\hline Agency 22 & & & & 1 & \\
\hline Agency 23 & & & & & 1 \\
\hline Agency 24 & & & & 1 & \\
\hline Agency 25 & & 1 & & & \\
\hline Agency 26 & 1 & & & & \\
\hline
\end{tabular}




\begin{tabular}{|c|c|c|c|c|c|}
\hline S1Q5 & Strongly Agree & Agree & Neutral & Disagree & $\begin{array}{l}\text { Strongly } \\
\text { Disagree }\end{array}$ \\
\hline Agency 1 & & & 1 & & \\
\hline Agency 2 & & & 1 & & \\
\hline Agency 3 & & & 1 & & \\
\hline Agency 4 & & & 1 & & \\
\hline Agency 5 & & & 1 & & \\
\hline Agency 6 & & & 1 & & \\
\hline Agency 7 & & & & 1 & \\
\hline Agency 8 & & 1 & & & \\
\hline Agency 9 & & & 1 & & \\
\hline Agency 10 & & 1 & & & \\
\hline Agency 11 & & & 1 & & \\
\hline Agency 12 & & & 1 & & \\
\hline Agency 13 & & & 1 & & \\
\hline Agency 14 & & & 1 & & \\
\hline Agency 15 & & & 1 & & \\
\hline Agency 16 & & & & 1 & \\
\hline Agency 17 & & & 1 & & \\
\hline Agency 18 & & & 1 & & \\
\hline Agency 19 & & & 1 & & \\
\hline Agency 20 & & & 1 & & \\
\hline Agency 21 & & 1 & & & \\
\hline Agency 22 & & & 1 & & \\
\hline Agency 23 & & 1 & & & \\
\hline Agency 24 & & & 1 & & \\
\hline Agency 25 & & & & 1 & \\
\hline Agency 26 & & & 1 & & \\
\hline
\end{tabular}




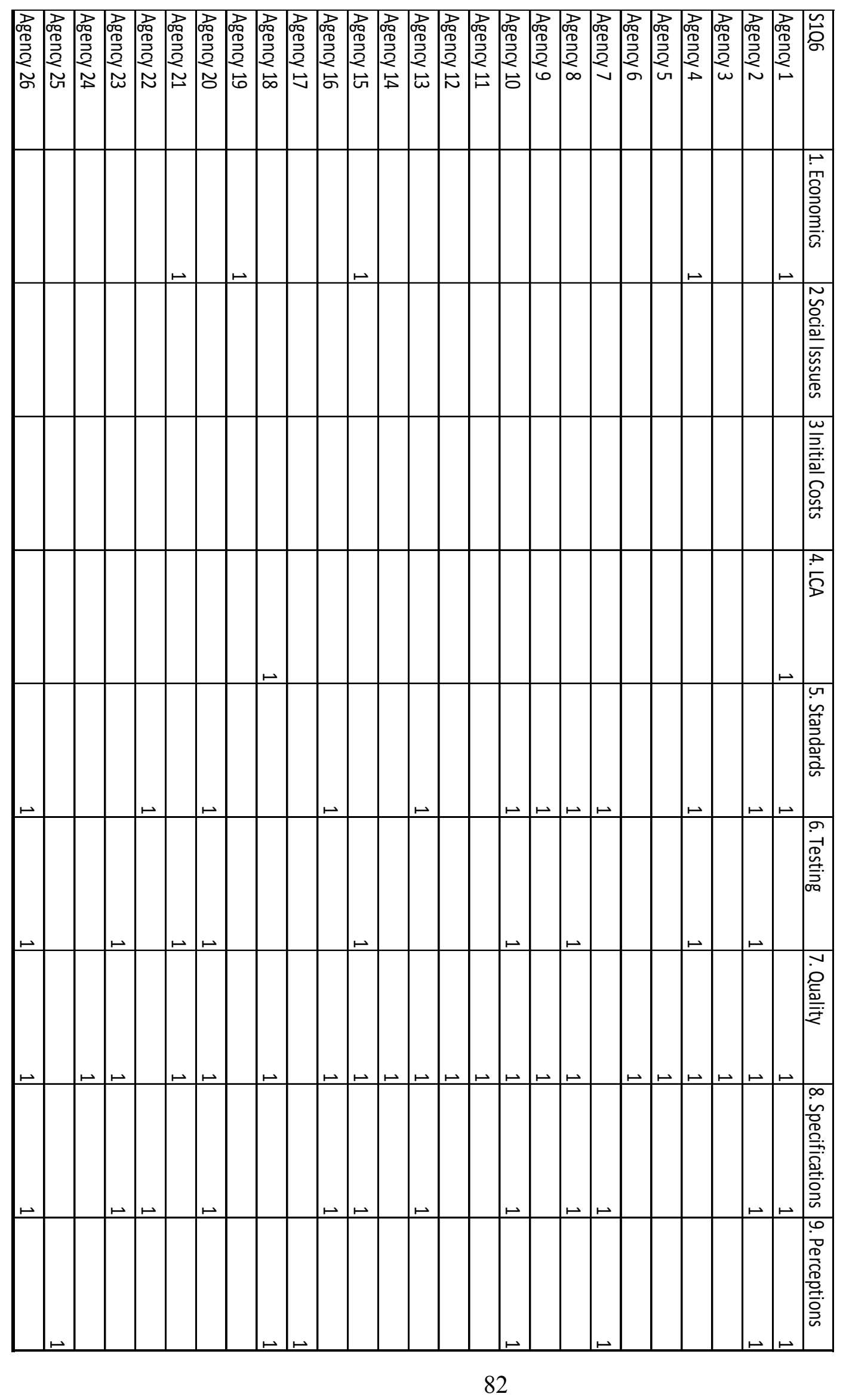




\begin{tabular}{|c|c|c|c|c|c|}
\hline S1Q7 & Strength & Durability & Mixture Design & $\begin{array}{l}\text { Presence of } \\
\text { Epoxy }\end{array}$ & Source \\
\hline Agency 1 & 1 & 2 & 4 & 3 & 5 \\
\hline Agency 2 & 3 & 2 & 1 & 5 & 4 \\
\hline Agency 3 & 3 & 2 & 4 & 5 & 1 \\
\hline Agency 4 & 1 & 1 & 2 & 5 & 4 \\
\hline Agency 5 & 2 & 3 & 4 & 5 & 1 \\
\hline Agency 6 & 3 & 1 & 4 & 5 & 2 \\
\hline Agency 7 & 4 & 2 & 3 & 5 & 1 \\
\hline Agency 8 & 4 & 3 & 2 & 5 & 1 \\
\hline Agency 9 & 3 & 5 & 4 & 2 & 1 \\
\hline Agency 10 & 4 & 3 & 2 & 5 & 1 \\
\hline Agency 11 & 2 & 3 & 4 & 5 & 1 \\
\hline Agency 12 & 4 & 2 & 3 & 5 & 1 \\
\hline Agency 13 & 2 & 1 & 4 & 5 & 3 \\
\hline Agency 14 & 3 & 2 & 5 & 4 & 1 \\
\hline Agency 15 & 2 & 1 & 3 & 5 & 4 \\
\hline Agency 16 & 5 & 5 & 3 & 1 & 4 \\
\hline Agency 17 & 2 & 1 & 3 & 4 & 5 \\
\hline Agency 18 & 2 & 1 & 4 & 5 & 3 \\
\hline Agency 19 & 2 & 3 & 4 & 5 & 1 \\
\hline Agency 20 & 4 & 5 & 4 & 1 & 4 \\
\hline Agency 21 & 2 & 3 & 4 & 5 & 1 \\
\hline Agency 22 & 2 & 3 & 1 & 5 & 4 \\
\hline Agency 23 & 3 & 2 & 1 & 5 & 4 \\
\hline Agency 24 & 2 & 1 & 3 & 5 & 4 \\
\hline Agency 25 & 2 & 3 & 4 & 5 & 1 \\
\hline Agency 26 & 1 & 1 & 4 & 5 & 1 \\
\hline
\end{tabular}




\begin{tabular}{|c|c|c|c|c|c|}
\hline S1Q8 & Strongly Agree & Agree & Neutral & Disagree & $\begin{array}{l}\text { Strongly } \\
\text { Disagree }\end{array}$ \\
\hline Agency 1 & & 1 & & & \\
\hline Agency 2 & & & 1 & & \\
\hline Agency 3 & & & 1 & & \\
\hline Agency 4 & & & & 1 & \\
\hline Agency 5 & & & 1 & & \\
\hline Agency 6 & & & & 1 & \\
\hline Agency 7 & & & & & 1 \\
\hline Agency 8 & & & 1 & & \\
\hline Agency 9 & & 1 & & & \\
\hline Agency 10 & & & & 1 & \\
\hline Agency 11 & & & 1 & & \\
\hline Agency 12 & & & & 1 & \\
\hline Agency 13 & & & & 1 & \\
\hline Agency 14 & & & & 1 & \\
\hline Agency 15 & & & & 1 & \\
\hline Agency 16 & & & & 1 & \\
\hline Agency 17 & & & & 1 & \\
\hline Agency 18 & & & & 1 & \\
\hline Agency 19 & & & & 1 & \\
\hline Agency 20 & & & & 1 & \\
\hline Agency 21 & & 1 & & & \\
\hline Agency 22 & & & & 1 & \\
\hline Agency 23 & & & & & 1 \\
\hline Agency 24 & & & 1 & & \\
\hline Agency 25 & & & & 1 & \\
\hline Agency 26 & & & & & 1 \\
\hline
\end{tabular}




\begin{tabular}{|c|c|c|c|c|c|}
\hline S109 & Strongly Agree & Agree & Neutral & Disagree & $\begin{array}{l}\text { Strongly } \\
\text { Disagree }\end{array}$ \\
\hline Agency 1 & 1 & & & & \\
\hline Agency 2 & & & 1 & & \\
\hline Agency 3 & & & & 1 & \\
\hline Agency 4 & & 1 & & & \\
\hline Agency 5 & & & 1 & & \\
\hline Agency 6 & & & & 1 & \\
\hline Agency 7 & & & & & 1 \\
\hline Agency 8 & & & 1 & & \\
\hline Agency 9 & & & & 1 & \\
\hline Agency 10 & & 1 & & & \\
\hline Agency 11 & & & 1 & & \\
\hline Agency 12 & & & & & 1 \\
\hline Agency 13 & & & & 1 & \\
\hline Agency 14 & & & & 1 & \\
\hline Agency 15 & & & 1 & & \\
\hline Agency 16 & & & 1 & & \\
\hline Agency 17 & & & 1 & & \\
\hline Agency 18 & & 1 & & & \\
\hline Agency 19 & & & 1 & & \\
\hline Agency 20 & & & 1 & & \\
\hline Agency 21 & & & & 1 & \\
\hline Agency 22 & & & 1 & & \\
\hline Agency 23 & & & & & 1 \\
\hline Agency 24 & & & & 1 & \\
\hline Agency 25 & & & & 1 & \\
\hline Agency 26 & & & 1 & & \\
\hline
\end{tabular}




\begin{tabular}{|c|c|c|c|c|c|}
\hline S1Q10 & Strongly Agree & Agree & Neutral & Disagree & $\begin{array}{l}\text { Strongly } \\
\text { Disagree }\end{array}$ \\
\hline Agency 1 & 1 & & & & \\
\hline Agency 2 & & & 1 & & \\
\hline Agency 3 & & & & 1 & \\
\hline Agency 4 & & & & 1 & \\
\hline Agency 5 & & & 1 & & \\
\hline Agency 6 & & & & & 1 \\
\hline Agency 7 & & & & & 1 \\
\hline Agency 8 & & & 1 & & \\
\hline Agency 9 & 1 & & & & \\
\hline Agency 10 & & & & 1 & \\
\hline Agency 11 & & & & 1 & \\
\hline Agency 12 & & & & & 1 \\
\hline Agency 13 & & 1 & & & \\
\hline Agency 14 & & & 1 & & \\
\hline Agency 15 & & & 1 & & \\
\hline Agency 16 & & & & 1 & \\
\hline Agency 17 & & & 1 & & \\
\hline Agency 18 & 1 & & & & \\
\hline Agency 19 & & & 1 & & \\
\hline Agency 20 & & & & 1 & \\
\hline Agency 21 & & & 1 & & \\
\hline Agency 22 & & 1 & & & \\
\hline Agency 23 & & & & & 1 \\
\hline Agency 24 & & & & 1 & \\
\hline Agency 25 & 1 & & & & \\
\hline Agency 26 & & & 1 & & \\
\hline
\end{tabular}




\begin{tabular}{|c|c|c|c|c|c|}
\hline S1Q11 & Strongly Agree & Agree & Neutral & Disagree & $\begin{array}{l}\text { Strongly } \\
\text { Disagree }\end{array}$ \\
\hline Agency 1 & 1 & & & & \\
\hline Agency 2 & & & 1 & & \\
\hline Agency 3 & & & 1 & & \\
\hline Agency 4 & & & & & 1 \\
\hline Agency 5 & & & 1 & & \\
\hline Agency 6 & & & 1 & & \\
\hline Agency 7 & & & 1 & & \\
\hline Agency 8 & & & 1 & & \\
\hline Agency 9 & & 1 & & & \\
\hline Agency 10 & & & 1 & & \\
\hline Agency 11 & & & 1 & & \\
\hline Agency 12 & & & & 1 & \\
\hline Agency 13 & & & 1 & & \\
\hline Agency 14 & 1 & & & & \\
\hline Agency 15 & & & 1 & & \\
\hline Agency 16 & & & 1 & & \\
\hline Agency 17 & & & 1 & & \\
\hline Agency 18 & & 1 & & & \\
\hline Agency 19 & & & 1 & & \\
\hline Agency 20 & & & 1 & & \\
\hline Agency 21 & & & 1 & & \\
\hline Agency 22 & & & 1 & & \\
\hline Agency 23 & & 1 & & & \\
\hline Agency 24 & & & & 1 & \\
\hline Agency 25 & 1 & & & & \\
\hline Agency 26 & & & 1 & & \\
\hline
\end{tabular}




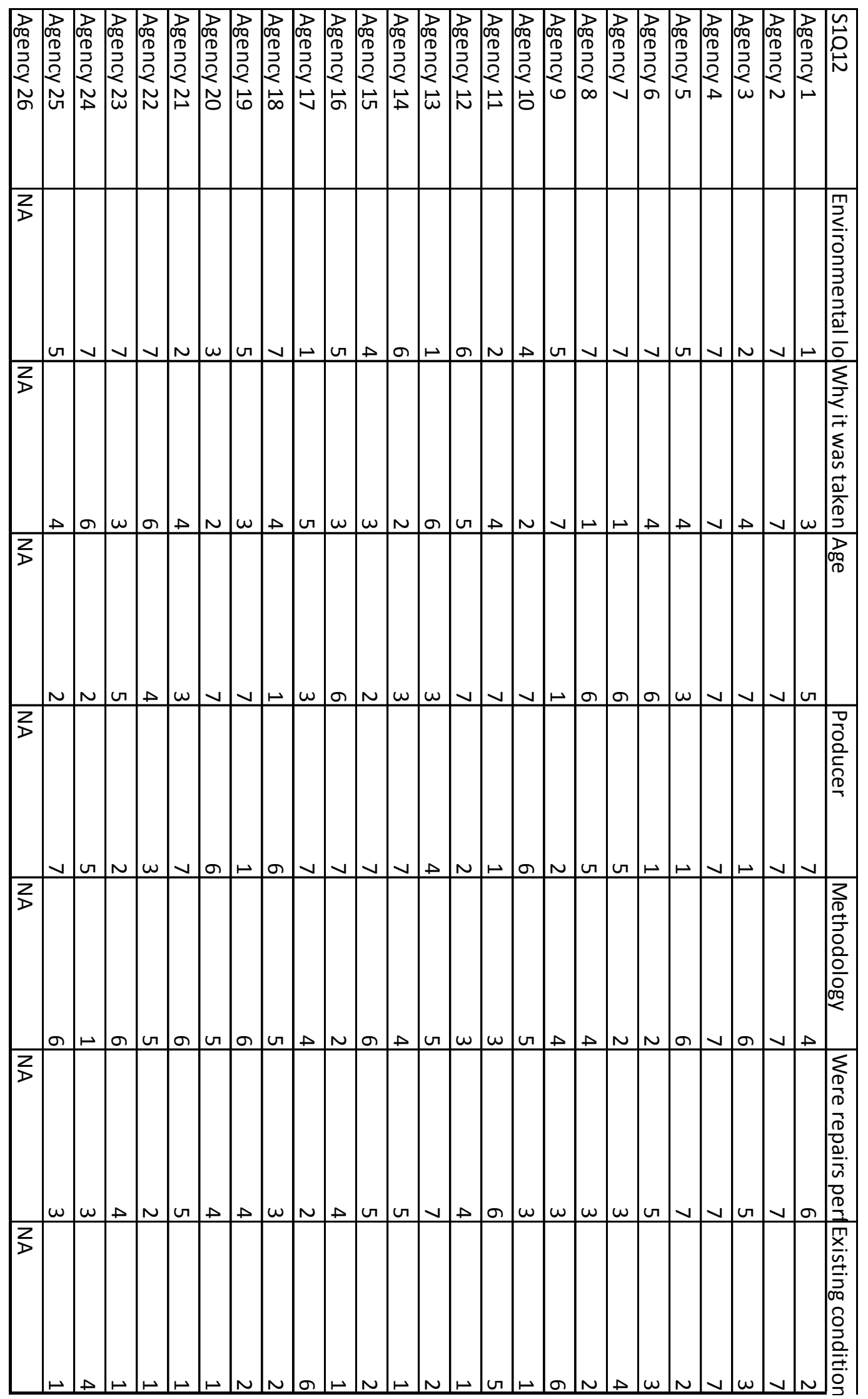




\begin{tabular}{|c|c|c|c|c|c|}
\hline S2Q1 & Strongly Agree & Agree & Neutral & Disagree & $\begin{array}{l}\text { Strongly } \\
\text { Disagree }\end{array}$ \\
\hline Agency 1 & 1 & & & & \\
\hline Agency 2 & & 1 & & & \\
\hline Agency 3 & & & & 1 & \\
\hline Agency 4 & 1 & & & & \\
\hline Agency 5 & & 1 & & & \\
\hline Agency 6 & & 1 & & & \\
\hline Agency 7 & & & & 1 & \\
\hline Agency 8 & 1 & & & & \\
\hline Agency 9 & 1 & & & & \\
\hline Agency 10 & 1 & & & & \\
\hline Agency 11 & 1 & & & & \\
\hline Agency 12 & & & & 1 & \\
\hline Agency 13 & & 1 & & & \\
\hline Agency 14 & & 1 & & & \\
\hline Agency 15 & & & & 1 & \\
\hline Agency 16 & 1 & & & & \\
\hline Agency 17 & 1 & & & & \\
\hline Agency 18 & & 1 & & & \\
\hline Agency 19 & & 1 & & & \\
\hline Agency 20 & & 1 & & & \\
\hline Agency 21 & 1 & & & & \\
\hline Agency 22 & 1 & & & & \\
\hline Agency 23 & & & & 1 & \\
\hline Agency 24 & & 1 & & & \\
\hline Agency 25 & 1 & & & & \\
\hline Agency 26 & & & & & \\
\hline
\end{tabular}




\begin{tabular}{|c|c|c|}
\hline$S 2 Q 2$ & Yes & No \\
\hline Agency 1 & & 1 \\
\hline Agency 2 & & 1 \\
\hline Agency 3 & & 1 \\
\hline Agency 4 & & 1 \\
\hline Agency 5 & & 1 \\
\hline Agency 6 & & 1 \\
\hline Agency 7 & & 1 \\
\hline Agency 8 & & 1 \\
\hline Agency 9 & & 1 \\
\hline Agency 10 & & 1 \\
\hline Agency 11 & . & 1 \\
\hline Agency 12 & & 1 \\
\hline Agency 13 & & 1 \\
\hline Agency 14 & & 1 \\
\hline Agency 15 & & 1 \\
\hline Agency 16 & & 1 \\
\hline Agency 17 & & 1 \\
\hline Agency 18 & & 1 \\
\hline Agency 19 & & 1 \\
\hline Agency 20 & . & 1 \\
\hline Agency 21 & & 1 \\
\hline Agency 23 & & 1 \\
\hline Agency 24 & & 1 \\
\hline Agency 25 & & 1 \\
\hline Agency 26 & 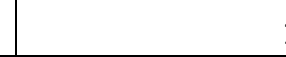 & 1 \\
\hline
\end{tabular}




\begin{tabular}{|c|c|c|c|c|c|c|}
\hline $\mathrm{S} 2 \mathrm{Q} 3$ & $\begin{array}{l}\text { Alkali-silica } \\
\text { reactivity }\end{array}$ & Residual cloride & Carbonation & Sulfate attack & Lower strengths & $\begin{array}{l}\text { Increased } \\
\text { shrinkage }\end{array}$ \\
\hline Agency 1 & 1 & $\begin{array}{r}1 \\
\end{array}$ & 1 & 1 & 1 & 1 \\
\hline Agency 2 & 1 & 1 & & & & \\
\hline \multicolumn{7}{|l|}{ Agency 3} \\
\hline Agency 4 & & & & & 1 & 1 \\
\hline Agency 5 & 1 & & & & 1 & \\
\hline Agency 6 & & & & & 1 & 1 \\
\hline Agency 7 & & 1 & & & 1 & 1 \\
\hline Agency 8 & & & & & 1 & 1 \\
\hline Agency 9 & 1 & & & & & 1 \\
\hline Agency 10 & 1 & 1 & & & 1 & 1 \\
\hline Agency 11 & 1 & 1 & 1 & 1 & 1 & 1 \\
\hline Agency 12 & & & & & 1 & 1 \\
\hline Agency 13 & 1 & & & 1 & & \\
\hline Agency 14 & 1 & 1 & & & 1 & 1 \\
\hline \multicolumn{7}{|l|}{ Agency 15} \\
\hline Agency 16 & 1 & 1 & & & & 1 \\
\hline Agency 17 & 1 & 1 & & & & \\
\hline Agency 18 & & 1 & & & 1 & 1 \\
\hline Agency 19 & & & & & 1 & 1 \\
\hline Agency 20 & 1 & 1 & & & 1 & 1 \\
\hline Agency 21 & 1 & 1 & & & & \\
\hline Agency 23 & 1 & 1 & & & 1 & 1 \\
\hline \multicolumn{7}{|l|}{ Agency 24} \\
\hline Agency 25 & 1 & 1 & & & & \\
\hline Agency 26 & 1 & & & & & 1 \\
\hline
\end{tabular}




\begin{tabular}{|c|c|c|c|c|c|c|}
\hline S2Q4 & Fill Material & Base Material & $\begin{array}{l}\text { Sub-base } \\
\text { Material }\end{array}$ & Pavements & Sidewalks & $\begin{array}{l}\text { Structural } \\
\text { Concrete }\end{array}$ \\
\hline Agency 1 & 1 & 1 & 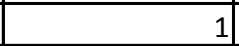 & & & \\
\hline Agency 2 & & & 1 & & & \\
\hline \multicolumn{7}{|l|}{ Agency 3} \\
\hline Agency 4 & 1 & 1 & 1 & 1 & 1 & \\
\hline Agency 5 & & 1 & & & & \\
\hline Agency 6 & & 1 & 1 & & & \\
\hline Agency 7 & & 1 & & 1 & & \\
\hline Agency 8 & 1 & & 1 & & & \\
\hline Agency 9 & 1 & 1 & 1 & & & \\
\hline Agency 10 & 1 & 1 & 1 & 1 & & \\
\hline Agency 11 & 1 & 1 & 1 & 1 & & \\
\hline Agency 12 & & 1 & & 1 & & \\
\hline Agency 13 & 1 & 1 & 1 & & & \\
\hline Agency 14 & & & & 1 & & \\
\hline Agency 15 & 1 & 1 & & 1 & & \\
\hline Agency 16 & 1 & 1 & 1 & 1 & 1 & 1 \\
\hline Agency 17 & 1 & 1 & 1 & & & \\
\hline Agency 18 & 1 & 1 & 1 & & 1 & \\
\hline Agency 19 & & 1 & & & 1 & \\
\hline Agency 20 & & 1 & 1 & 1 & 1 & \\
\hline Agency 21 & 1 & 1 & & & & \\
\hline Agency 23 & 1 & 1 & 1 & & & \\
\hline Agency 24 & 1 & 1 & 1 & 1 & 1 & \\
\hline Agency 25 & 1 & 1 & 1 & & & \\
\hline Agency 26 & & & & 1 & 1 & \\
\hline
\end{tabular}




\begin{tabular}{|l|r|l|}
\hline S3Q1 & Yes & No \\
\hline Agency 1 & 1 & \\
\hline Agency 2 & 1 & \\
\hline Agency 4 & 1 & \\
\hline Agency 5 & 1 & \\
\hline Agency X & 1 & \\
\hline Agency 6 & 1 & \\
\hline Agency 7 & 1 & \\
\hline Agency 8 & 1 & \\
\hline Agency 9 & 1 & \\
\hline Agency 10 & 1 & \\
\hline Agency 11 & & \\
\hline Agency 12 & 1 & \\
\hline Agency 13 & 1 & \\
\hline Agency 14 & 1 & \\
\hline Agency 15 & 1 & \\
\hline Agency 16 & 1 & \\
\hline Agency 17 & 1 & \\
\hline Agency 18 & 1 & \\
\hline Agency 19 & 1 & \\
\hline Agency 20 & & \\
\hline Agency 21 & & \\
\hline Agency 23 & & \\
\hline Agency 26 & & \\
\hline
\end{tabular}




\begin{tabular}{|l|r|l|}
\hline S3Q2 & yes & no \\
\hline Agency 1 & 1 & \\
\hline Agency 2 & 1 & \\
\hline Agency 4 & 1 & \\
\hline Agency 5 & & \\
\hline Agency X & 1 & \\
\hline Agency 6 & 1 & \\
\hline Agency 7 & 1 & \\
\hline Agency 8 & 1 & \\
\hline Agency 9 & 1 & \\
\hline Agency 10 & 1 & \\
\hline Agency 11 & & \\
\hline Agency 12 & 1 & \\
\hline Agency 13 & 1 & \\
\hline Agency 14 & 1 & \\
\hline Agency 15 & 1 & \\
\hline Agency 16 & 1 & \\
\hline Agency 17 & 1 & \\
\hline Agency 18 & 1 & \\
\hline Agency 19 & 1 & \\
\hline Agency 20 & & \\
\hline Agency 21 & & \\
\hline Agency 23 & & \\
\hline Agency 26 & & \\
\hline
\end{tabular}




\begin{tabular}{|l|l|}
\hline S3Q3 & $\begin{array}{l}\text { Over 300 lines of answers were provided by the individual State DOTs and } \\
\text { FHWA agencies. These answers can be made available upon request of the } \\
\text { PI, Dr. Jason H. Ideker - Jason.ideker@oregonstate.edu }\end{array}$ \\
\hline
\end{tabular}

\begin{tabular}{|l|l|}
\hline $\begin{array}{l}\text { Individual } \\
\text { Responses }\end{array}$ & $\begin{array}{l}\text { S3Q4: Internet or Database Software that would be the most useful for } \\
\text { tracking RCA }\end{array}$ \\
\hline & No opinion. \\
\hline & website \\
\hline & testing department \\
\hline & I am familiar with MS Access \\
\hline & Database structure that could work with a GIS system and Sitemanager. \\
\hline & An Access tool and an a windows-based expert system \\
\hline & Website look-up. \\
\hline & $\begin{array}{l}\text { Although we do not have a strong preference, either a website or a } \\
\text { downloadable spreadsheet would be fine. }\end{array}$ \\
\hline & $\begin{array}{l}\text { 1st }=\text { A Website } \\
\text { 2nd }=\text { Excel }\end{array}$ \\
\hline & website \\
\hline & Website \\
\hline & Wicrosoft Excel \\
\hline & Geb-based format. XML schema. \\
\hline & $\begin{array}{l}\text { Website with a map for location and symbol for volume available and } \\
\text { someone to call to get more information. Some indicator of grading and } \\
\text { variability of the materials available would be helpful. }\end{array}$ \\
\hline & any will work \\
\hline & Internet based that can be searched and provide data easily to users. \\
\hline
\end{tabular}




\begin{tabular}{|c|c|}
\hline & S3Q5 Ways of searching the database that would be the most useful. \\
\hline & No opinion. \\
\hline & location \\
\hline & testing department \\
\hline & location \\
\hline & location, properties of the RCA, source of the RCA \\
\hline & Mix design, Project type, project type \\
\hline & $\begin{array}{l}1 \text {-- Location first, since logistics and hual distance are important. } \\
2 \text {-- Quantity available, since small quantaties may not be worth fooling } \\
\text { with } \\
3 \text {-- Variability of sources and varability of properties and quality }\end{array}$ \\
\hline & $\begin{array}{l}\text { Location with filters for quantity. We would not be interested in small } \\
\text { volumes. }\end{array}$ \\
\hline & location \\
\hline & location, mix type, source \\
\hline & By material content \\
\hline & Supplier \\
\hline & By performance parameters as noted above in your list. \\
\hline & Location \\
\hline & By location since transportation may be the critical factor. \\
\hline & Location \\
\hline & All input fields should be able to be searched. \\
\hline
\end{tabular}




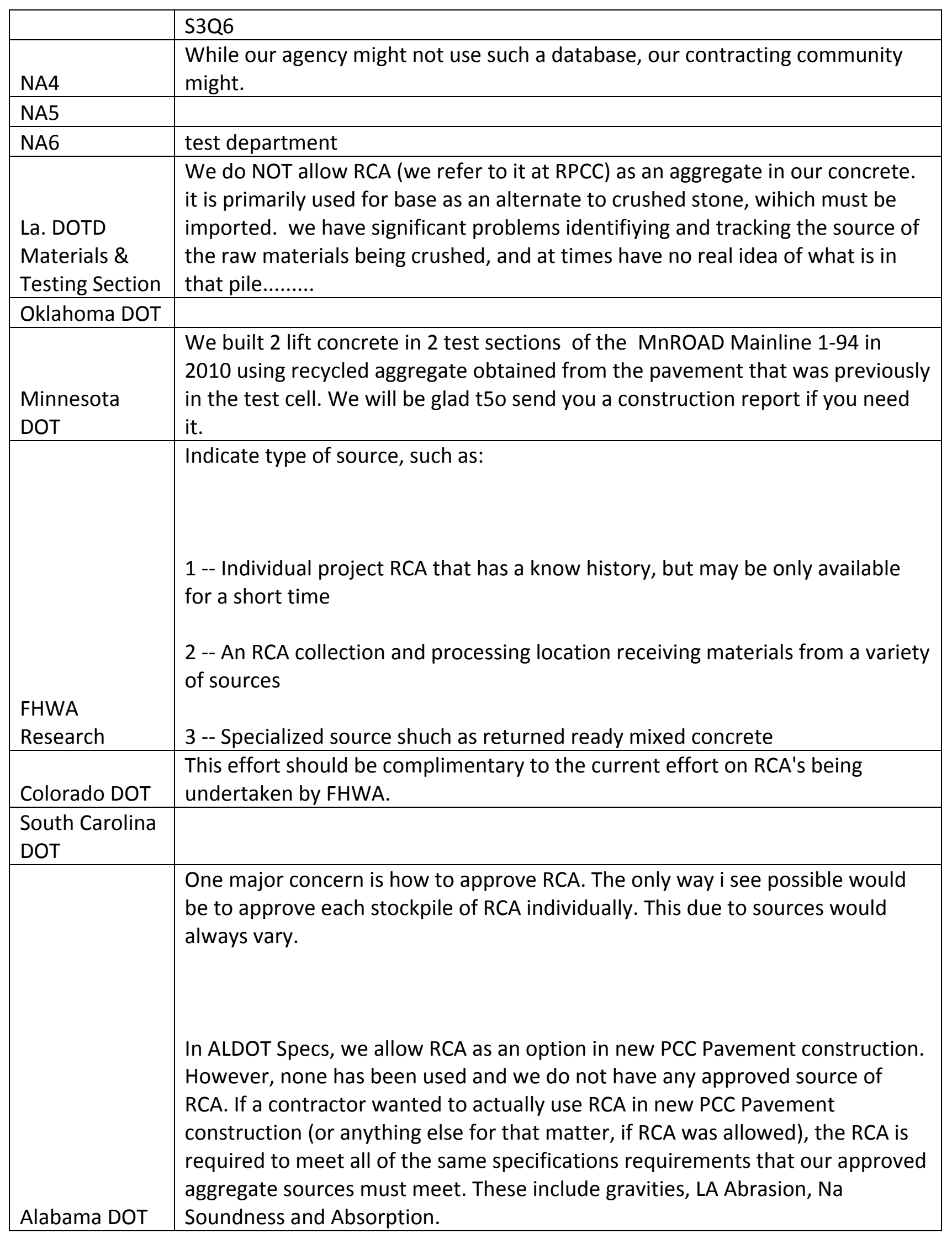




\begin{tabular}{|c|c|}
\hline & S3Q6 (Continued) \\
\hline $\begin{array}{l}\text { Caltrans (CA } \\
\text { DOT) }\end{array}$ & $\begin{array}{l}\text { We currently have provisions for the use of RCA in minor concrete and sub- } \\
\text { base/sub-grade material. Industry/Caltrans committee (Rock Products) is } \\
\text { looking at our state's current requirements per ASTM C33 and Caltrans } \\
\text { specifications for aggreagate properties related to RCA. In addition, Industry } \\
\text { interested in the use of return plastic concrete in minor concrete (which we } \\
\text { currently do not use). The Rock Products Committee is currently reviewing the } \\
\text { use of return plastic concrete. We are also considering sponsering research } \\
\text { regarding RCA through our Department's Pavement Research Program. Should } \\
\text { you have any questions, please contact me at 916-227-7287. Regards, Rob Reis }\end{array}$ \\
\hline & $\begin{array}{l}\text { We already maintain a list of approved GDOT sources so this may not really be } \\
\text { of benefit if the sources listed are not approved sources. It may provide the } \\
\text { Constractors that were interested in using RCA a means to contact sources to } \\
\text { let them know they would be used if they were approved. }\end{array}$ \\
\hline Georgia DOT & $\begin{array}{l}\text { I would have liked to answer 'Maybe" to questions 1) and 2) on this page but } \\
\text { was not given the option. }\end{array}$ \\
\hline FHWA-TFHRC & $\begin{array}{l}\text { Since I am with FHWA research my answers are general in nature. I know the } \\
\text { AASHTO Subcommittee on Materials, Tech Section on Aggregates is working on } \\
\text { a specification for RCA with the help of lowa State University. If RCA can be } \\
\text { produced in a clean environment to specific gradings for fine aggregate, coarse } \\
\text { aggregate, and graded aggregate base I think it could be marketed and used } \\
\text { like any other aggregate. For any use the engineer, producer, and/or } \\
\text { contractor would have to look at quality, specifications, and suitability for the } \\
\text { specific application -- and some trial batches or trial compaction pads may be } \\
\text { needed to make the final determination on its use or blending with other } \\
\text { aggregates. -- Richard.Meininger@dot.gov, FHWA-TFHRC, Ph 202-493-3191. }\end{array}$ \\
\hline NYS DOT & $\begin{array}{l}\text { Database could be useful if appropriate oversight of RCA is managed. the } \\
\text { problem with RCA is that it is more expensive than virgin materials in our state, } \\
\text { the sources of the RCA are typically unknown, vary widely, often contain } \\
\text { contamination from other building materials, and result in inconsistent } \\
\text { material. There is a significant QC/QA cost associated with RCA. If thru the } \\
\text { database sources, quality, and QC/QA can be tracked and managed then there } \\
\text { may be a benefit. Without consistent and quality material RCA is best suited as } \\
\text { a fill product and should not be used in concrete applications. }\end{array}$ \\
\hline \multicolumn{2}{|l|}{$\begin{array}{l}\text { Idaho } \\
\text { Transportation } \\
\text { Department }\end{array}$} \\
\hline $\begin{array}{l}\text { Washington } \\
\text { State DOT }\end{array}$ & \\
\hline
\end{tabular}





\section{GOTREC \\ AND EDUCATION CONSORTIUM}

P.O. Box 751

Portland, OR 97207

OTREC is dedicated to stimulating and conducting collaborative multi-disciplinary research on multi-modal surface transportation issues, educating a diverse array of current practitioners and future leaders in the transportation field, and encouraging implementation of relevant research results. 